\title{
Improvement of Water Resistance by Fe203/TiO2 Photoelectrocatalysts for Formaldehyde Removal: Experimental and Theoretical Investigation
}

\section{Jing Dong}

Huaqiao University College of Chemical Engineering

\section{Qing Li}

Huaqiao University College of Chemical Engineering

\section{Wenjie Xia}

Northwestern University Department of Civil and Environmental Engineering

\section{Bihong LV}

Huaqiao University College of Chemical Engineering

\section{Guohua Jing}

Huaqiao University College of Chemical Engineering

Huazhen Shen ( $\triangle$ hzhshen@hqu.edu.cn)

Huaqiao University College of Chemical Engineering

\section{Chung-shin Yuan}

National Sun Yat-sen University IEE: National Sun Yat-sen University Institute of Environmental Engineering

\section{Research Article}

Keywords: photoelectrocatalytic, formaldehyde, TiO2, Fe203, DFT

Posted Date: June 4th, 2021

DOI: https://doi.org/10.21203/rs.3.rs-164964/v1

License: (a) This work is licensed under a Creative Commons Attribution 4.0 International License. Read Full License

Version of Record: A version of this preprint was published at Environmental Science and Pollution Research on October 1st, 2021. See the published version at https://doi.org/10.1007/s11356-021-16459w. 
7 Jing Dong ${ }^{1}$, Qing $\mathrm{Li}^{1}$, Wenjie $\mathrm{Xia}^{2}$, Bihong $\mathrm{Lv}^{1}$, Guohua Jing, Huazhen 8 9

\section{Improvement of Water Resistance by $\mathrm{Fe}_{2} \mathrm{O}_{3} / \mathrm{TiO}_{2}$ Photoelectrocatalysts for Formaldehyde Removal: Experimental and Theoretical Investigation}

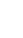
Shen ${ }^{1 *}$, Chung-shin Yuan ${ }^{3 *}$ (n) 


\section{ABSTRACT}

$\mathrm{TiO}_{2}$-based photocatalysts are a potential technology for removing indoor formaldehyde $(\mathrm{CHOH})$ owing to their strong photooxidation ability. However, their photooxidation performance is generally weakened when suffering from the competitive adsorption of $\mathrm{H}_{2} \mathrm{O}$. In a method inspired by the oxygen evolution reaction (OER) to generate intermediates with hydroxyl radicals on the anode electrode catalysts, an electric field was employed in this research and applied to the photooxidation of $\mathrm{CHOH}$ to prevent the competitive adsorption of $\mathrm{H}_{2} \mathrm{O}$. Additionally, $0.5-5 \% \mathrm{Fe}_{2} \mathrm{O}_{3}$ decorated $\mathrm{TiO}_{2}$ was employed to improve the photoelectrocatalytic activity. The influence of an electric field on hydroxyl-radical production was investigated by both density functional theory (DFT) with direct-imposed dipole momentum and photoelectrocatalytic experimental tests. The surface characterization of the photocatalysts, including transmission electron microscopy (TEM), X-ray photoelectron spectroscopy (XPS), and electron paramagnetic resonance (EPR), was conducted. DFT results show that a positive electric field with a strength of $0.05 \AA / \mathrm{V}$ was more favorable to produce hydroxyl on $\mathrm{Fe}_{2} \mathrm{O}_{3} / \mathrm{TiO}_{2}(010)$ than was a negative electric field. $\mathrm{Fe}_{2} \mathrm{O}_{3}$ decoration can significantly boost hydroxyl formation, resulting from a decrease in the binding energy between the $\mathrm{Fe}$ of $\mathrm{Fe}_{2} \mathrm{O}_{3}$ and the oxygen and hydrogen atoms of $\mathrm{H}_{2} \mathrm{O}$. The dissociated hydrogen atom of the $\mathrm{H}_{2} \mathrm{O}$ preferentially remained on the catalysts' surface rather than being released into the gas flow. The experimental results demonstrated that the application of a low-voltage of $150 \mathrm{~V}$ could not directly enhance the photooxidation of $\mathrm{CHOH}$ by either $\mathrm{TiO}_{2}$ or $\mathrm{Fe}_{2} \mathrm{O}_{3} / \mathrm{TiO}_{2}$ but that 
40 it could relieve the $\mathrm{H}_{2} \mathrm{O}$ inhibitory effect by more than $10 \%$ on the $\mathrm{Fe}_{2} \mathrm{O}_{3} / \mathrm{TiO}_{2}$.

41 Keywords: photoelectrocatalytic; formaldehyde; $\mathrm{TiO}_{2} ; \mathrm{Fe}_{2} \mathrm{O}_{3} ;$ DFT 


\section{Introduction}

Formaldehyde $(\mathrm{CHOH})$ is one of China's most harmful indoor air pollutants and poses a dangerous threat to human health (Kim et al., 2011; Tang et al., 2009). Various removal technologies including adsorption (Yang et al., 2017), solvent absorption ( Yang et al., 2017), catalytic conversion (Guo et al., 2019; Li et al., 2020; Miao et al., 2019; Nie et al., 2016), and photooxidation, can effectively address indoor $\mathrm{CHOH}$ pollution. Due to their photoinduced holes and electrons, photocatalysts can produce highly oxidative hydroxyl or superoxide radicals, thus being good candidates for the photooxidation of $\mathrm{CHOH}$ (Wang et al., 2017; Yu et al., 2013; Zhang et al., 2017). However, because of the competitive adsorption of the oxygen in $\mathrm{H}_{2} \mathrm{O}$ and the carbonyl group in $\mathrm{CHOH}$, photocatalysts suffer from $\mathrm{H}_{2} \mathrm{O}$ interference with several-order concentrations higher than $\mathrm{CHOH}$ under a specific humidity, which would enormously undermine their photocatalytic activity. A key to solving the inhibitory effect of gaseous $\mathrm{H}_{2} \mathrm{O}$ is activating the $\mathrm{H}_{2} \mathrm{O}$ molecule and producing more surface hydroxyl radicals. However, $\mathrm{H}_{2} \mathrm{O}$ splitting for hydroxyl production cannot proceed spontaneously and requires an enormous amount of energy to overcome the energy barrier of hydroxyl formation (Chen et al., 2014; Ding et al., 2018). It is well known that under overpotentials in an electrochemical cell, the oxygen evolution reaction (OER) on anode catalysts produces an intermediate of hydroxyl radicals by abstracting one hydrogen atom of $\mathrm{H}_{2} \mathrm{O}$. Then, the released electrons are transported to the anodes, following Eq. (1) below,

$$
\mathrm{H}_{2} \mathrm{O}+* \rightarrow * \mathrm{OH}+\mathrm{H}^{+}+\mathrm{e}^{-}
$$


where * represents the coordinatively unsaturated sites of the catalyst (Valdés et al., 2008). Although the OER commonly occurs in an aqueous environment, it is vital to experimentally and theoretically investigate whether it can proceed between a gas-solid interface. Another question was whether photooxidation of gaseous $\mathrm{H}_{2} \mathrm{O}$ to produce hydroxyls could be strengthened under an external electric field, thus substantially enhancing the removal of $\mathrm{CHOH}$.

Theoretical calculation methods are currently employed to simulate the electrochemical catalysis, including

(a) The computational hydrogen electrode (CHE) method, proposed by Nøskov et al. (Nørskov et al., 2004);

(b) A double reference method with a modification of the electrical double layer (EDL) (Filhol and Neurock, 2006; Lozovoi and Alavi, 2003);

(c) Direct-imposed dipole momentum on a periodic surface slab representing an electric field (Deshlahra et al., 2009; Jörg and Matthias, 1992).

The CHE model can successfully analyze the overpotential of the OER on a none charged catalyst slab, but it is difficult to simulate the dependence of physiochemical adsorption on an applied external field. The EDL model could well reflect the dependence by adding one or more extra charges and identical compensating charges, which is suitable for analyzing a liquid-solid slab system (Duan and Henkelman, 2019; Filhol and Neurock, 2006). The third method is widely used to simulate a charged gassolid catalytic reaction system by introducing a dipole momentum on a slab + adsorbates to embody an external electrostatic field (Deshlahra et al., 2009; Jörg and 
Matthias, 1992). Herein, the third method of introducing a dipole moment as implemented in Vienna Ab-initio Simulation Package (VASP) was employed to investigate the synergetic effect of photoelectrocatalytic oxidation on the formation of $*_{-} \mathrm{OH}$. It is worth noting that unlike when a hydrogen atom diffuses into the electrolyte after producing a hydroxyl radical $(\cdot \mathrm{OH})$ on a liquid-solid interface, hydrogen would be attached to catalysts or transported away by carrier gases on a gas-solid interface. Accordingly, the free energy of the formation of the two terminates was calculated in this research, where (a) one remains on the catalyst's surface as $*_{-} \cdot \mathrm{OH}+*_{-} \mathrm{H}$ and (b) the other leaves to form $*_{-} \cdot \mathrm{OH}+\mathrm{H}^{+}$(gas).

$\mathrm{TiO}_{2}$, due to its strong photoredox ability, excellent chemical stability, low cost, and few secondary derivatives, has been widely investigated for photodegrading formaldehyde. Under UV irradiation, strong oxidative free radicals, $\cdot \mathrm{O}_{2}{ }^{-}$and $\cdot \mathrm{OH}$, are produced at the surface of $\mathrm{TiO}_{2}$ and can effectively react with $\mathrm{CHOH}$ to form formate and the final products of $\mathrm{CO}_{2}$ and $\mathrm{H}_{2} \mathrm{O}$ (Sun et al., 2010; Tasbihi et al., 2015). Thus, it has great potential to be employed as a commercial photocatalyst inside air cleaners to treat indoor $\mathrm{CHOH}$ (Cremer et al., 2014; Liang et al., 2012). However, because of the rapid recombination of photoinduced electron-hole pairs for $\mathrm{TiO}_{2}$, the photocatalytic activity of $\mathrm{TiO}_{2}$ is not high enough to degrade $\mathrm{CHOH}$ efficiently (Yu et al., 2013). How to slow the recombination of photogenerated electron-hole pairs plays a vital role in enhancing the photocatalytic activity of $\mathrm{TiO}_{2}$.

Thus, a material with low resistance or impedance to modify $\mathrm{TiO}_{2}$ is needed to enhance photodegrading $\mathrm{CHOH}$ assisted with an electric field. $\mathrm{Fe}_{2} \mathrm{O}_{3}$, a cheap 
ferromagnetic material, possesses good electrical properties, such as high capacity, high charging rate, long-life usage, and low resistance, which can effectively decrease the insulating behavior of $\mathrm{TiO}_{2}$ (Piva et al., 2016; Ding et al., 2017). Additionally, the interface of $\mathrm{Fe}_{2} \mathrm{O}_{3}$ and $\mathrm{TiO}_{2}$ can accelerate the transfer of photoinduced electrons from the conduction band of $\mathrm{Fe}_{2} \mathrm{O}_{3}$ to that of $\mathrm{TiO}_{2}$ (Moniz et al., 2014; Wang et al., 2014). Thus, decorating $\mathrm{Fe}_{2} \mathrm{O}_{3}$ on $\mathrm{TiO}_{2}$ was employed to enhance the photoelectrical activity. Therefore, the photoelectrical catalytic oxidation of $\mathrm{H}_{2} \mathrm{O}$ to produce hydroxyl on $\mathrm{TiO}_{2}$ and $\mathrm{Fe}_{2} \mathrm{O}_{3}$ decorated $\mathrm{TiO}_{2}$ was explored using DFT calculations. The surface characterization of photocatalysts, including transmission electron microscopy (TEM), X-ray photoelectron spectroscopy (XPS), electron paramagnetic resonance (EPR), was conducted. Furthermore, this study experimentally investigated the photoelectrical catalytic oxidation of gaseous $\mathrm{CHOH}$ by $\mathrm{Fe}_{2} \mathrm{O}_{3}$-decorated $\mathrm{TiO}_{2}$ under an external electric field with and without humidity.

\section{Experimental Methods}

\subsection{Preparation for $\mathrm{Fe}_{2} \mathrm{O}_{3} / \mathrm{TiO}_{2}$}

$\mathrm{Fe}_{2} \mathrm{O}_{3} / \mathrm{TiO}_{2}$ was prepared by the impregnation method. A weight of $1.00 \mathrm{~g}$ commercial $\mathrm{TiO}_{2}$ (Tianhe Environmental Engineering Co., Ltd., Baoding) was mixed into $70 \mathrm{~mL}$ distilled water and then stirred continuously for $30 \mathrm{~min}$ at room temperature. Then, $0.5 \%, 3.0 \%$, and $5 \% \mathrm{Fe}_{2} \mathrm{O}_{3} / \mathrm{TiO}_{2}$ samples were prepared by adding $0.025,0.150$, and $0.250 \mathrm{~g} \mathrm{FeCl}_{3} \cdot 6 \mathrm{H}_{2} \mathrm{O}$ into the $\mathrm{TiO}_{2}$ solution, respectively. After continuous stirring for $90 \mathrm{~min}$ at room temperature, the mixtures were dried at $105^{\circ} \mathrm{C}$ in a rotary evaporator at a reduced pressure of $0.01 \mathrm{kPa}$ to dry the residue $\mathrm{H}_{2} \mathrm{O}$. Then, the dried samples were 
calcinated at $500{ }^{\circ} \mathrm{C}$ for $12 \mathrm{~h}$ in an air atmosphere to form $\mathrm{Fe}_{2} \mathrm{O}_{3} / \mathrm{TiO}_{2}$. Before each $\mathrm{CHOH}$ degrading test, the prepared $\mathrm{Fe}_{2} \mathrm{O}_{3} / \mathrm{TiO}_{2}$ s catalysts were loaded onto glass fiber as follows: $1.0 \mathrm{~g}$ photocatalysts were dispersed in $1 \mathrm{~L}$ of distilled water with ultrasonic treatment for $10 \mathrm{~min}$. Cylindrical glass fiber was immersed in the $\mathrm{Fe}_{2} \mathrm{O}_{3} / \mathrm{TiO}_{2}$ solution for at least $5 \mathrm{~h}$ and then dried for $2 \mathrm{~h}$ at $105{ }^{\circ} \mathrm{C}$. The filled amount of $\mathrm{Fe}_{2} \mathrm{O}_{3} / \mathrm{TiO}_{2}$ was the weight difference of the glass fiber before and after the loading treatment.

\subsection{Characterization of $\mathrm{Fe}_{2} \mathrm{O}_{3} / \mathrm{TiO}_{2}$}

A scanning electron microscope (SEM) was used to obtain the morphologies of the $\mathrm{Fe}_{2} \mathrm{O}_{3} / \mathrm{TiO}_{2}$ s with a beam accelerating voltage and current of $20 \mathrm{kV}$ and $20 \mu \mathrm{A}$, respectively. High-resolution transmission electron microscopy (HR-TEM) was performed on a Tecnai G2 F20 (FEI, USA) with an accelerating voltage of $200 \mathrm{kV}$. An X-ray diffraction (XRD) analyzer was used to analyze the crystal pattern of $\mathrm{TiO}_{2}$ and $\mathrm{Fe}_{2} \mathrm{O}_{3} / \mathrm{TiO}_{2}$ (s) with a Shimadzu X-ray beam with $\mathrm{Cu}-\mathrm{Ka}$ radiation. Raman spectra of the specimens were obtained using a SenterraII (BRUCK, USA) with a scanning range of $100-1000 \mathrm{~cm}^{-1}$. The photoluminescence spectra (PL) of the $\mathrm{TiO}_{2}$ and $\mathrm{Fe}_{2} \mathrm{O}_{3} / \mathrm{TiO}_{2} \mathrm{~S}$ catalysts were recorded on a Varian Cary Eclipse spectrometer with an excitation wavelength of $325 \mathrm{~nm}$. UV-vis spectra of the photocatalysts were recorded in the range of 200-800 nm by a Shimadzu UV-vis (UV-2550) spectrometer equipped with a diffuse reflection accessory. $\mathrm{BaSO}_{4}$ was employed as the reference substance. Electrochemical impedance spectroscopy (EIS) and linear sweep voltammetry (LSV) were performed using an electrochemical workstation (CHI604E, C.H. Inc.). The EIS and LSV were measured at a constant A.C. amplitude of $5.0 \mathrm{mV}$ with a sweep frequency of $10^{5}-0.1$ 
152

153

154

155

156

157

158

159

160

161

162

163

164

165

166

167

$\mathrm{Hz}$. The voltage ranged from -0.3 to $0.2 \mathrm{~V}$ for the $\mathrm{LSV}$ measurement with $0.1 \mathrm{M} \mathrm{Na}_{2} \mathrm{SO}_{4}$ solution as the electrolyte. The Mott-Schottky plots were established with the A.C. amplitude of $10 \mathrm{mV}$ at $100 \mathrm{~Hz}$. The sweep voltage ranged from -1.2 to $0.5 \mathrm{~V}$. The EPR measurements were performed using a Bruker ER200D operated in the X-band. Approximately $10-50 \mathrm{mg}$ of photocatalyst was placed into a particular spectroscopically pure quartz cell.

\subsection{DFT experimental methods}

The commercial $\mathrm{TiO}_{2}$ exhibits a predominantly exposed (010) facet, which was also illustrated in the following TEM characterization results. Thus, an anatase $\mathrm{TiO}_{2}$ (010) slab was constructed to simulate the $\mathrm{TiO}_{2}$ base. Before constructing the slab, we first optimized the unit cell of anatase $\mathrm{TiO}_{2}$. The crystal lattice spacing was optimized to be $\mathrm{a}=\mathrm{b}=3.80$ and $\mathrm{c}=9.50 \AA$; this optimization was in agreement with previous research (Shen et al., 2021). The $\mathrm{TiO}_{2}(010)$ slab consisted of four layers and 48 atoms $\left(\mathrm{Ti}_{16} \mathrm{O}_{32}\right)$, and a vacuum height of $20 \AA$ oriented along the c-axis. The $\mathrm{Fe}_{2} \mathrm{O}_{3}$ decoration was assembled by loading one $\left(\mathrm{Fe}_{2} \mathrm{O}_{3}\right)$ cluster consisting of $2 \mathrm{Fe}$ and $3 \mathrm{O}$ atoms on the $\mathrm{TiO}_{2}(010)$, as shown in Figure 9. An external electric field was applied vertically to the slab by an approach proposed by Naugebeaur and Scheffler. Positive and negative electric fields with strengths of 0.05 and $-0.05 \mathrm{eV} / \AA$ were imposed on the supercell to simulate different electric-field directions. A positive external electric field led to a distribution of positive charges on the upper side of the slab, and the negative external electric field led to opposite results (Deshlahra et al., 2009). The formation of hydroxyl radicals with (or without) the dissociated hydrogen atom of $\mathrm{H}_{2} \mathrm{O}$ connected on $\mathrm{TiO}_{2}(010)$ 
and $\mathrm{Fe}_{2} \mathrm{O}_{3} / \mathrm{TiO}_{2}(010)$ was constructed as follows: for the case of hydrogen atoms anchored at the surface, the hydroxyl was connected to an unsaturated five-coordinate Ti atom $\left(\mathrm{Ti}_{5 \mathrm{c}}\right)$ and an atop four-coordinate $\mathrm{Fe}$ atom $\left(\mathrm{Fe}_{4 \mathrm{c}}\right)$, for $\mathrm{TiO}_{2}(010)$ and $\mathrm{Fe}_{2} \mathrm{O}_{3} / \mathrm{TiO}_{2}(010)$, respectively. The hydrogen atom was then linked to the adjacent oxygen atom of the $\mathrm{Ti}_{5 c}\left(\mathrm{Fe}_{4 c}\right)$ on $\mathrm{TiO}_{2}(010)\left(\mathrm{Fe}_{2} \mathrm{O}_{3} / \mathrm{TiO}_{2}(010)\right)$. In the absence of hydrogen, which was taken away from slabs, only a hydroxyl was bonded to the $\mathrm{Ti}_{5 \mathrm{c}}$ $\left(\mathrm{Fe}_{4 c}\right)$ for the $\mathrm{TiO}_{2}(010)\left(\mathrm{Fe}_{2} \mathrm{O}_{3} / \mathrm{TiO}_{2}(010)\right)$. The free energies of hydroxyl formation with $\left(\triangle \mathrm{G}^{*-\mathrm{OH}}+{ }^{*}{ }_{-\mathrm{H}}\right)$ and without hydrogen $\left(\triangle \mathrm{G}^{*}{ }_{-\mathrm{OH}}\right)$ under an external electric field were determined by Eqs. (2)-(3), respectively,

$$
\begin{aligned}
& \triangle \mathrm{G}^{*-\mathrm{OH}+{ }^{*} \mathrm{H}}=\mathrm{G}^{*-\mathrm{OH}+{ }^{*}-\mathrm{H}}-\mathrm{G}_{\mathrm{bare}}{ }^{*}-\mathrm{G}_{\mathrm{H} 2 \mathrm{O}(\mathrm{g})}-\mathrm{eU} \\
& \triangle \mathrm{G}_{-\mathrm{-OH}}=\mathrm{G}^{*-\mathrm{OH}}-\mathrm{G}_{\text {bare}}-\mathrm{G}_{\mathrm{H} 2 \mathrm{O}(\mathrm{g})}+1 / 2 \mathrm{G}_{\mathrm{H}+}-\mathrm{eU}
\end{aligned}
$$

where $\mathrm{G}_{*-\mathrm{OH}+{ }^{*} \mathrm{H}}$ and $\mathrm{G}_{*-\mathrm{OH}}$ are the free energies of hydroxyl (with or without hydrogen atoms) connected to charged $\mathrm{TiO}_{2}(010)$ and $\mathrm{Fe}_{2} \mathrm{O}_{3} / \mathrm{TiO}_{2}(010)$ and calculated within the applied electric field. $\mathrm{G}_{\text {bare* }}$ is the free energy of the charged catalysts within the electric field without any hydroxyl or hydrogen atom from $\mathrm{H}_{2} \mathrm{O} . \mathrm{G}_{\mathrm{H} 2 \mathrm{O}(\mathrm{g})}$, and $\mathrm{G}_{\mathrm{H}+}$ are the free energies of $\mathrm{H}_{2} \mathrm{O}$ and hydrogen atoms without any charges, respectively, which were calculated in the absence of an external electric field. $U$ is the overpotential relative to the standard potential of a hydrogen electrode. Additionally, the difference in zero-point energies and the entropy change in $\mathrm{T} \triangle \mathrm{S}$ were corrected by determining the vibrational frequencies of the adsorbed -OH with and without hydrogen (Valdés et al., 2008). The reaction temperature was set to $298 \mathrm{~K}$.

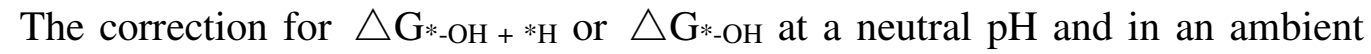


environment was also carried out based on Nernst's equation by Eq. (4). Herein, the photocatalysts were enveloped under neutral conditions without any acid or alkaline components in the continuous injection of gaseous $\mathrm{H}_{2} \mathrm{O}$. Thus, the $\mathrm{pH}$ was set to 7.0 to simulate the neutral environment on the gas-solid interface.

$$
\triangle \mathrm{G}_{\mathrm{pH}}(\mathrm{pH})=2.30 \times \mathrm{k}_{\mathrm{B}} \mathrm{T} \times \mathrm{pH}
$$

The model calculation was determined based on the generalized gradient approximation with the Perdew-Burke-Ernzerhof exchange-correlation function (GGA-PBE). Hubbard U values ( $\mathrm{U}_{\text {eff }}$ ) of 4.20 and $5.00 \mathrm{eV}$ were applied for Ti 3d and Fe 3d atomic orbitals, respectively, referring to previous research (Shim et al., 2009). The Brillouin zone was determined automatically with the gamma center in the Monkhorst-Pack scheme. The energy cutoff was set to $400 \mathrm{eV}$. The convergence criteria for the energy (EDIFF) and force (EDIFFG) were $10^{-4} \mathrm{eV}$ and $-0.02 \mathrm{eV} / \mathrm{A}$, respectively. All atoms in the slabs were relaxed in all the structure optimizations. All the determinations mentioned above were performed with the VASP.

\subsection{Photoelectrocatalytic measurements}

The photoelectrocatalytic reaction system consisted of a $\mathrm{CHOH}$ generation system, a photoelectric catalytic reactor, and an online detector, as shown in Figure 1. Gaseous $\mathrm{CHOH}$ was produced from a permeable tube enclosed in a U-shaped glass tube filled with a few glass beads to keep the influent gas cross-sectionally uniform. The Ushaped tube was placed in a water bath at a constant temperature of $80^{\circ} \mathrm{C}$. Pure $\mathrm{N}_{2}$ (99.99\%) was used as the carrier gas. The influent concentration of $\mathrm{CHOH}$ was set to $1.50 \mathrm{ppm}$ for each test. Additionally, $\mathrm{O}_{2}(99.9 \%)$ and $\mathrm{H}_{2} \mathrm{O}_{(\mathrm{g})}$ were also injected into the 
reactor. Different humidities of the influent gas flow were adjusted by changing the flow rate of $\mathrm{N}_{2}$ purged into an impinger bottle containing water, which was measured by a humidity detector. The overall influent flow rate was set to $700 \mathrm{~mL} / \mathrm{min}$. Before entering the reactor, all the gas components were thoroughly mixed in a chamber, which contained a magnetic stirrer, at a stirring rate of $200 \mathrm{r} / \mathrm{min}$. All pipelines were made of polytetrafluoroethylene to prevent the adhesion of the $\mathrm{CHOH}$. The photoelectrocatalytic reactor had a cylindrical shape with a height of $600 \mathrm{~mm}$ and an interior diameter of $150 \mathrm{~mm}$. A quartz cover on the top of the reactor was used to receive UV irradiation. A UV lamp $(\lambda=254 \mathrm{~nm}, \mathrm{P}=15 \mathrm{~W})$ was placed directly above the reactor at a distance of $15 \mathrm{~cm}$ from the fixed catalysts, and the fluence rate $(\psi)$ was evaluated to be $5.3 \mathrm{~mW} / \mathrm{cm}^{2}$. Two pieces of round woven mesh made of stainless steel were used not only as a support for catalyst-coated glass fibers but also as the positive and negative electrodes, which were connected with a self-designed direct-current (DC) voltage output device. To avoid the consumption of energy, the supplied power $(\mathrm{P})$ was as low as $5 \mathrm{~W}$. The output voltage between the two electrodes was measured to be approximately $150 \mathrm{~V}$. Correspondingly, the strength of the electric field was determined to be $5000 \mathrm{~V} / \mathrm{m}$ since the distance between the two pieces of woven mesh was approximately $3.0 \mathrm{~cm}$. For each test, the fiberglass filter coated with $\mathrm{Fe}_{2} \mathrm{O}_{3} / \mathrm{TiO}_{2}$ was sandwiched between the woven mesh. The superficial velocity for the photoelectric reaction was determined to be $3.96 \mathrm{~cm} / \mathrm{min}$. The reaction temperature inside the reactor was approximately $25^{\circ} \mathrm{C}$. A working air conditioner was used to cool the reactor. A $\mathrm{CHOH}$ detector (4160-19.99 $\mathrm{m}$, Interscan) was used to monitor the effluent 
concentration of $\mathrm{CHOH}$ online.

The removal efficiency was determined as the ratio of the difference in the influent and effluent concentrations of $\mathrm{CHOH}$ over the influent concentration, as shown in Eq. (5) described,

$$
\eta=\frac{c_{0}-C_{i}}{c_{0}} \times 100 \%
$$

where $\boldsymbol{C}_{\boldsymbol{\theta}}(\mathrm{ppm})$ is the influent concentration of $\mathrm{CHOH}$, and $\boldsymbol{C}_{\boldsymbol{i}}(\mathrm{ppm})$ is the effluent concentration of $\mathrm{CHOH}$.

The removal rate $\boldsymbol{r}$ was calculated as the mass of $\mathrm{CHOH}$ reduced per unit time (min) and unit mass catalyst (g) described below:

$$
\boldsymbol{r}=\left(\boldsymbol{C}_{\mathbf{0}}-\boldsymbol{C}_{\boldsymbol{i}}\right) \times \frac{\boldsymbol{M}_{\mathrm{CHOH} \cdot \times \boldsymbol{Q}}}{24.45 \cdot \mathrm{m}}(\mathrm{ng} / \mathrm{min} / \mathrm{g})
$$

where $\boldsymbol{M}_{\mathbf{C H O H}}$ is the molar mass of $\mathrm{CHOH}(30 \mathrm{~g} / \mathrm{mol}), \boldsymbol{Q}$ is the overall influent flow rate $(700 \mathrm{~mL} / \mathrm{min})$, and $\boldsymbol{m}$ is the catalyst mass (g) loading on the glass fibers.

\section{Results and discussion}

\subsection{Surface characterization of $\mathrm{TiO}_{2}$ and $\mathrm{Fe}_{2} \mathrm{O}_{3} / \mathrm{TiO}_{2}$}

\subsubsection{Morphology of $\mathrm{TiO}_{2}$ and $\mathrm{Fe}_{2} \mathrm{O}_{3} / \mathrm{TiO}_{2}$}

Figure 2 shows the SEM and TEM morphologies of the commercial $\mathrm{TiO}_{2}$ and $5 \% \mathrm{Fe}_{2} \mathrm{O}_{3} / \mathrm{TiO}_{2}$. The morphologies of $\mathrm{TiO}_{2}$ and $\mathrm{Fe}_{2} \mathrm{O}_{3} / \mathrm{TiO}_{2}$ exhibited similar granule shapes according to SEM (Figure 2(a) and (e)). The TEM images of $\mathrm{TiO}_{2}$ clearly showed that most of these granules displayed elongated tetragonal cuboids with a dspace of $0.37 \mathrm{~nm}$ in Figure 2(b), which highly approached that of the exposed facet of the (010) plane (Pan et al., 2011). Thus, we inferred that the (010) plane accounted for a considerably large proportion of the exposed facet of the $\mathrm{TiO}_{2}$. Additionally, a minor 
portion of granules with a d-space of $0.24 \mathrm{~nm}$ was attributed to the (103) plane (Ciancio et al., 2012). The average diameter of the $\mathrm{TiO}_{2}$ granules was statistically estimated to be $12.9 \pm 4.9 \mathrm{~nm}$, as shown in Figure 2(d). After the decoration of $\mathrm{Fe}_{2} \mathrm{O}_{3}$, the 3.0\% $\mathrm{Fe}_{2} \mathrm{O}_{3} / \mathrm{TiO}_{2}$ also presented a primarily cuboid shape similar to that of $\mathrm{TiO}_{2}$ (Figures 2(f)-(g)). The primary d-space of the $3.0 \% \mathrm{Fe}_{2} \mathrm{O}_{3} / \mathrm{TiO}_{2}$ cuboid granule was measured to be $0.37 \mathrm{~nm}$, corresponding to the (010) plane, and $0.25 \mathrm{~nm}$ for the minor interplane space, assigned to the (110) anatase plane. Thus, the morphology of the prepared $\mathrm{Fe}_{2} \mathrm{O}_{3} / \mathrm{TiO}_{2}$ was not substantially altered compared with that of pristine $\mathrm{TiO}_{2}$. Nevertheless, the average size of the $3.0 \% \quad \mathrm{Fe}_{2} \mathrm{O}_{3} / \mathrm{TiO}_{2}$ was estimated to be approximately $14.6 \pm 4.6 \mathrm{~nm}$, resembling $\mathrm{TiO}_{2}$.

\subsubsection{Crystal structure and Raman spectra}

Figure 3(a) shows that the XRD peaks of $\mathrm{TiO}_{2}$ occurring at $25.3^{\circ}, 37.8^{\circ}$, and $48.0^{\circ}$ corresponded to the (101), (004), and (020) planes of anatase. The decoration of $\mathrm{Fe}_{2} \mathrm{O}_{3}$ did not give rise to the characteristic peaks at $2 \theta=24.1^{\circ}(012), 33.2^{\circ}(104), 35.6^{\circ}(110)$ for $\alpha-\mathrm{Fe}_{2} \mathrm{O}_{3}$ (Maslen et al., 1994), or 36.9 ${ }^{\circ}(222), 42.9^{\circ}(400)$ for $\gamma-\mathrm{Fe}_{2} \mathrm{O}_{3}$ (Jørgensen et al., 2007) in $0.5-5 \% \mathrm{Fe}_{2} \mathrm{O}_{3} / \mathrm{TiO}_{2}$, implying that $\mathrm{Fe}_{2} \mathrm{O}_{3}$ was mainly present in a highly dispersed amorphous phase, or as tiny crystals on the surface of $\mathrm{TiO}_{2}$ that could not be detected by XRD (Fang et al., 2007). However, the decoration of $\mathrm{Fe}_{2} \mathrm{O}_{3}$ substantially influenced the diffraction profiles of the $\mathrm{TiO}_{2} \mathrm{~s}$. For instance, the (020) peak intensity was much higher for $\mathrm{Fe}_{2} \mathrm{O}_{3} / \mathrm{TiO}_{2} \mathrm{~S}$ than $\mathrm{TiO}_{2}$, as shown in Figure 3(a) and Supplementary Table 1. Additionally, the (020) peak of $\mathrm{Fe}_{2} \mathrm{O}_{3} / \mathrm{TiO}_{2} \mathrm{~S}$ was much sharper than that of $\mathrm{TiO}_{2}$, which was probably associated with the expansion of $\mathrm{TiO}_{2}$ crystals 
along the [001] direction (Liu et al., 2017), suggesting that $\mathrm{Fe}_{2} \mathrm{O}_{3}$ loading could break the strain balance between the top and sublayers of $\mathrm{TiO}_{2}$, thus influencing the epitaxy processes of $\mathrm{TiO}_{2}$ during calcination. Additionally, the full width at half maximum (FWHM) at the $25.3^{\circ}$ peak representing the (101) plane was $0.646^{\circ}, 0.593^{\circ}, 0.585^{\circ}$, and $0.520^{\circ}$ for $\mathrm{TiO}_{2}$ and $0.5-5 \% \mathrm{Fe}_{2} \mathrm{O}_{3} / \mathrm{TiO}_{2}$, respectively. The FWHM was determined according to the Debye-Scherrer equation (Eq. (7)),

$$
\mathrm{D}=\mathrm{K} \lambda / \beta \cos \theta
$$

where $\mathrm{D}(\mathrm{nm})$ is the average particulate size and $\beta$ (without the value) is the FWHM. The particle size of $0.5-7 \% \mathrm{Fe}_{2} \mathrm{O}_{3} / \mathrm{TiO}_{2}$ increased slightly, since the $\beta$ for the peak corresponding to the $\mathrm{Fe}_{2} \mathrm{O}_{3} / \mathrm{TiO}_{2}$ 's (101) plane was larger than that of $\mathrm{TiO}_{2}$, unveiling that decoration of $\mathrm{Fe}_{2} \mathrm{O}_{3}$ slightly promoted the growth in $\mathrm{TiO}_{2}$ size, highly concurring with the size distribution as shown in the TEM images.

Figure 3(b) shows the Raman spectra of $\mathrm{TiO}_{2}$ and $0.5-5 \% \mathrm{Fe}_{2} \mathrm{O}_{3} / \mathrm{TiO}_{2}$. The Raman peaks at $144,396,515$, and $640 \mathrm{~cm}^{-1}$ corresponded to the $\mathrm{Eg}, \mathrm{B}_{1} \mathrm{~g}, \mathrm{~B}_{2} \mathrm{~g}$, and $\mathrm{Eg}$ modes of $\mathrm{TiO}_{2}$. The characteristic peaks of $\mathrm{Fe}_{2} \mathrm{O}_{3}$ were not present in the Raman patterns of $0.5-5 \% \mathrm{Fe}_{2} \mathrm{O}_{3} / \mathrm{TiO}_{2}$ such as those for $\alpha-\mathrm{Fe}_{2} \mathrm{O}_{3}$ occurring at $220\left(\mathrm{~A}_{1 \mathrm{~g}}\right), 243\left(\mathrm{E}_{\mathrm{g}}\right), 290\left(\mathrm{E}_{\mathrm{g}}\right)$, $408\left(\mathrm{E}_{\mathrm{g}}\right), 611\left(\mathrm{E}_{\mathrm{g}}\right), 638\left(\mathrm{E}_{\mathrm{g}}\right)$ and $1318 \mathrm{~cm}^{-1}\left(\mathrm{E}_{\mathrm{g}}\right)$ (Kodan et al., 2019), as well as those for $\gamma-\mathrm{Fe}_{2} \mathrm{O}_{3}$ at $350\left(\mathrm{E}_{\mathrm{g}}\right), 395\left(\mathrm{~T}_{2 \mathrm{~g}}\right), 507\left(\mathrm{~T}_{2 \mathrm{~g}}\right), 670\left(\mathrm{~A}_{1 \mathrm{~g}}\right)$, and $708 \mathrm{~cm}^{-1}\left(\mathrm{~A}_{1 \mathrm{~g}}\right)($ Pawan et al., 2014). The similar Raman patterns between $\mathrm{TiO}_{2}$ and $0.5-5 \% \mathrm{Fe}_{2} \mathrm{O}_{3} / \mathrm{TiO}_{2}$ agreed with the XRD results, revealing that the decorated $\mathrm{Fe}_{2} \mathrm{O}_{3}$ on $\mathrm{TiO}_{2}$ formed an amorphous phase or tiny crystallite cell. Nevertheless, the intensities of the 144 and $130 \mathrm{~cm}^{-1}$ peaks assigned to the symmetric stretching vibration of the O-Ti-O bonds were relatively 
lower for $\mathrm{Fe}_{2} \mathrm{O}_{3} / \mathrm{TiO}_{2}$ than for the $\mathrm{TiO}_{2} \mathrm{~s}$, particularly that of $144 \mathrm{~cm}^{-1}$ in $5 \% \mathrm{Fe}_{2} \mathrm{O}_{3} / \mathrm{TiO}_{2}$ spectrum, which dropped notedly. The lower intensity of the $E_{g}$ vibration mode of the $\mathrm{Fe}_{2} \mathrm{O}_{3} / \mathrm{TiO}_{2}$ s probably resulted from the decrease in the O-Ti-O number on the exposed facet of anatase $\mathrm{TiO}_{2}$ due to the surface cover of amorphous $\mathrm{Fe}_{2} \mathrm{O}_{3}$.

\subsubsection{X-ray photoelectron spectroscopy}

Figure 4(a) shows the binding energy of $\mathrm{Ti} 2 \mathrm{p}$ for $\mathrm{TiO}_{2}$ and $3 \% \mathrm{Fe}_{2} \mathrm{O}_{3} / \mathrm{TiO}_{2}$. The binding energies of 464.4 and $458.5 \mathrm{eV}$ were assigned to $\mathrm{Ti}^{4+} 2 \mathrm{p} 1 / 2$ and $3 / 2$ of $\mathrm{TiO}_{2}$, respectively (Tsai et al., 2013). After the surface loading of $\mathrm{Fe}_{2} \mathrm{O}_{3}$, two small subpeaks emerged at lower binding energies of 463.4 and $457.7 \mathrm{eV}$, suggesting that the electron density of the $\mathrm{Ti}^{4+} 2 \mathrm{p}$ orbital increased with the loading of $\mathrm{Fe}$ due to the formation of Fe-O-Ti. The intensity of the Fe 2p peak, as shown on the Y-axis scale in Figure 4(b), was much smaller than that of $\mathrm{Ti}^{4+}$, indicating that the content of surface $\mathrm{Fe}$ atoms was far lower than that of $\mathrm{Ti}$. The main peaks at approximately 710.2 and $724.6 \mathrm{eV}$ were ascribed to the $\mathrm{Fe}^{3+} 2 \mathrm{p} 1 / 2$ and $2 \mathrm{p} 3 / 2$ orbitals of $\mathrm{Fe}_{2} \mathrm{O}_{3}$, respectively, illustrating that $\mathrm{Fe}^{3+}$ dominated most surface $\mathrm{Fe}$ atoms. Additionally, minor shake-up peaks were present in the range of 713-720 eV, which resulted from an electron transition from a $3 d$ orbital to an empty 4s orbital as the ejection of the Fe 2p electrons (Yin et al., 1974).

\subsubsection{UV-Visible spectra}

Figure 5 illustrates the UV-vis spectra of $\mathrm{TiO}_{2}$ and $\mathrm{Fe}_{2} \mathrm{O}_{3} / \mathrm{TiO}_{2} \mathrm{~S}$. Their band gaps were determined from the intercept between the extrapolated tangent line at the maximum first-derivative points of the absorption edge and the $\mathrm{X}$-axis. The band gap of $\mathrm{TiO}_{2}$ was approximately $3.20 \mathrm{eV}$, which was in agreement with the $\mathrm{UV}$-vis absorption feature of anatase $\mathrm{TiO}_{2}$. The absorption edge was gradually redshifted with the $\mathrm{Fe}_{2} \mathrm{O}_{3}$ 
content loaded on $\mathrm{TiO}_{2}$. The corresponding band gaps of the $0.5 \%, 3 \%$, and $5 \% \mathrm{Fe}_{2} \mathrm{O}_{3} / \mathrm{TiO}_{2}$ dropped to $3.14,2.99$, and $2.87 \mathrm{eV}$, respectively. The $\mathrm{UV}$-vis spectrum of $\mathrm{Fe}_{2} \mathrm{O}_{3}$ illustrated a noticeable redshift compared with those of $\mathrm{TiO}_{2}$ and $0.5-5 \%$ $\mathrm{Fe}_{2} \mathrm{O}_{3} / \mathrm{TiO}_{2}$. The adsorption edge occurring at 530-650 $\mathrm{nm}$ of the pristine $\mathrm{Fe}_{2} \mathrm{O}_{3}$ is probably related to the ligand field transition of $2\left({ }^{6} \mathrm{~A}_{1}\right) \rightarrow\left({ }^{4} \mathrm{~T}_{1}\right)$ (Huang et al., 2017). The band gap was approximately $1.84 \mathrm{eV}$, approaching $1.88 \mathrm{eV}$, as reported by Wang et al. (Mansour et al., 2020). Thus, the redshift for $0.5-5.0 \% \mathrm{Fe}_{2} \mathrm{O}_{3} / \mathrm{TiO}_{2}$ compared with $\mathrm{TiO}_{2}$ was principally attributed to the loading of the $\mathrm{Fe}_{2} \mathrm{O}_{3}$ cluster.

\subsubsection{Photoluminescence spectra and electric properties}

Figure 6(a) shows the PL spectra of $\mathrm{TiO}_{2}$ and $\mathrm{Fe}_{2} \mathrm{O}_{3} / \mathrm{TiO}_{2}$ s. The PL emission peaks at $474 \mathrm{~nm}(2.61 \mathrm{eV})$ and $500 \mathrm{~nm}(2.48 \mathrm{eV})$ were ascribed to the recombination of photoinduced electrons with holes trapped around surface oxygen vacancies (Abdullah et al., 2018). No distinct peak emerged for the $\mathrm{Fe}_{2} \mathrm{O}_{3} / \mathrm{TiO}_{2} \mathrm{~s}$, indicating that the decoration of $\mathrm{Fe}_{2} \mathrm{O}_{3}$ did not result in new interstitial recombination centers. Nevertheless, the PL intensity decreased with the decorated content of $\mathrm{Fe}_{2} \mathrm{O}_{3}$, particularly for $5 \% \mathrm{Fe}_{2} \mathrm{O}_{3} / \mathrm{TiO}_{2}$, illustrating improvement of the separation of photoinduced holes and electrons for the $\mathrm{Fe}_{2} \mathrm{O}_{3} / \mathrm{TiO}_{2} \mathrm{~S}$ as compared to $\mathrm{TiO}_{2}$.

The simulated EIS patterns of $\mathrm{TiO}_{2}$ and $\mathrm{Fe}_{2} \mathrm{O}_{3} / \mathrm{TiO}_{2} \mathrm{~S}$ are presented in Figure 6(b).

The simulated EIS radius of $\mathrm{TiO}_{2}$ was much larger than those of $\mathrm{Fe}_{2} \mathrm{O}_{3} / \mathrm{TiO}_{2} \mathrm{~S}$, illustrating that the decoration of $\mathrm{Fe}_{2} \mathrm{O}_{3}$ greatly reduced the interface charge transfer resistance between the electrode and electrolyte, which was probably attributed to the lower electronic resistivity of $\mathrm{Fe}_{2} \mathrm{O}_{3}$ (Chang et al., 2014). Moreover, the simulated EIS 
351

352

decreased with the content of surface $\mathrm{Fe}_{2} \mathrm{O}_{3}$, probably owing to an increase in tiny crystals within the $\mathrm{Fe}_{2} \mathrm{O}_{3}$, which could significantly reduce the electronic resistivity, although the XRD results did not discern the $\alpha-$ or $\gamma-\mathrm{Fe}_{2} \mathrm{O}_{3}$ crystalline phase (Piva et al., 2016).

The LSV spectra of $\mathrm{TiO}_{2}$ and $\mathrm{Fe}_{2} \mathrm{O}_{3} / \mathrm{TiO}_{2} \mathrm{~S}$ were measured under UV illumination, as illustrated in Figure 6(c). The photocurrent density of $\mathrm{TiO}_{2}$ was much lower than that of $\mathrm{Fe}_{2} \mathrm{O}_{3} / \mathrm{TiO}_{2}$ in the applied voltage range of $-0.25-0.3 \mathrm{~V}$. Additionally, the photocurrent density of the specimens also increased with the content of $\mathrm{Fe}_{2} \mathrm{O}_{3}$. The EIS and LSV results confirmed that the surface decoration of $\mathrm{Fe}_{2} \mathrm{O}_{3}$ could promote the separation efficiency of photogenerated electron-hole pairs of $\mathrm{TiO}_{2}$.

\subsubsection{Electronic structure}

The Mott-Schottky plots for $\mathrm{TiO}_{2}$ and $0.5-5 \% \mathrm{Fe}_{2} \mathrm{O}_{3} / \mathrm{TiO}_{2}$ were constructed at 100 $\mathrm{Hz}$ using an $\mathrm{Ag} / \mathrm{AgCl}$ electrode at $\mathrm{pH}=7.0$, as shown in Figure $7(\mathrm{a})$. The results illustrated that the slope of $1 / \mathrm{C}^{2}$ versus the applied potential was positive for both $\mathrm{TiO}_{2}$ and $0.5-5 \% \mathrm{Fe}_{2} \mathrm{O}_{3} / \mathrm{TiO}_{2}$, demonstrating that they were attributed to n-type semiconductors. Thus, the edges of the flat band (FB) of $\mathrm{TiO}_{2}$ and $0.5-5 \% \mathrm{Fe}_{2} \mathrm{O}_{3} / \mathrm{TiO}_{2}$ are nearly equal to those of the conduction band (CB), as shown in Eq. (8),

$$
\mathrm{CB} \approx \mathrm{FB}(\mathrm{NHE}, \mathrm{pH}=7.0)
$$

The $\mathrm{CBs}$ of $\mathrm{TiO}_{2}$ and $0.5-5 \% \mathrm{Fe}_{2} \mathrm{O}_{3} / \mathrm{TiO}_{2}$ were $-0.86,-0.91,-1.01$, and $-1.07 \mathrm{eV}$, respectively. The corresponding edges of the valence band (VB) could be obtained from the band gap (Eg) and CB as described by Eq. (9),

$$
\mathrm{VB}=\mathrm{CB}+\mathrm{Eg}
$$



respectively. Their VBs were determined to be $2.34,2.23,1.98$, and $1.80 \mathrm{eV}$, respectively, as shown in Figure $7(\mathrm{~b})$. The $\mathrm{CBs}$ of $0.5-5 \% \mathrm{Fe}_{2} \mathrm{O}_{3} / \mathrm{TiO}_{2}$ were higher than that of $\mathrm{TiO}_{2}(-0.86 \mathrm{eV})$. This result is possibly related to the realignment of the two Fermi levels of $\mathrm{Fe}_{2} \mathrm{O}_{3}$ and $\mathrm{TiO}_{2}$ after the $\mathrm{Fe}_{2} \mathrm{O}_{3}$ and $\mathrm{TiO}_{2}$ contacted (Liu et al., 2015). As shown in the schematic diagram of the electronic structure of hybrid $\mathrm{Fe}_{2} \mathrm{O}_{3} / \mathrm{TiO}_{2}$ (see Figure 7(c)), the photogenerated electrons transferred from the conduction band of $\mathrm{Fe}_{2} \mathrm{O}_{3}$ to that of $\mathrm{TiO}_{2}$, while the holes moved from the valence band of $\mathrm{TiO}_{2}$ to $\mathrm{Fe}_{2} \mathrm{O}_{3}$. Thus, $\mathrm{Fe}_{2} \mathrm{O}_{3} / \mathrm{TiO}_{2}$ is beneficial for separating the photogenerated electron-hole pairs.

\subsubsection{EPR}

ratio of $1(\mathrm{~g} \approx 1.990): 2(\mathrm{~g} \approx 2.003): 2(\mathrm{~g} \approx 2.012): 1(\mathrm{~g} \approx 2.021)$ for the $\mathrm{TiO}_{2}$ and ascertained on the $3 \% \mathrm{Fe}_{2} \mathrm{O}_{3} / \mathrm{TiO}_{2}$ than on $\mathrm{TiO}_{2}$, implying that the decoration of $\mathrm{Fe}_{2} \mathrm{O}_{3}$ was more conducive to increasing $\cdot \mathrm{OH}$, which was attributed to the efficient photoinduced electron-hole pairs on the interface of $\mathrm{Fe}_{2} \mathrm{O}_{3}$ and $\mathrm{TiO}_{2}$ (Sun et al., 2012).

\subsection{DFT Calculations}

Figure 9(a) shows the effect of the electric field on the free energy of formation of hydroxyl and hydrogen on $\mathrm{TiO}_{2}(010)$ and $\mathrm{Fe}_{2} \mathrm{O}_{3} / \mathrm{TiO}_{2}(010)$. In the absence of an electric field, energies of 1.56 and $0.70 \mathrm{eV}$ were required for the formation of hydroxyl and hydrogen on $\mathrm{TiO}_{2}(010)$ and $\mathrm{Fe}_{2} \mathrm{O}_{3} / \mathrm{TiO}_{2}(010)$, respectively, indicating that the decomposition of $\mathrm{H}_{2} \mathrm{O}$ to produce hydroxyl and hydrogen could not proceed spontaneously on these slabs; this decomposition reaction resembled the first reaction 
step of the OER for anatase $\mathrm{TiO}_{2}$ in aqueous conditions (Malik et al., 2020). Nevertheless, for $\mathrm{Fe}_{2} \mathrm{O}_{3} / \mathrm{TiO}_{2}(010)$, the free energy of $*_{-} \mathrm{OH}+*_{-} \mathrm{H}$ formation decreased by approximately half compared with $\mathrm{TiO}_{2}$. The top Ti-O bond length $(2.427 \AA$ ) was also reduced to $2.123 \AA$ due to the decoration of amorphous $\mathrm{Fe}_{2} \mathrm{O}_{3}$, meaning that atop $\mathrm{Fe}_{2} \mathrm{O}_{3}$ on $\mathrm{TiO}_{2}(010)$ was more active for splitting $\mathrm{H}_{2} \mathrm{O}$ than $\mathrm{TiO}_{2}(010)$. When a positive external electric field with a strength of $0.05 \mathrm{eV} / \AA$ was applied for $\mathrm{TiO}_{2}(010)$, the free energy $(1.44 \mathrm{eV})$ of $*_{-} \mathrm{OH}+*_{-} \mathrm{H}$ formation decreased slightly. It is worth noting that the free energy of formation on $\mathrm{Fe}_{2} \mathrm{O}_{3} / \mathrm{TiO}_{2}(010)$ decreased dramatically to $-1.04 \mathrm{eV}$ with a positive electric field, thus spontaneously driving the splitting of $\mathrm{H}_{2} \mathrm{O}$ into hydroxyl radicals.

To better understand the effect of the electric field on the formation of hydroxyl and hydrogen, the variation in dipole moment $\left(\mu_{0}\right)$ of hydroxyl and hydrogen as a whole adsorbed on $\mathrm{TiO}_{2}(010)$ and $\mathrm{Fe}_{2} \mathrm{O}_{3} / \mathrm{TiO}_{2}(010)$ was compared. $\mu_{0}$ is equivalent to the difference between the dipole moment of $*_{-} \mathrm{OH}+*_{-} \mathrm{H}\left(*_{-} \mathrm{OH}\right)$ and that of the bare catalyst slab (Deshlahra et al., 2009), which were both obtained from the resulting DFT file. Without an electric field, the dipole moments of $*_{-} \mathrm{OH}+{ }^{*}-\mathrm{H}$ for $\mathrm{TiO}_{2}(010)$ and $\mathrm{Fe}_{2} \mathrm{O}_{3} / \mathrm{TiO}_{2}(010)$ were 0.019 and $0.171 \mathrm{e} \AA$, respectively, which suggested the more negative charges were distributed on the oxygen atoms of the hydroxyl and on the hydrogen atoms of the $\mathrm{Fe}_{2} \mathrm{O}_{3} / \mathrm{TiO}_{2}(010)$ than those of the $\mathrm{TiO}_{2}(010)$. The change in free energy $(\Delta \mathrm{E}, \mathrm{eV})$ of ${ }^{*} \mathrm{OH}+{ }^{*}-\mathrm{H}$ formation due to exposure to an electric field can be predicted by the first-order Stark effect as

$$
\Delta \mathrm{E}=-\mu_{0} \times \mathrm{F}
$$


where $\mu_{0}(\mathrm{e} \AA)$ is the dipole moment of the adsorbate without an electric field and F $(\mathrm{V} / \AA)$ is the strength of an external electric field. The $\Delta \mathrm{E}$ was -0.00865 and $-0.00097 \mathrm{eV}$ for $\mathrm{Fe}_{2} \mathrm{O}_{3} / \mathrm{TiO}_{2}(010)$ and $\mathrm{TiO}_{2}(010)$, respectively, according to Eq. (10), when the electric field was set to $0.05 \mathrm{eV} / \AA$. Although both $\Delta \mathrm{E}$ values obtained by Eq. (10) were much smaller than those calculated based on the structure optimization results, the $\Delta \mathrm{E}$ of $\mathrm{Fe}_{2} \mathrm{O}_{3} / \mathrm{TiO}_{2}(010)$ was higher than that of $\mathrm{TiO}_{2}(010)$; this trend demonstrated that the external electric field in the positive direction favors the formation of hydroxyl and hydrogen on the surface of $\mathrm{Fe}_{2} \mathrm{O}_{3} / \mathrm{TiO}_{2}(010)$. Additionally, the $\mathrm{Fe}-\mathrm{O}$ bond length (2.077) between the Fe atom and hydroxyl and the O-H bond (1.262 $\AA$ ) of hydroxyl were much shorter than the corresponding lengths without an electric field, which were 2.123 and $1.274 \AA$, as shown in Figure 9(a), suggesting that the hydroxyl was bonded more closely to the $\mathrm{Fe}_{2} \mathrm{O}_{3} / \mathrm{TiO}_{2}(010)$ under a positive electric field. It is noted that with the positive electric field, the dissociated hydrogen atom from $\mathrm{H}_{2} \mathrm{O}$ preferred to interact with one Fe atom at a shorter distance of $2.392 \AA$, while before the electric field was added, the hydrogen atom was physically connected to one oxygen atom of $\mathrm{Fe}_{2} \mathrm{O}_{3}$ at a distance of $2.994 \AA$. In contrast, a more stable structure was assigned to an unbroken $\mathrm{H}_{2} \mathrm{O}$ molecule adsorbed on $\mathrm{TiO}_{2}(010)$ without the formation of hydroxyl and hydrogen moieties under a positive electric field. The distance between the surface oxygen and surface $\mathrm{Ti}$ atom was elongated to $3.208 \AA$, suggesting that $\mathrm{H}_{2} \mathrm{O}$ was more difficult to oxidize and split into hydroxyl on $\mathrm{TiO}_{2}(010)$ than on $\mathrm{Fe}_{2} \mathrm{O}_{3} / \mathrm{TiO}_{2}(010)$ under a positive electric field. The effect of a negative electric field on the formation of hydroxyl was also investigated. According to Eq. (10), the predicted $\Delta \mathrm{E}$ for the change in the formation 
energy would be 0.00865 and $0.00097 \mathrm{eV}$ for $\mathrm{TiO}_{2}(010)$ and $\mathrm{Fe}_{2} \mathrm{O}_{3} / \mathrm{TiO}_{2}(010)$ under a field strength of $-0.05 \mathrm{~V} / \AA$, indicating that an electric field in the negative direction was not beneficial for splitting $\mathrm{H}_{2} \mathrm{O}$ compared with the positive electric field. The formation free energies of the hydroxyl and hydrogens were also determined based on structure optimization, as shown in Figure 9(a), which were $1.01 \mathrm{eV}$ for $\mathrm{TiO}_{2}(010)$ and $-0.22 \mathrm{eV}$ for $\mathrm{Fe}_{2} \mathrm{O}_{3} / \mathrm{TiO}_{2}(010)$. They were much lower than those under a positive electric field, demonstrating that a positive electric field was more effective than a negative electric field to promote hydroxyl production. Additionally, the atomic distance between the oxygen atom of the hydroxyl and the $\mathrm{Fe}$ or $\mathrm{Ti}$ atom, and the distance between the dissociated hydrogen atom and the $\mathrm{Fe}$ atom became longer under a negative electric field, as shown in Figure 9(a).

When the detached hydrogen atom of $\mathrm{H}_{2} \mathrm{O}$ was lost under the gaseous flow, the production of hydroxyl could not still proceed spontaneously regardless of the direction in which the electric field was applied, as illustrated in Figure 9(b). For instance, the free energy of $*_{-} \mathrm{OH}$ formation for $\mathrm{TiO}_{2}(010)$ was $1.759 \mathrm{eV}$, while it was $1.445 \mathrm{eV}$ for $\mathrm{Fe}_{2} \mathrm{O}_{3} / \mathrm{TiO}_{2}(010)$. The free energy of $*_{-} \mathrm{OH}$ formation alone increased to $2.927 \mathrm{eV}$ and $2.423 \mathrm{eV}$ for $\mathrm{TiO}_{2}(010)$ and $\mathrm{Fe}_{2} \mathrm{O}_{3} / \mathrm{TiO}_{2}(010)$, respectively, when a positive electric field was added. Likewise, the negative electric field resulted in free energies of 1.445 $\mathrm{eV}$ and $0.7817 \mathrm{eV}$. The results implied that the hydrogen atom that was dissociated from the $\mathrm{H}_{2} \mathrm{O}$ molecule was more likely to remain on the $\mathrm{TiO}_{2}(010)$ and $\mathrm{Fe}_{2} \mathrm{O}_{3} / \mathrm{TiO}_{2}(010)$ than to be taken away by flow gases.

Figure 10 illustrates the electric field's influence on the density of states of 
$\mathrm{Fe}_{2} \mathrm{O}_{3} / \mathrm{TiO}_{2}$ and $\mathrm{Fe}_{2} \mathrm{O}_{3} / \mathrm{TiO}_{2}(010)$ with the adsorbed hydroxyl and hydrogen. The band gap of $\mathrm{Fe}_{2} \mathrm{O}_{3} / \mathrm{TiO}_{2}$ was approximately $2.30 \mathrm{eV}$, as shown in the total density state $\mathrm{Fe}_{2} \mathrm{O}_{3} / \mathrm{TiO}_{2}$ in Figure 10(a). No distinct energy state emerged within the band gap of $\mathrm{Fe}_{2} \mathrm{O}_{3} / \mathrm{TiO}_{2}$, concurring with the PL profile of $\mathrm{Fe}_{2} \mathrm{O}_{3} / \mathrm{TiO}_{2}$. Additionally, the projected density state showed that the profile of Fe $3 \mathrm{~d}$ mainly resided on the edge of the conduction band. Figure 10(b)-(d) shows that the band gaps of $\mathrm{Fe}_{2} \mathrm{O}_{3} / \mathrm{TiO}_{2}(010)$ with adsorbed hydroxyl and hydrogen with and without an electric field were all $2.30 \mathrm{eV}$, suggesting the external electric field did not change the magnitude of the band gap of $\mathrm{Fe}_{2} \mathrm{O}_{3} / \mathrm{TiO}_{2}(010)$. However, without the electric field, a few energy states were distributed within the band gap for the $\mathrm{Fe}_{2} \mathrm{O}_{3} / \mathrm{TiO}_{2}(010)$ that had adsorbed hydroxyl and hydrogen; these energy states were mainly derived from the interaction between Fe $3 \mathrm{~d}$ and the sp hybrid orbitals of the surface hydrogen and oxygen atoms, indicating a strong bond formed between the Fe and atom oxygen and hydrogen, as shown in Figure 10(b). However, once the positive electric field was applied to the $\mathrm{Fe}_{2} \mathrm{O}_{3} / \mathrm{TiO}_{2}(010)$ with adsorbed hydroxyl and hydrogen, most of the band gap density states vanished, particularly at the higher energy level. Only two states closer to the valance band margin remained, revealing that the bond energy between the $\mathrm{Fe} 3 \mathrm{~d}$ and hybrid $\mathrm{OH}$ orbitals became more stable under a positive electric field, thus promoting the bond to be much stronger (see Figure 10(c)). In contrast, if a negative electric field was added, the location and number of the energy state remained almost unchanged, suggesting that a negative direction less influenced the bond of the $\mathrm{Fe} 3 \mathrm{~d}$ and $\mathrm{OH}$ hybrid orbitals, as illustrated in Figure 10(d). 

band, was $-0.72 \mathrm{eV}$, while that of $\mathrm{Fe}_{2} \mathrm{O}_{3} / \mathrm{TiO}_{2}+$ hydroxyl + hydrogen was $1.12 \mathrm{eV}$, as shown in Figure 10(a) and (b). The remarkable shift of the Fermi level towards the conduction band margin for $\mathrm{Fe}_{2} \mathrm{O}_{3} / \mathrm{TiO}_{2}+$ hydroxyl + hydrogen resulted from the new mid-gap state of the interaction between $\mathrm{Fe} 3 \mathrm{~d}$ and atop hydrogen and oxygen atoms.

When an external positive electric field was applied to the slab, the Fermi level $(0.09$ $\mathrm{eV}$ ) decreased markedly in comparison to that without an electric field, as shown in Figure 10(c). This implied that the positive electric field attracted more positive charges that accumulated on the surface of $\mathrm{Fe}_{2} \mathrm{O}_{3} / \mathrm{TiO}_{2}$, thus decreasing the Fermi level decreasing the formation of hydroxyl and hydrogen. atom of $\mathrm{CHOH}$, as well as the surface oxygen and carbon atom of $\mathrm{CHOH}$. Then, the 
506

507

508

509

510

511

512

513

514

515

516

517

518

519

520

521

522

523

524

525

526

527

fragments of $\mathrm{C}-\mathrm{O}$ and $\mathrm{H}$ then reacted with $\mathrm{O}_{2}$ to produce $\mathrm{CO}_{2}$ and $\mathrm{H}_{2} \mathrm{O}$. The $\mathrm{Fe}_{2} \mathrm{O}_{3} / \mathrm{TiO}_{2} \mathrm{~s}$ had a much higher removal efficiency than neat $\mathrm{TiO}_{2}$, reaching more than $80 \%$, particularly for $3 \% \mathrm{Fe}_{2} \mathrm{O}_{3} / \mathrm{TiO}_{2}$, which had the highest removal efficiency of $86 \%$ among these catalysts. The enhancement of the removal efficiency by $\mathrm{Fe}_{2} \mathrm{O}_{3} / \mathrm{TiO}_{2}$ was probably due to the stronger interaction between the surface $\mathrm{Fe}_{2} \mathrm{O}_{3} / \mathrm{TiO}_{2}$ and $\mathrm{CHOH}$ than between $\mathrm{TiO}_{2}$ and $\mathrm{CHOH}$, whose adsorption energies were determined to be -1.49 and $-1.08 \mathrm{eV}$, respectively, as illustrated in Figure S-1. When an external voltage of 150 $\mathrm{V}$ was introduced into the reactor, the removal efficiencies were nearly the same as those without the addition of applied voltage for both $\mathrm{TiO}_{2}$ and $\mathrm{Fe}_{2} \mathrm{O}_{3} / \mathrm{TiO}_{2} \mathrm{~s}$, conveying that an external voltage of $150 \mathrm{~V}$ on the catalysts could not directly influence the interaction between $\mathrm{CHOH}$ and $\mathrm{TiO}_{2}\left(\mathrm{Fe}_{2} \mathrm{O}_{3} / \mathrm{TiO}_{2} \mathrm{~s}\right)$.

Figure 11(b) shows that when the UV irradiation was added, the photocatalytic removal efficiencies of $\mathrm{CHOH}$ were approximately $68 \%$ and $85-97 \%$ by $\mathrm{TiO}_{2}$ and $\mathrm{Fe}_{2} \mathrm{O}_{3} / \mathrm{TiO}_{2} \mathrm{~s}$, respectively, an overall increase of 5-10\% compared with their removal efficiency without UV irradiation. The increase in the removal efficiencies was attributed to the oxidation of $\mathrm{CHOH}$ by hydroxyl radicals derived from the photoinduced holes with surface adsorbed $\mathrm{H}_{2} \mathrm{O}$, as described by Eqs. (11)-(12),

$$
\begin{aligned}
& \cdot \mathrm{OH}+\mathrm{CHOH} \rightarrow \mathrm{H}_{2} \mathrm{O}+\mathrm{CHO} \cdot \\
& 2 \mathrm{CHO}+\mathrm{O}_{2} \rightarrow \mathrm{HCOOH}+\mathrm{CO}_{2}
\end{aligned}
$$

Additionally, the increment contributed by $\mathrm{Fe}_{2} \mathrm{O}_{3} / \mathrm{TiO}_{2} \mathrm{~s}$ was $7-10 \%$, much higher than $5 \%$ by $\mathrm{TiO}_{2}$, owing to the interfacial transportation of photoinduced electrons and a lower electrical impedance of $\mathrm{Fe}_{2} \mathrm{O}_{3} / \mathrm{TiO}_{2}$. When the electric field and $\mathrm{UV}$ irradiation 
were simultaneously applied to the reaction system, the removal efficiencies of $\mathrm{CHOH}$ were not further enhanced, suggesting that the interaction between the surface Ti and Fe atoms and $\mathrm{CHOH}$ could not be influenced by such a relatively low electric field, even if electrons had moved freely within their conduction band.

When a mixed flue gas with a relative humidity of $50 \%$ was supplied into the reactor, the removal efficiencies of $\mathrm{CHOH}$ by $\mathrm{TiO}_{2}$ and $0.5-5 \% \mathrm{Fe}_{2} \mathrm{O}_{3} / \mathrm{TiO}_{2}$ under irradiation or not were all depressed compared to those without $\mathrm{H}_{2} \mathrm{O}$ interference, as illustrated in Figure 12(a) and (b), indicating that $\mathrm{H}_{2} \mathrm{O}$ caused competitive adsorption with $\mathrm{CHOH}$. Nevertheless, either the catalytic $(41 \%)$ or photocatalytic $(51 \%)$ removal efficiencies of $\mathrm{CHOH}$ by $\mathrm{TiO}_{2}$ were lower than $54-60 \%$ and $70-80 \%$ by $0.5-$ $5 \% \mathrm{Fe}_{2} \mathrm{O}_{3} / \mathrm{TiO}_{2}$, implying that the decoration of $\mathrm{Fe}_{2} \mathrm{O}_{3}$ can relieve $\mathrm{H}_{2} \mathrm{O}$ inhibition to some degree. When an external voltage of $150 \mathrm{~V}$ was introduced, the catalytic removal efficiencies of $\mathrm{CHOH}$ by $\mathrm{TiO}_{2}$ and $\mathrm{Fe}_{2} \mathrm{O}_{3} / \mathrm{TiO}_{2}$ were still not enhanced without irradiation. Noticeably, once UV irradiation was added, their photocatalytic activity was markedly promoted, and the removal efficiencies had increased by approximately $5 \%$ and $10 \%$ for $\mathrm{TiO}_{2}$ and $\mathrm{Fe}_{2} \mathrm{O}_{3} / \mathrm{TiO}_{2}$, respectively. Consistent with the DFT results, the combined effect of the applied electric field and UV irradiation on the $\mathrm{Fe}_{2} \mathrm{O}_{3} / \mathrm{TiO}_{2}$ was more beneficial for enhancing the removal efficiency of $\mathrm{CHOH}$ than $\mathrm{TiO}_{2}$. Additionally, the $\mathrm{pH}$ of the effluent gas during the photoelectrical catalytic degradation of $\mathrm{CHOH}$ under a relative humidity of $50 \%$ was sampled at the outlet and measured to be neutral, experimentally revealing that the protons were not taken away by the carrier gases with the external electric field. Additionally, after the reaction finished, we observed that the 
$\mathrm{Fe}_{2} \mathrm{O}_{3} / \mathrm{TiO}_{2}$ retained the same faint, slightly yellowish as it had when it was fresh, revealing that the electric field-assisted photooxidation of $\mathrm{CHOH}$ on $\mathrm{Fe}_{2} \mathrm{O}_{3} / \mathrm{TiO}_{2}$ does not cause an accumulation of photogenerated electrons or holes on the $\mathrm{Fe}_{2} \mathrm{O}_{3} / \mathrm{TiO}_{2}$, therefore avoiding drastic changes in its structure. The photogenerated holes were principally distributed on $\mathrm{Fe}_{2} \mathrm{O}_{3}$, which finally participated in the formation of hydroxyl radicals to oxidize $\mathrm{CHOH}$. The photogenerated electrons trapped by the $\mathrm{Ti}^{3+}$ had different reaction pathways, dominantly including a) reacting with $\mathrm{O}_{2}$ to produce $\cdot \mathrm{O}_{2}{ }^{-}$ for $\mathrm{CHOH}$ oxidation or directly participating in the attachment of the carbonyl of $\mathrm{CHOH}$ to $\mathrm{Ti}^{3+}$ (Cremer et al., 2014), or (b) moving towards the positive electrode of the input DC device, particularly for those produced by the $\mathrm{TiO}_{2}$ or $\mathrm{Fe}_{2} \mathrm{O}_{3} / \mathrm{TiO}_{2}$ nanogranules having physical contact with the mesh plates.

Additionally, the photoelectrical removal efficiencies of $\mathrm{CHOH}$ under different relative humidity $(20-80 \%)$ conditions were much higher than their photooxidation efficiency of $\mathrm{CHOH}$, as illustrated in Figure S-2. Therefore, combining the DFT and EPR results, the resistance to the competitive adsorption of $\mathrm{H}_{2} \mathrm{O}$ was attributed to the more hydroxyl radicals were photoelectrical splitting of $\mathrm{H}_{2} \mathrm{O}$ molecules.

By adjusting the distance between the two mesh plates to change the electric field's strength, we investigated the relationship between the applied electric field's strength and the incremental change in removal efficiency and rate compared to those of the samples without an applied electric field, as shown in Figure 13(a). The results illustrated that the removal efficiencies of $\mathrm{CHOH}$ by $3 \% \mathrm{Fe}_{2} \mathrm{O}_{3} / \mathrm{TiO}_{2}$ were $74.3 \pm 1.83 \%$, $76.8 \pm 1.57 \%, 86.8 \pm 1.30 \%$, and $89.9 \pm 1.57 \%$, under electric field strengths of 0,2500 
5000 , and $7500 \mathrm{~V} / \mathrm{m}$, respectively, suggesting an increase in the removal efficiencies with the electric field strength. However, the relationship between the increments of removal rate and the electric field magnitude was not a good linear relationship, as illustrated in Figure 13(b). The results implied that the formation of free energy of hydroxyl depends on the electric field strength, and other reaction parameters such as the energy barrier are possibly influenced

The removal rates of $\mathrm{CHOH}$ with various low levels of power input were compared in Figure 14. Without competitive adsorption of $\mathrm{H}_{2} \mathrm{O}$, 15-W lump irradiation could improve the removal rates by $7 \%$ and $10 \%$, reaching maximum removal rates of 2954 and $4129 \mathrm{ng} / \mathrm{g} / \mathrm{min}$ for $\mathrm{TiO}_{2}$ and $3 \% \mathrm{Fe}_{2} \mathrm{O}_{3} / \mathrm{TiO}_{2}$, respectively, while the $5-\mathrm{W}$ electric field contributed little to the enhancement. Under a relative humidity of 50\%, the removal rates of $\mathrm{CHOH}$ significantly dropped for both $\mathrm{TiO}_{2}$ and $\mathrm{Fe}_{2} \mathrm{O}_{3} / \mathrm{TiO}_{2}$ without any input energy. However, after introducing $15-\mathrm{W}$ irradiation, the removal rates of $\mathrm{CHOH}$ increased by $26 \%$ and $24 \%$ for $\mathrm{TiO}_{2}$ and $3 \% \mathrm{Fe}_{2} \mathrm{O}_{3} / \mathrm{TiO}_{2}$, respectively. Moreover, the 5-W electric field was further added, the removal rates increased further by $13 \%$ and $23 \%$, particularly for $3 \% \mathrm{Fe}_{2} \mathrm{O}_{3} / \mathrm{TiO}_{2}$, which had nearly the same efficacy as the 15-W input power. Additionally, the final photoelectrocatalytic oxidation rate reached $3747 \mathrm{ng} / \mathrm{g} / \mathrm{min}$ for $3 \% \mathrm{Fe}_{2} \mathrm{O}_{3} / \mathrm{TiO}_{2}$, which approached its highest $\mathrm{H}_{2} \mathrm{O}$-free removal rate of $4130 \mathrm{ng} / \mathrm{g} / \mathrm{min}$. Therefore, a total of $20-\mathrm{W}$ low-power input was verified to effectively resist the inhibition of $\mathrm{H}_{2} \mathrm{O}$ on the $\mathrm{CHOH}$ removal by $3 \% \mathrm{Fe}_{2} \mathrm{O}_{3} / \mathrm{TiO}_{2}$.

\section{Conclusions}


environment was theoretically and experimentally investigated in this study. The DFT results demonstrated that a positive electric field was beneficial for splitting $\mathrm{H}_{2} \mathrm{O}$ into a hydroxyl and a hydrogen atom on $\mathrm{TiO}_{2}$ and $\mathrm{Fe}_{2} \mathrm{O}_{3} / \mathrm{TiO}_{2}$ than a negative electric field, and without any electric fields. The $\mathrm{Fe}_{2} \mathrm{O}_{3}$ decoration can enhance the formation of hydroxyls than $\mathrm{TiO}_{2}$ under the positive electric field. The DOS result showed that the bond energy of $\mathrm{Fe} 3 \mathrm{~d}$ orbital and the sp hybrid orbital of $\mathrm{OH}$ decreased to a lower energy state, thus leading to the hydroxyl formation. Additionally, it was favorable for the dissociated hydrogen atom from the $\mathrm{H}_{2} \mathrm{O}$ molecule to attach to the surface of catalysts rather than being transported by flow gas. The experimental results demonstrated that the addition of a low-energy external field could not directly improve the removal efficiency of $\mathrm{CHOH}$ but could relieve the adsorptive adsorption of the $\mathrm{H}_{2} \mathrm{O}$ molecule, concurring with the DFT results. $\mathrm{Fe}_{2} \mathrm{O}_{3} / \mathrm{TiO}_{2}$ exhibited a higher $\mathrm{H}_{2} \mathrm{O}$ resistance than $\mathrm{TiO}_{2}$, which was attributed to more hydroxyl radicals produced on $\mathrm{Fe}_{2} \mathrm{O}_{3} / \mathrm{TiO}_{2}$. In the future, we will focus on the influence of a high-voltage electric field on the photooxidation of $\mathrm{CHOH}$ by more active modified $\mathrm{TiO}_{2}$, and investigate the direct influence of dipole moment of $\mathrm{CHOH}$, adsorption of $\mathrm{CHOH}$.

\section{Acknowledgment}

This study was performed under the auspices of the Xiamen Science \& Technology Plan, under the contract number of 3502Z20183026, the National Key Research and Development Program (2019YFC0214305), and the National Natural Science Foundation of China, China, (Grant No. 51908230). The authors are grateful to their financial supports in order to accomplish this study. The supplemented materials have 
616 other 1 table and 2 figures.

617 
Ethics approval and consent to participate: Not applicable

\section{Consent for publication: Not applicable}

Competing interests: The authors declare that they have no competing interests

Availability of data and materials: Not applicable

Funding: This study was performed under the auspices of the Xiamen Science \& Technology Plan, under the contract number of 3502Z20183026, the National Key Research and Development Program (2019YFC0214305), and the National Natural Science Foundation of China, China, (Grant No. 51908230). W. Xia gratefully acknowledge the support from the Department of Civil \& Environmental Engineering at North Dakota State University.

\section{Authors' contributions: Not applicable}

Dong Jing: Writing-original draft preparation; Data curation; Methodology.

Li Qing: Data curation; Methodology.

Xia Wenjie: Writing-reviewing and editing; Software; Validation.

Lv Bihong: Writing-reviewing and editing.

Jing Guohua: Writing-reviewing and editing.

Shen Huazhen: Conceptualization; Writing-reviewing and editing.

Yuan Chung-shin: Conceptualization; Writing-reviewing and editing. 


\section{References}

Abdullah SA, Sahdan MZ, Nafarizal N, Saim H, Bakri AS, Rohaida CHC, Adriyanto F, Sari Y (2018) Photoluminescence study of trap-state defect on $\mathrm{TiO}_{2}$ thin films at different substrate temperature via RF magnetron sputtering. J Phys: Conf Ser 995: 012067.

Adawiah MARa, Zaidon A, Izreen FAN, Bakar ES, Hamami SM, Paridah MT (2012) Addition of urea as formaldehyde scavenger for low moleclar water phenol formaldehyde-treated compeg wood. J Tropical Forest Sci 24: 348-357.

Chang KC, Ji WF, Lai MC, Hsiao YR, Hsu CH, Chuang TL, Wei Y, Yeh JM, Liu WR (2014) Synergistic effects of hydrophobicity and gas barrier properties on the anticorrosion property of PMMA nanocomposite coatings embedded with graphene nanosheets. Polym Chem 5: 1049-1056.

Chen BB, Zhu XB, Crocker M, Wang Y, Shi C (2014) FeOx-supported gold catalysts for catalytic removal of formaldehyde at room temperature. Appl Catal, B 154-155: 73-81.

Ciancio R, Carlino E, Rossi G, Aruta C, Uccio USd, Vittadini A, Selloni A (2012) Magn'eli-like phases in epitaxial anatase $\mathrm{TiO}_{2}$ thin films. Phys Rev B 86: 104110.

Cremer T, Jensen SC, Friend CM (2014) Enhanced photo-oxidation of formaldehyde on highly reduced o- $\mathrm{TiO}_{2}(110)$. J Phys Chem C 118: 29242-29251.

Deshlahra P, Wolf EE, Schneider WF (2009) A periodic density functional theory analysis of $\mathrm{CO}$ chemisorption on $\mathrm{Pt}(111)$ in the presence of uniform eectric fields. J Phys Chem A 113: 4125-4133.

Ding CS, Nohira T, Hagiwara R (2017) $\mathrm{TiO}_{2}-\mathrm{Fe}_{2} \mathrm{O}_{3}$ nanocomposites as high-capacity negative electrode materials for rechargeable sodium-ion batteries. Sustainable Energy \& Fuels 1: 371-376.

Ding JJ, Rui ZB, Lyu PT, Liu YL, Liu XK, Ji HB (2018) Enhanced formaldehyde oxidation performance over Pt/ZSM-5 through a facile nickel cation modification. Appl Sur Sci 457: 670-675.

Duan ZY, Henkelman G (2019) Theoretical resolution of the exceptional oxygen reduction activity of $\mathrm{Au}(100)$ in alkaline media. ACS Catal 9: 5567-5573.

Fang J, Bi XZ, Si DJ, Jiang ZQ, Huang WX (2007) Spectroscopic studies of interfacial structures of $\mathrm{CeO}_{2}-\mathrm{TiO}_{2}$ mixed oxides. Appl Surf Sci 253: 8952-8961.

Filhol JS, Neurock M (2006) Elucidation of the electrochemical activation of water over Pd by first principles. Angew Chem Int Ed 45: 402-406.

Guo JH, Lin CX, Jiang CJ, Zhang PY (2019) Review on noble metal-based catalysts for formaldehyde oxidation at room temperature. Appl Surf Sci 475: 237-255.

Huang RK, Liang RW, Fan HM, Ying SM, Wu L, Wang XX, Yan GY (2017) Enhanced photocatalytic fuel denitrification over $\mathrm{TiO}_{2} / \alpha-\mathrm{Fe}_{2} \mathrm{O}_{3}$ nanocomposites under visible light irradiation. Sci Rep 7: 7858.

Huang ZW, Du YY, Zhang J, Wu XM, Shen HZ, Jing GH (2019) Exceptional activity over the submonolayer $\mathrm{MoO}_{3}$ motif on $\mathrm{TiO}_{2}$ for nitrogen oxide emission abatement. Environ Sci Technol 53: 5309-5318. 
Jörg N, Matthias S (1992) Adsorbate-substrate and adsorbate-adsorbate interactions of $\mathrm{Na}$ and K adlayers on Al(111). Phys Rev B 46: 16067-16080.

Jørgensen JE, Mosegaard L, Thomsen LE, ensen JR, Hanson JC (2007) Formation of $\gamma-\mathrm{Fe}_{2} \mathrm{O}_{3}$ nanoparticles and vacancy ordering: An in situ X-ray powder diffraction study. J Solid State Chem 180: 180-185.

Kim KH, Jahan SA, Lee JT (2011) Exposure to formaldehyde and its potential human health hazards. J Environ Sci Health Part C-Environ Carcinog Ecotoxico Rev 29: 277-299.

Kodan N, Agarwal K, Mehta BR (2019) All-oxide $\alpha-\mathrm{Fe}_{2} \mathrm{O}_{3} / \mathrm{H}: \mathrm{TiO}_{2}$ heterojunction photoanode: A platform for stable and enhanced photoelectrochemical performance through favorable band edge alignment. J Phys Chem C 123: 33263335.

Li R, Huang Y, Zhu DD, Ho WK, Lee SC, Cao JJ (2020) A Review of $\mathrm{Co}_{3} \mathrm{O}_{4}$-based Catalysts for Rormaldehyde Oxidation at Low Temperature: Effect parameters and reaction mechanism. Aerosol Sci Eng 4: 147-168.

Liang WJ, Li J, Jin YQ (2012) Photo-catalytic degradation of gaseous formaldehyde by $\mathrm{TiO}_{2} / \mathrm{UV}, \mathrm{Ag} / \mathrm{TiO}_{2} / \mathrm{UV}$ and $\mathrm{Ce} / \mathrm{TiO}_{2} / \mathrm{UV}$. Build Environ 51: 345-350.

Liu J, Yang SL, Wu W, Tian QY, Cui SY, Dai ZG, Ren F, Xiao XH, Jiang CZ (2015) $3 \mathrm{D}$ flowerlike $\alpha-\mathrm{Fe}_{2} \mathrm{O}_{3} @ \mathrm{TiO}_{2}$ core-shell nanostructures: general synthesis and enhanced photocatalytic performance. ACS Sustain Chem Eng 3:2975-2984.

Liu J, Olds D, Peng R, Yu L, Foo GS, Qian S, Keum J, Guiton BS, Wu ZL, Page K (2017) Quantitative analysis of the morphology of $\{101\}$ and $\{001\}$ faceted anatase $\mathrm{TiO}_{2}$ nanocrystals and its implication on photocatalytic activity. Chem Mater 29: 5591-5604.

Lozovoi AY, Alavi A (2003) Reconstruction of charged surfaces: General trends and a case study of Pt(110) and $\mathrm{Au}(110)$. Phys Rev B 68: 245416.

Malik AS, Liu TF, Dupuis M, Li RG, Li C (2020) Water oxidation on $\mathrm{TiO}_{2}$ : A comparative DFT study of $1 \mathrm{e}^{-}, 2 \mathrm{e}^{-}$, and $4 \mathrm{e}^{-}$processes on rutile, anatase, and brookite. J Phys Chem C 124: 8094-8100.

Mansour H, Omri K, Bargougui R, Ammar S (2020) Novel $\alpha-\mathrm{Fe}_{2} \mathrm{O}_{3} / \mathrm{TiO}_{2}$ nanocomposites with enhanced photocatalytic activity. Appl Phys A 126: 151.

Maslen EN, Streltsov VA, Streltsova NR, N. Ishizawa (1994) Synchrotron X-ray study of the electron density in $\alpha-\mathrm{Fe}_{2} \mathrm{O}_{3}$. Acta Crystallographica Section B 50: 435-441.

Miao L, Wang JL, Zhang PY (2019) Review on manganese dioxide for catalytic oxidation of airborne formaldehyde. Appl Surf Sci 466: 441-453.

Moniz SJA, Shevlin SA, An X, Guo ZX, Tang Jw (2014) $\mathrm{Fe}_{2} \mathrm{O}_{3}-\mathrm{TiO}_{2}$ nanocomposites for enhanced charge separation and photocatalytic activity. Chem-A Europe J 20: 15571-15579.

Nie LH, Yu JG, Jaroniec M, Tao FF (2016) Room-temperature catalytic oxidation of formaldehyde on catalysts. Catal Sci Technol 6: 3649-3669.

Nørskov JK, Rossmeisl J, Logadottir A, Lindqvist J, Kitchin JR, Bligaard T, Jónsson H (2004) Origin of the overpotential for oxygen reduction at a fuel-cell cathode. J Phys Chem B 108: 17886-17892.

Pan J, Liu G, Lu GQ, Cheng HM (2011) On the true photoreactivity order of $\{001\}$, 
$\{010\}$, and $\{101\}$ facets of anatase $\mathrm{TiO}_{2}$ crystals. Angew Chem Int Ed 50: 21332137.

Pawan K, Heung NL, Rajesh K (2014) Synthesis of phase pure iron oxide polymorphs thin films and their enhanced magnetic properties. J Mater Sci: Mater Electron 25: 4553-4561.

Piva DH, Piva RH, Venturini J, Ramon J, Caldas V, Morelli MR, Bergmann CP (2016) Effect of $\mathrm{Fe}_{2} \mathrm{O}_{3}$ content on the electrical resistivity of aluminous porcelain applied to electrical insulators. Ceram Int 42: 5045-5052.

Shen Hz, Lin MJ, Wang LD, Huang ZW, Wu XM, Jiang XQ, Li Q, Chen CL, Zhao JX, Jing GH, Yuan CS (2021) Experimental and theoretical investigation of the enhancement of the photo-oxidation of $\mathrm{Hg}^{0}$ by $\mathrm{CeO}_{2}$-modified morphologycontrolled anatase $\mathrm{TiO}_{2}$. J Hazard Mater 406: 124535.

Shim SH, Bengtson A, Morgan D, Sturhahn W, Catalli K, Zhao JY, Lerche M, Prakapenka V (2009) Electronic and magnetic structures of the postperovskite-type $\mathrm{Fe}_{2} \mathrm{O}_{3}$ and implications for planetary magnetic records and deep interiors. Proc Nat Acad Sci 106: 5508.

Sun Q, Leng WH, Li Z, Xu Y (2012) Effect of surface $\mathrm{Fe}_{2} \mathrm{O}_{3}$ clusters on the photocatalytic activity of $\mathrm{TiO}_{2}$ for phenol degradation in water. J Hazard Mater 229-230: 224-232.

Sun S, Ding JJ, Bao J, Gao C, Qi ZM, Li CX (2010) Photocatalytic oxidation of gaseous formaldehyde on $\mathrm{TiO}_{2}$ : An in-situ DRIFTS study. Catal Lett 137: 239-246.

Tang XJ, Bai Y, Duong A, Smith MT, Li LY, Zhang LP (2009) Formaldehyde in China: Production, consumption, exposure levels, and health effects. Environ Int 35: $1210-1224$.

Tasbihi M, Bendyna JK, Notten P, Hintzen H (2015) A short review on photocatalytic degradation of formaldehyde. J Nanosci Nanotech 15: 6386-6396.

Tiewcharoen S, Warakulwit C, Lapeyre V, Garrigue P, Fourier L, Elissalde C, Buffière S, Legros P, Marion Gayot, Limtrakul J, Kuhn A (2017) Anisotropic metal deposition on $\mathrm{TiO}_{2}$ particles by electric-field-induced charge separation. Angew Chem Int Ed 56: 11431-11435.

Tsai CY, Hsi HC, Kuo TH, Chang YM, Liou JH (2013) Preparation of Cu-doped $\mathrm{TiO}_{2}$ photocatalyst with thermal plasma torch for low-concentration mercury removal. Aerosol Air Qual Res 13: 639-648.

Valdés Á, Qu ZW, Kroes GJ, Rossmeisl J, Nørskov JK (2008) Oxidation and photooxidation of water on $\mathrm{TiO}_{2}$ surface. J Phys Chem C 112: 9872-9879.

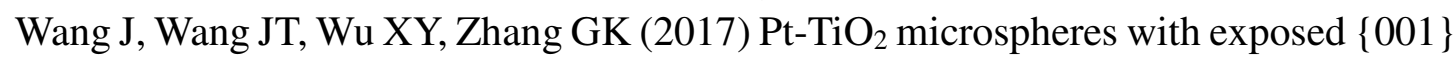
facets for degradation of formaldehyde in air: Formation mechanism and enhanced visible light photocatalytic activity. Mater Res Bull 96: 262-269.

Wang S, Lian JS, Zheng WT, Jiang Q (2012) Photocatalytic property of Fe doped anatase and rutile $\mathrm{TiO}_{2}$ nanocrystal particles prepared by sol-gel technique. Appl Surf Sci 263: 260-265.

Wang YS, Wang SR, Zhang HX, Gao XL, Yang JD, Wang LW (2014) Brookite $\mathrm{TiO}_{2}$ decorated $\alpha-\mathrm{Fe}_{2} \mathrm{O}_{3}$ nanoheterostructures with rod morphologies for gas sensor 
application. J Mater Chem A 2: 7935-7943.

Wu GF, Zhao CH, Guo CQ, Chen JH, Zhang YB, Li YQ (2018) DFT study on the interaction of $\mathrm{TiO}_{2}$ (001) surface with $\mathrm{HCHO}$ molecules. Appli Surf Sci 428: 954963.

Yang S, Zhu ZX, Wei F, Yang XD (2017) Enhancement of formaldehyde removal by activated carbon fiber via in situ growth of carbon nanotubes. Build Environ 126: 27-33.

Yin L, Adler I, Tsang T, Matienzo LJ, Grim SO (1974) Paramagnetism and shake-up satellites in X-ray photoelectron spectra. Chem Phys Lett 24: 81-84.

Yu JG, Wang SH, Low JX, Xiao W (2013) Enhanced photocatalytic performance of direct Z-scheme $\mathrm{g}_{-} \mathrm{C}_{3} \mathrm{~N}_{4}-\mathrm{TiO}_{2}$ photocatalysts for the decomposition of formaldehyde in air. Phys Chem Chem Phys 15: 16883-16890.

Zhang GX, Sun ZM, Wei Y, Ma R, Zheng S (2017) Synthesis of nano- $\mathrm{TiO}_{2} /$ diatomite composite and its photocatalytic degradation of gaseous formaldehyde. Appli Surf Sci 412: 105-112. 


\section{Figure captions}

Figure 1. Diagram of the photoelectrical catalytic reaction system.

Figure 2. Morphology of $\mathrm{TiO}_{2}$ (a) SEM, (b)-(c) TEM, (d) size distribution, and $3 \% \mathrm{Fe}_{2} \mathrm{O}_{3} / \mathrm{TiO}_{2}$ (e) SEM, (f)-(g) TEM, (h) size distribution.

Figure 3. (a) XRD and (b) Raman patterns of $\mathrm{TiO}_{2}$ and $0.5-5 \% \mathrm{Fe}_{2} \mathrm{O}_{3} / \mathrm{TiO}_{2}$.

Figure 4. Binding energies of (a) $\mathrm{Ti} 2 \mathrm{p}_{1 / 2}$, $\mathrm{Ti} 2 \mathrm{p}_{3 / 2}$ for $\mathrm{TiO}_{2}$ and $3 \% \mathrm{Fe}_{2} \mathrm{O}_{3} / \mathrm{TiO}_{2}$, and (b) Fe 2p1/2.

Figure 5. UV-Visible spectra of $\mathrm{TiO}_{2}, 0.5-5 \% \mathrm{Fe}_{2} \mathrm{O}_{3} / \mathrm{TiO}_{2}$, and $\mathrm{Fe}_{2} \mathrm{O}_{3}$.

Figure 6. (a) PL spectra, (b) simulated EIS, and (c) LSV patterns of $\mathrm{TiO}_{2}$ and 0.5$5 \% \mathrm{Fe}_{2} \mathrm{O}_{3} / \mathrm{TiO}_{2}$.

Figure 7. (a) Mott-Schottky plots of $\mathrm{TiO}_{2}, 0.5-5 \% \mathrm{Fe}_{2} \mathrm{O}_{3} / \mathrm{TiO}_{2}$, and $\mathrm{Fe}_{2} \mathrm{O}_{3}$ at $100 \mathrm{~Hz}$ using an $\mathrm{Ag} / \mathrm{AgCl}$ electrode at $\mathrm{pH}=7.0$, (b) electronic structure of $\mathrm{TiO}_{2}$ and $0.5-5 \% \mathrm{Fe}_{2} \mathrm{O}_{3} / \mathrm{TiO}_{2}$, (c) schematic diagram of photogenerated electron-hole pairs transferring at the interface of $\mathrm{Fe}_{2} \mathrm{O}_{3} / \mathrm{TiO}_{2}$, and $\mathrm{Fe}_{2} \mathrm{O}_{3}$.

Figure 8. EPR patterns of $\mathrm{TiO}_{2}$ and $\mathrm{Fe}_{2} \mathrm{O}_{3} / \mathrm{TiO}_{2}$.

Figure 9. Free energy of formation of (a) slab + hydroxyl $+H$, and (b) slab + hydroxyl.

Figure 10. Projected density of state for bare $\mathrm{Fe}_{2} \mathrm{O}_{3} / \mathrm{TiO}_{2}$ (a), $\mathrm{Fe}_{2} \mathrm{O}_{3} / \mathrm{TiO}_{2}+$ hydroxyl + hydrogen (b) without an electric field, (c) $\mathrm{Fe}_{2} \mathrm{O}_{3} / \mathrm{TiO}_{2}+$ hydroxyl + hydrogen with a positive electric field, and (d) with a negative electric field, respectively. Dashed lines denote the Fermi level.

Figure 11. Removal efficiency of $\mathrm{CHOH}$ by neat $\mathrm{TiO}_{2}$ and $0.5-5 \% \mathrm{Fe}_{2} \mathrm{O}_{3} / \mathrm{TiO}_{2}$ without $\mathrm{H}_{2} \mathrm{O}$, (a) in the absence and (b) presence of UV irradiation.

Figure 12. Removal efficiency of $\mathrm{CH}_{2} \mathrm{O}$ by neat $\mathrm{TiO}_{2}$ and $0.5-5 \% \mathrm{Fe}_{2} \mathrm{O}_{3} / \mathrm{TiO}_{2}$ at a relative humidity of $50 \%$, (a) in the absence and (b) presence of UV irradiation.

Figure 13. (a) Removal efficiency of $\mathrm{CHOH}$ by $3 \% \mathrm{Fe}_{2} \mathrm{O}_{3} / \mathrm{TiO}_{2}$, and (b) increment of the removal rates of $\mathrm{CHOH}$ by $3 \% \mathrm{Fe}_{2} \mathrm{O}_{3} / \mathrm{TiO}_{2}$ at a relative humidity of $50 \%$ under different strengths of electric field.

Figure 14. Removal rate of $\mathrm{CHOH}$ with different energy input (a) without $\mathrm{H}_{2} \mathrm{O}$, and (b) with $\mathrm{H}_{2} \mathrm{O}$. 


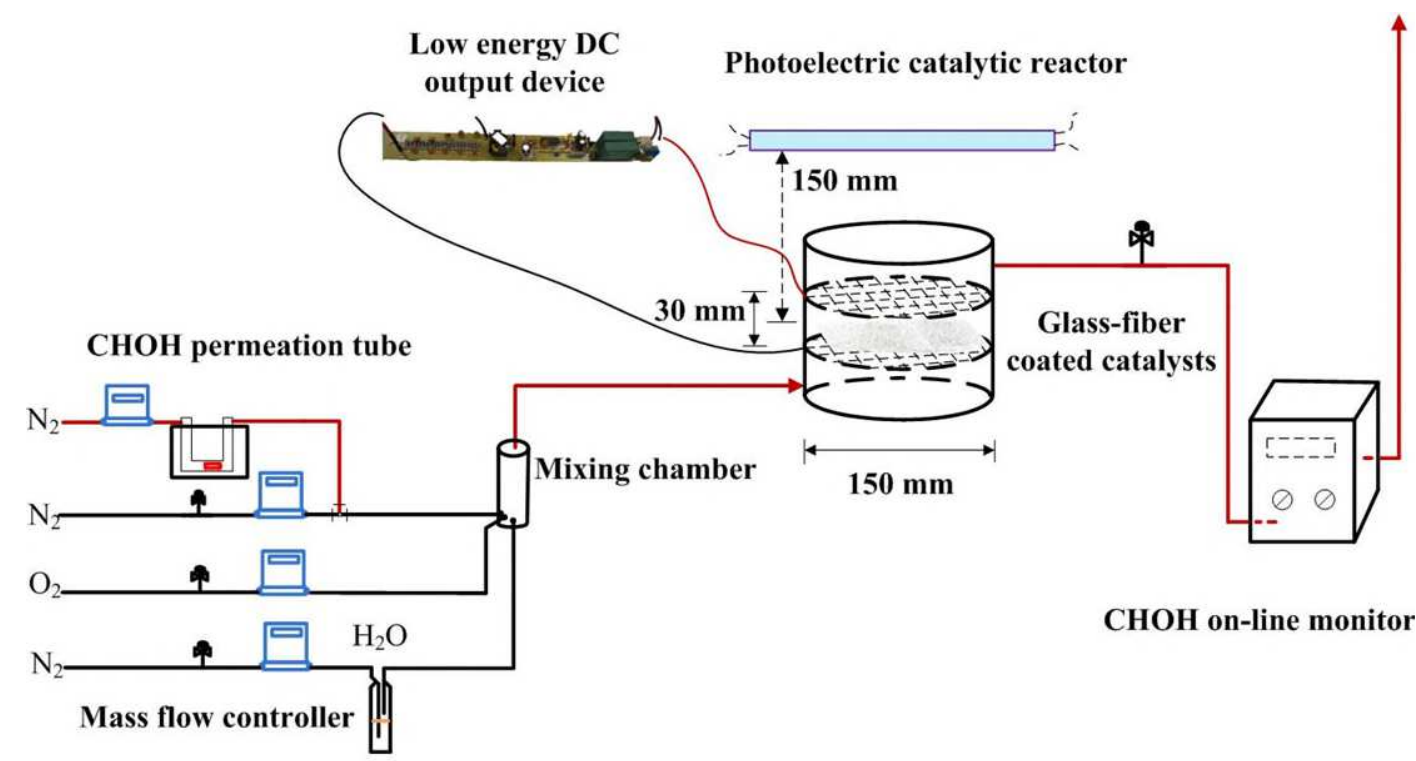

Figure 1. Diagram of the photoelectrical catalytic reaction system. 

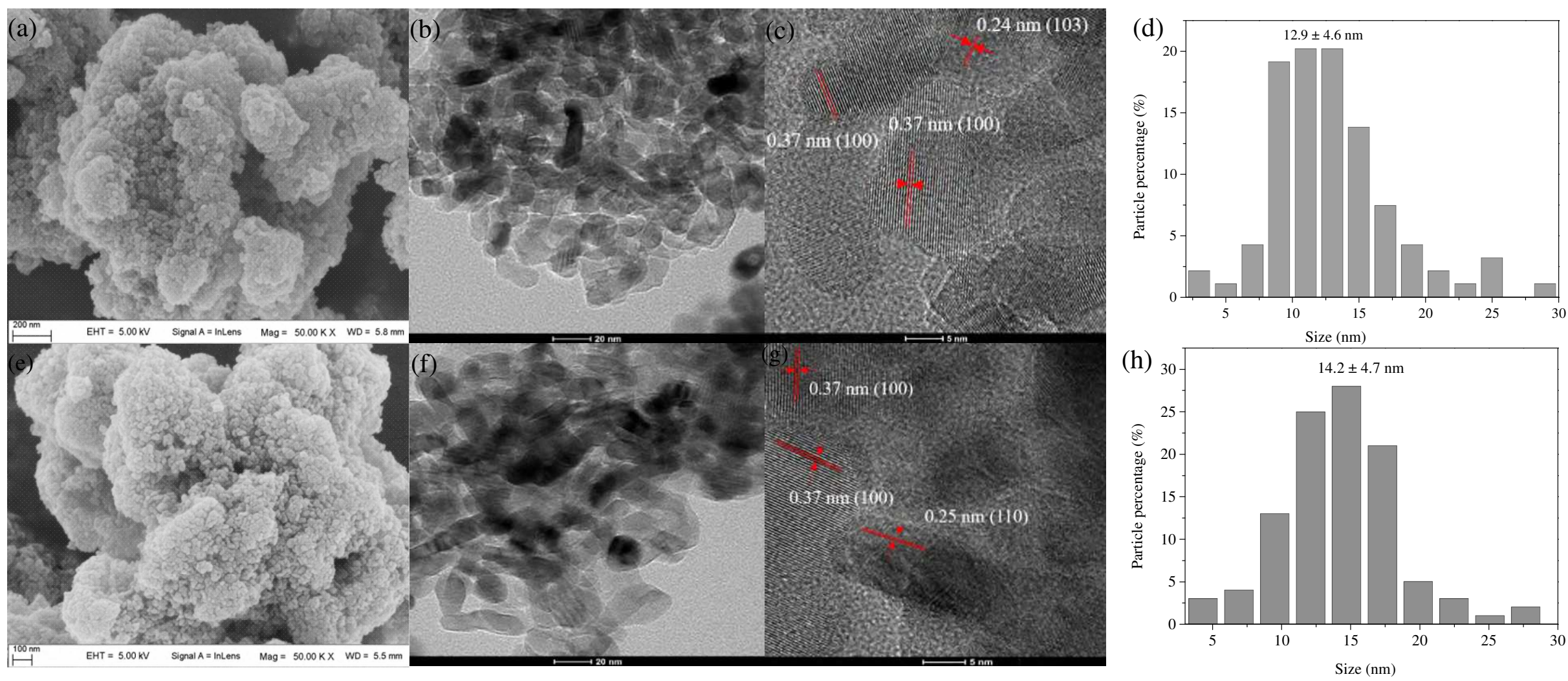

Figure 2. Morphology of $\mathrm{TiO}_{2}$ (a) SEM, (b)-(c) TEM, (d) size distribution, and 3\% $\mathrm{Fe}_{2} \mathrm{O}_{3} / \mathrm{TiO}_{2}$ (e) SEM, (f)-(g) TEM, (h) size distribution. 
(a)

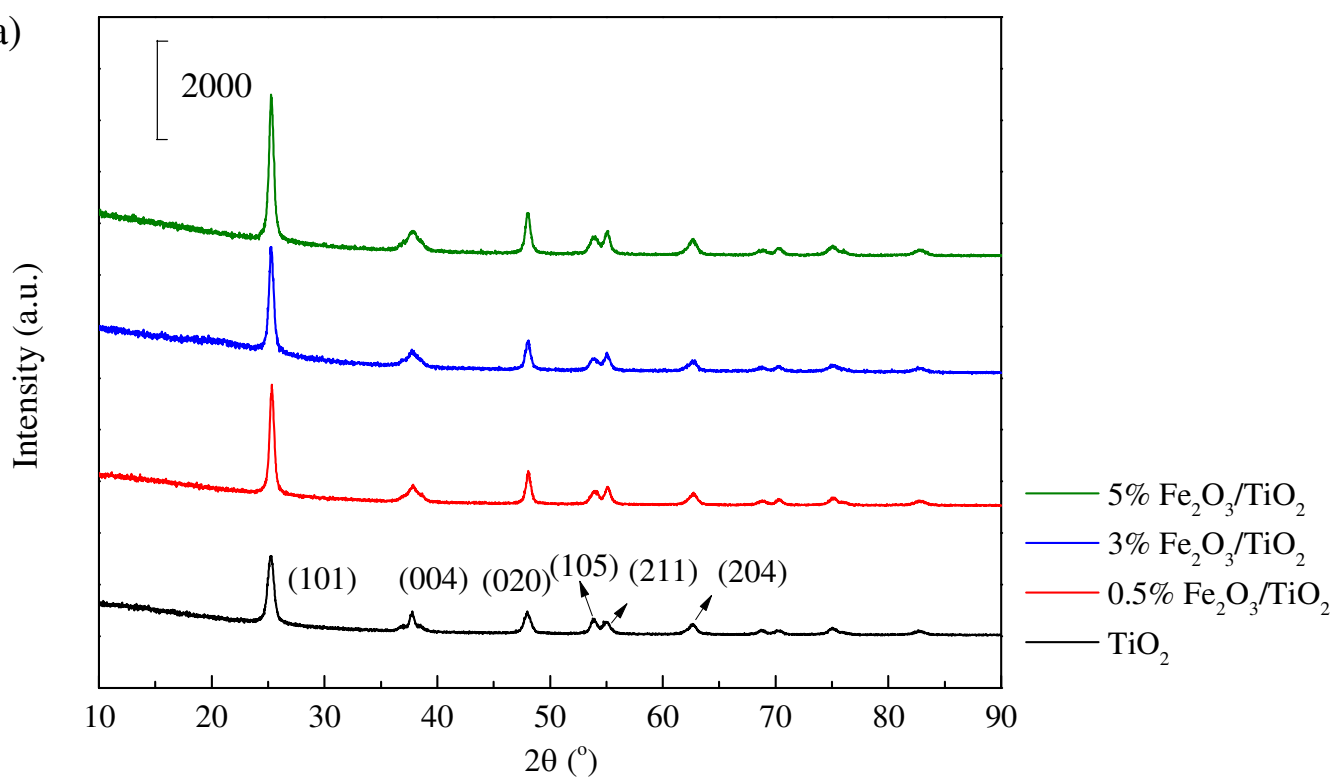

(b)

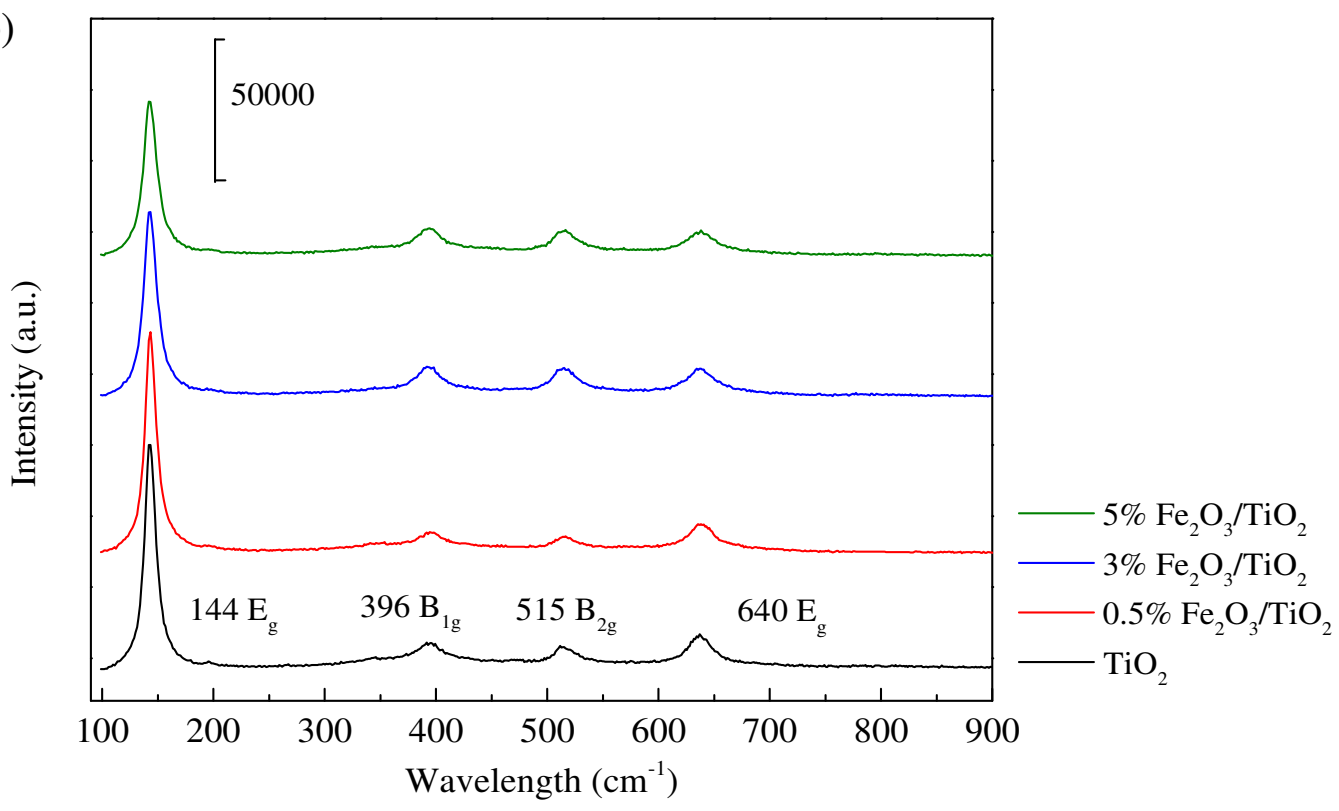

Figure 3. (a) XRD and (b) Raman patterns of $\mathrm{TiO}_{2}$ and $0.5-5 \% \mathrm{Fe}_{2} \mathrm{O}_{3} / \mathrm{TiO}_{2}$. 
(a)
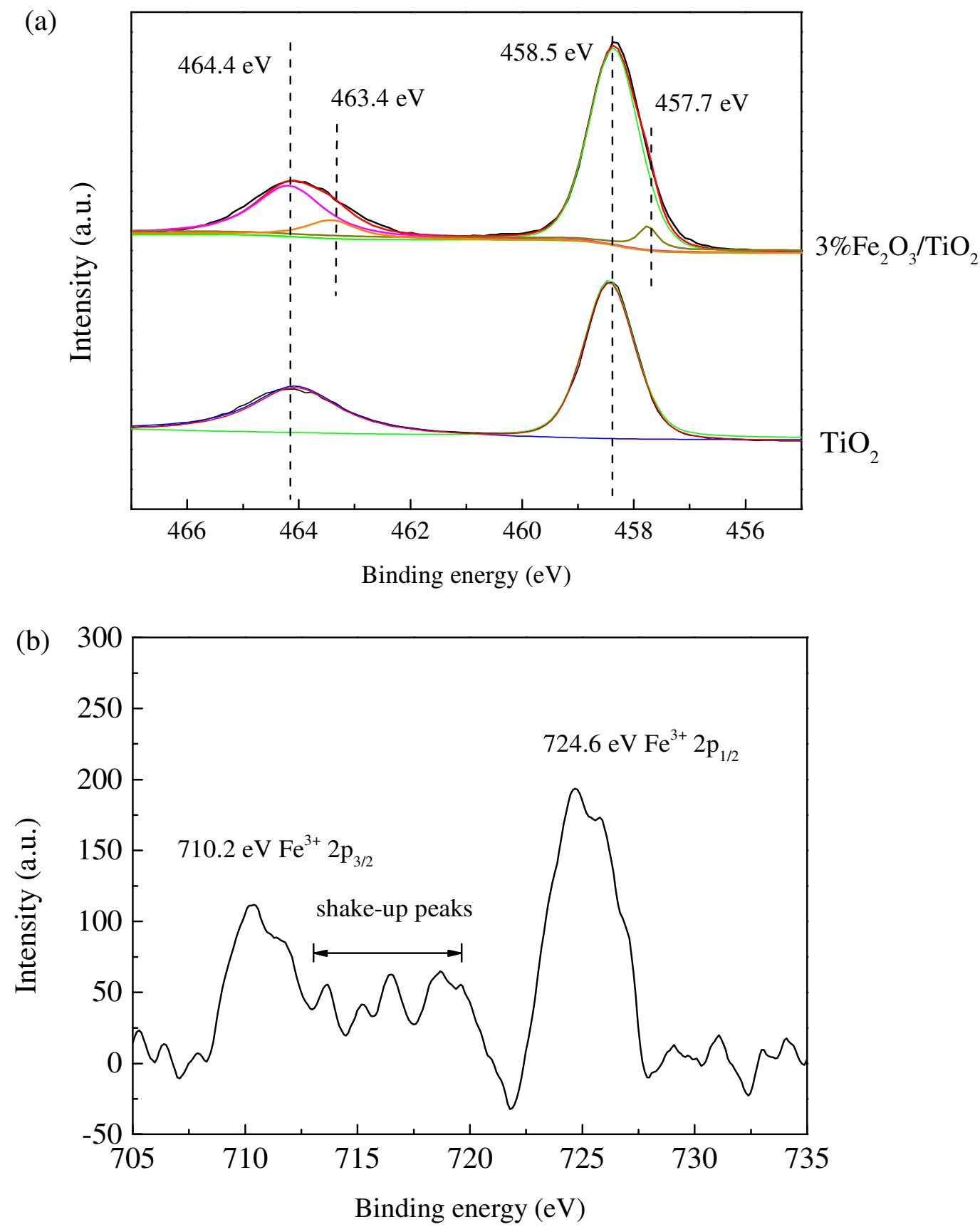

Figure 4. Binding energies of (a) $\mathrm{Ti} 2 \mathrm{p}_{1 / 2}$, Ti $2 \mathrm{p}_{3 / 2}$ for $\mathrm{TiO}_{2}$ and $3 \% \mathrm{Fe}_{2} \mathrm{O}_{3} / \mathrm{TiO}_{2}$, and (b) Fe 2p1/2. 


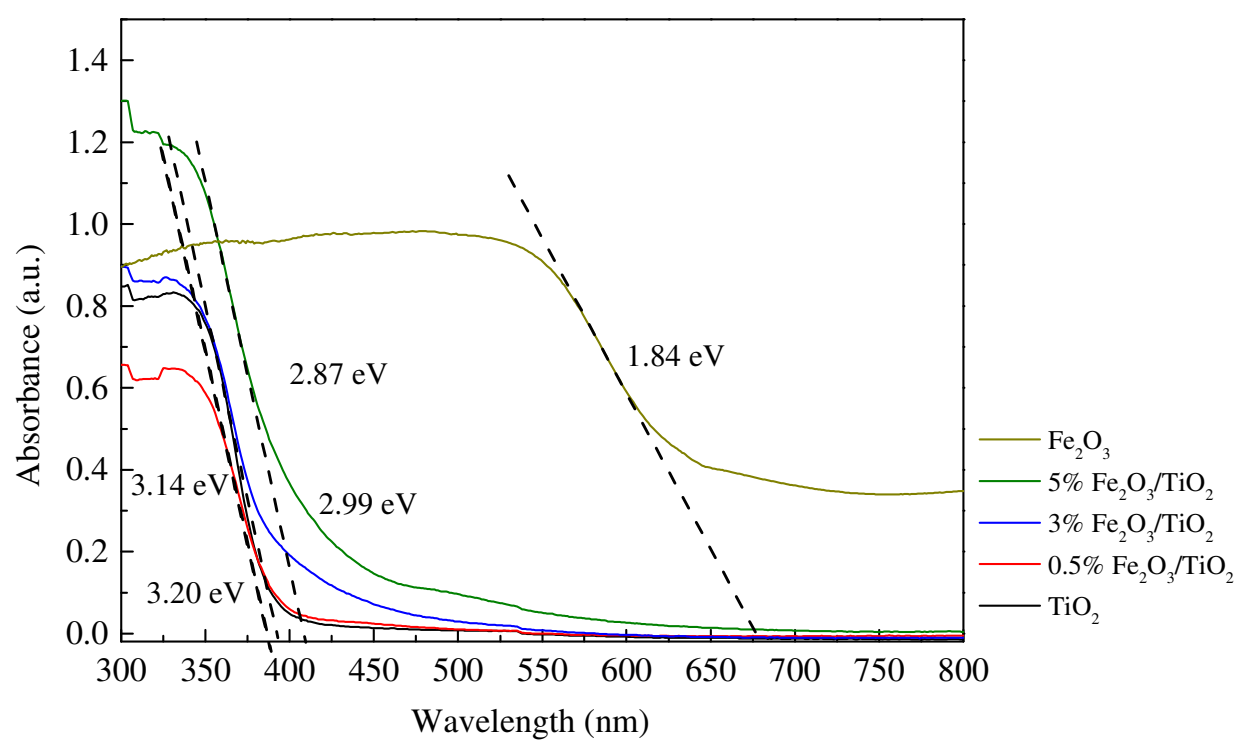

Figure 5. UV-Visible spectra of $\mathrm{TiO}_{2}, 0.5-5 \% \mathrm{Fe}_{2} \mathrm{O}_{3} / \mathrm{TiO}_{2}$, and $\mathrm{Fe}_{2} \mathrm{O}_{3}$. 
(a)

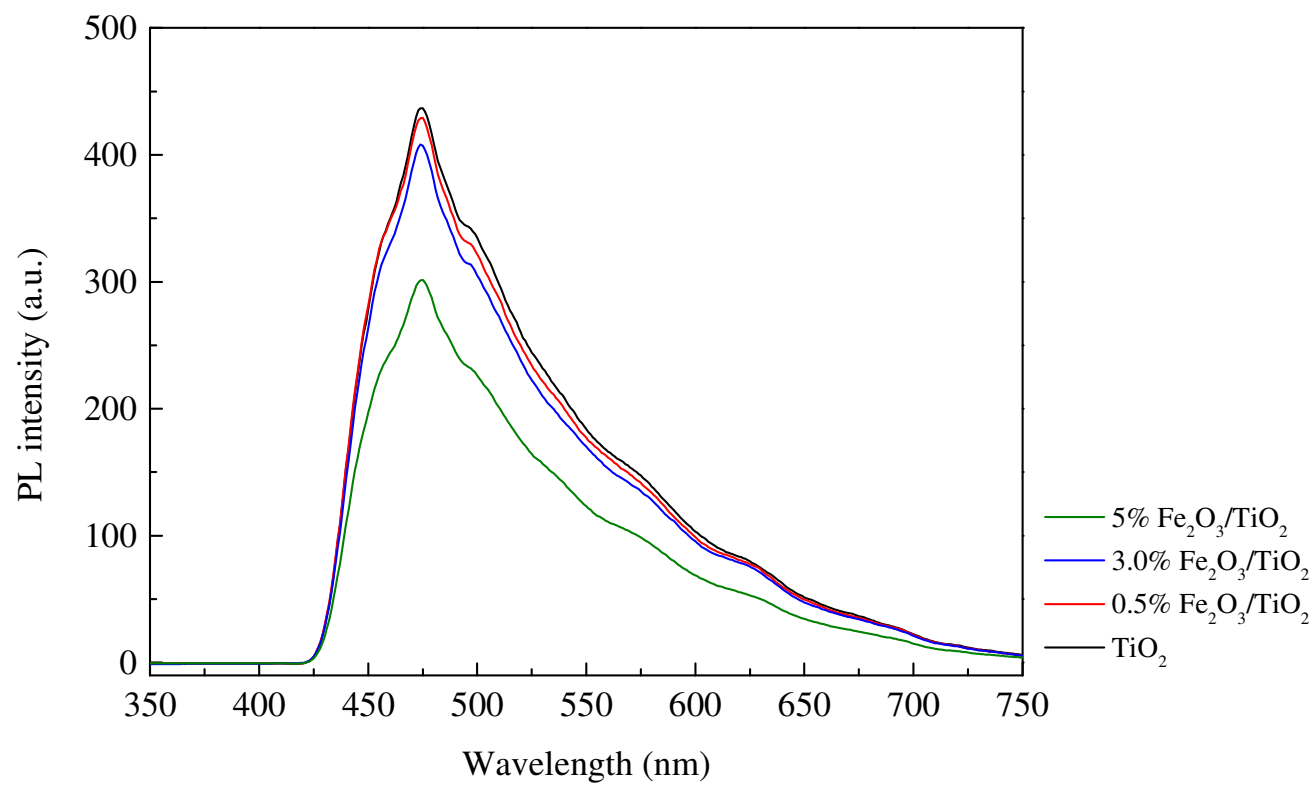

(b)

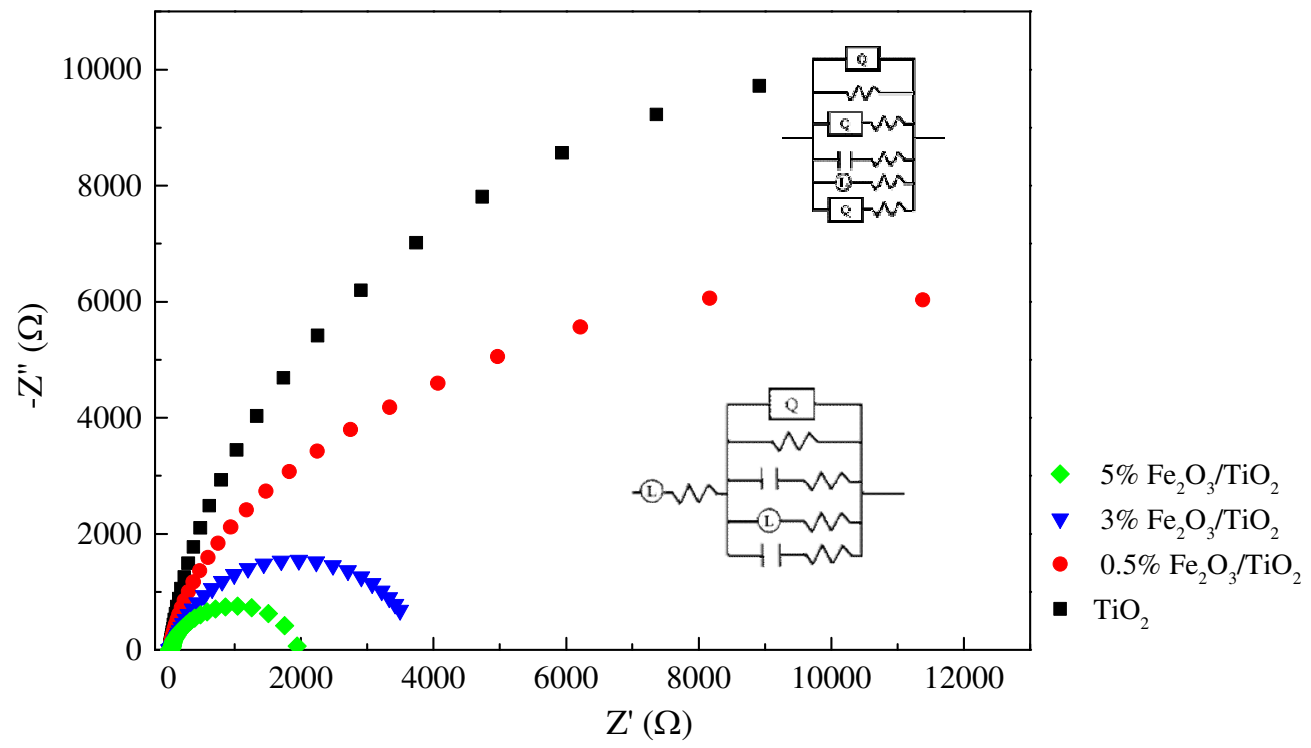




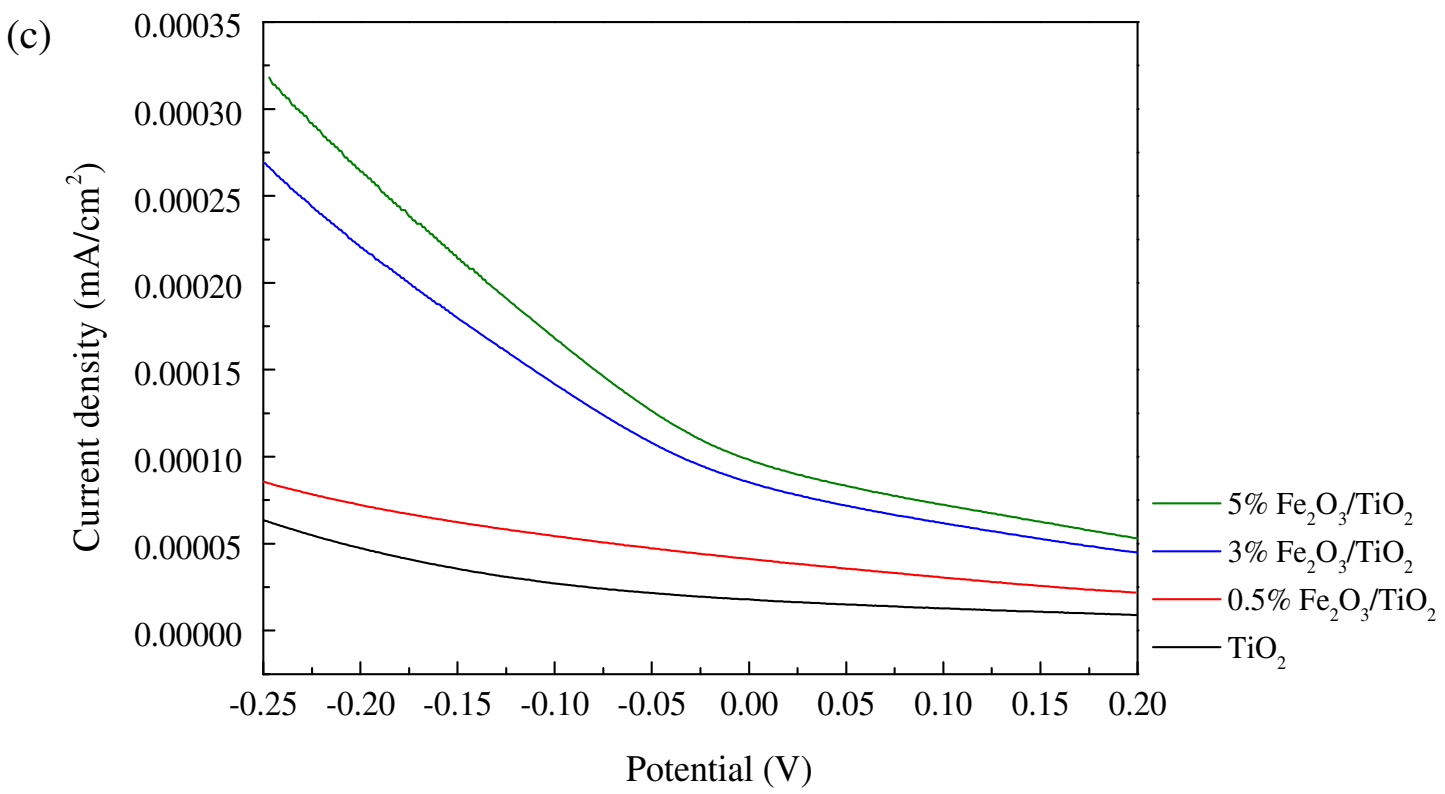

Figure 6. (a) PL spectra, (b) simulated EIS, and (c) LSV patterns of $\mathrm{TiO}_{2}$ and 0.5$5 \% \mathrm{Fe}_{2} \mathrm{O}_{3} / \mathrm{TiO}_{2}$. 
(a)

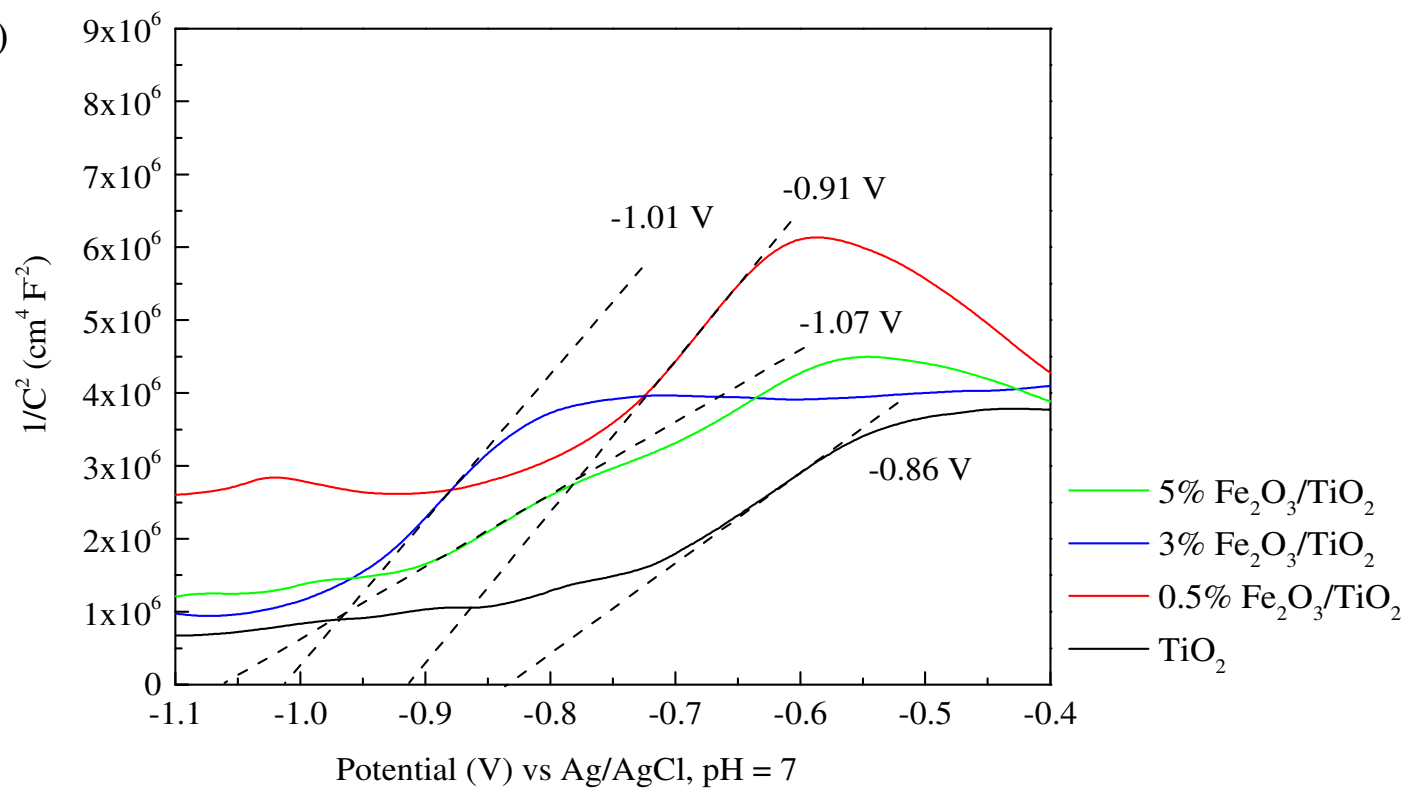

(b)

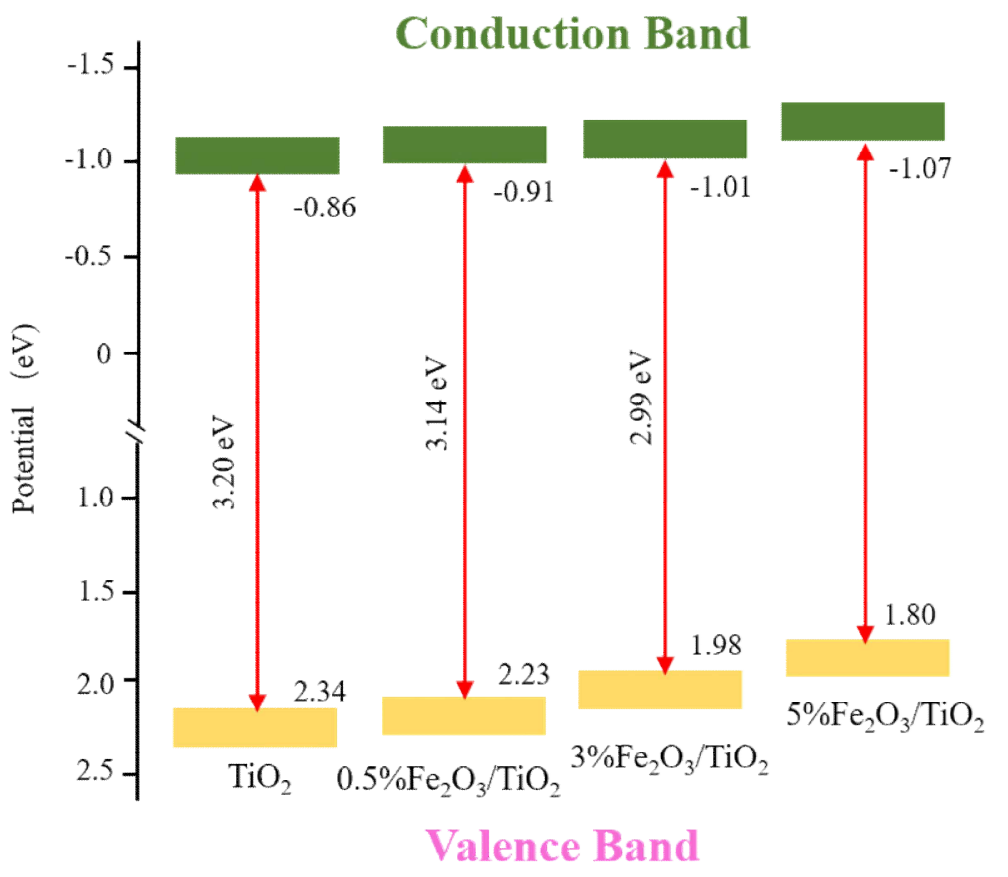


(c)

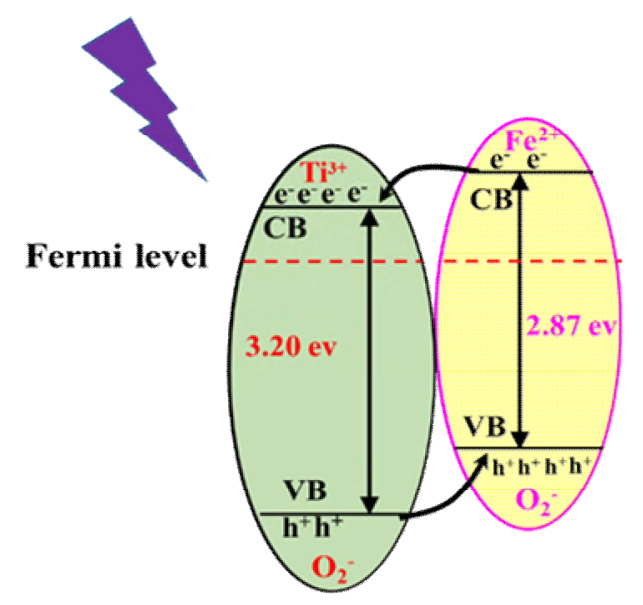

\section{$\mathrm{TiO}_{2} \quad \mathrm{Fe}_{2} \mathrm{O}_{3}$}

Figure 7. (a) Mott-Schottky plots of $\mathrm{TiO}_{2}, 0.5-5 \% \mathrm{Fe}_{2} \mathrm{O}_{3} / \mathrm{TiO}_{2}$, and $\mathrm{Fe}_{2} \mathrm{O}_{3}$ at $100 \mathrm{~Hz}$ using an $\mathrm{Ag} / \mathrm{AgCl}$ electrode at $\mathrm{pH}=7.0$, (b) electronic structure of $\mathrm{TiO}_{2}$ and $0.5-5 \% \mathrm{Fe}_{2} \mathrm{O}_{3} / \mathrm{TiO}_{2}$, (c) schematic diagram of photogenerated electron-hole pairs transferring at the interface of $\mathrm{Fe}_{2} \mathrm{O}_{3} / \mathrm{TiO}_{2}$, and $\mathrm{Fe}_{2} \mathrm{O}_{3}$. 


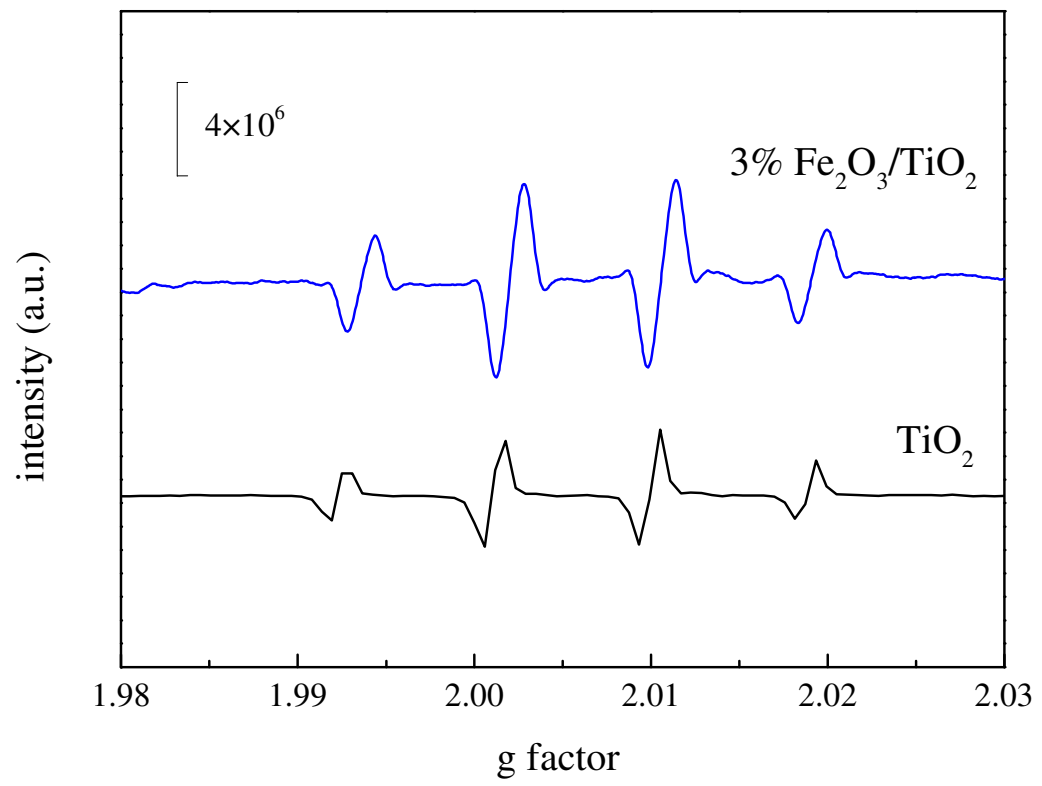

Figure 8. EPR patterns of $\mathrm{TiO}_{2}$ and $\mathrm{Fe}_{2} \mathrm{O}_{3} / \mathrm{TiO}_{2}$. 
(a)

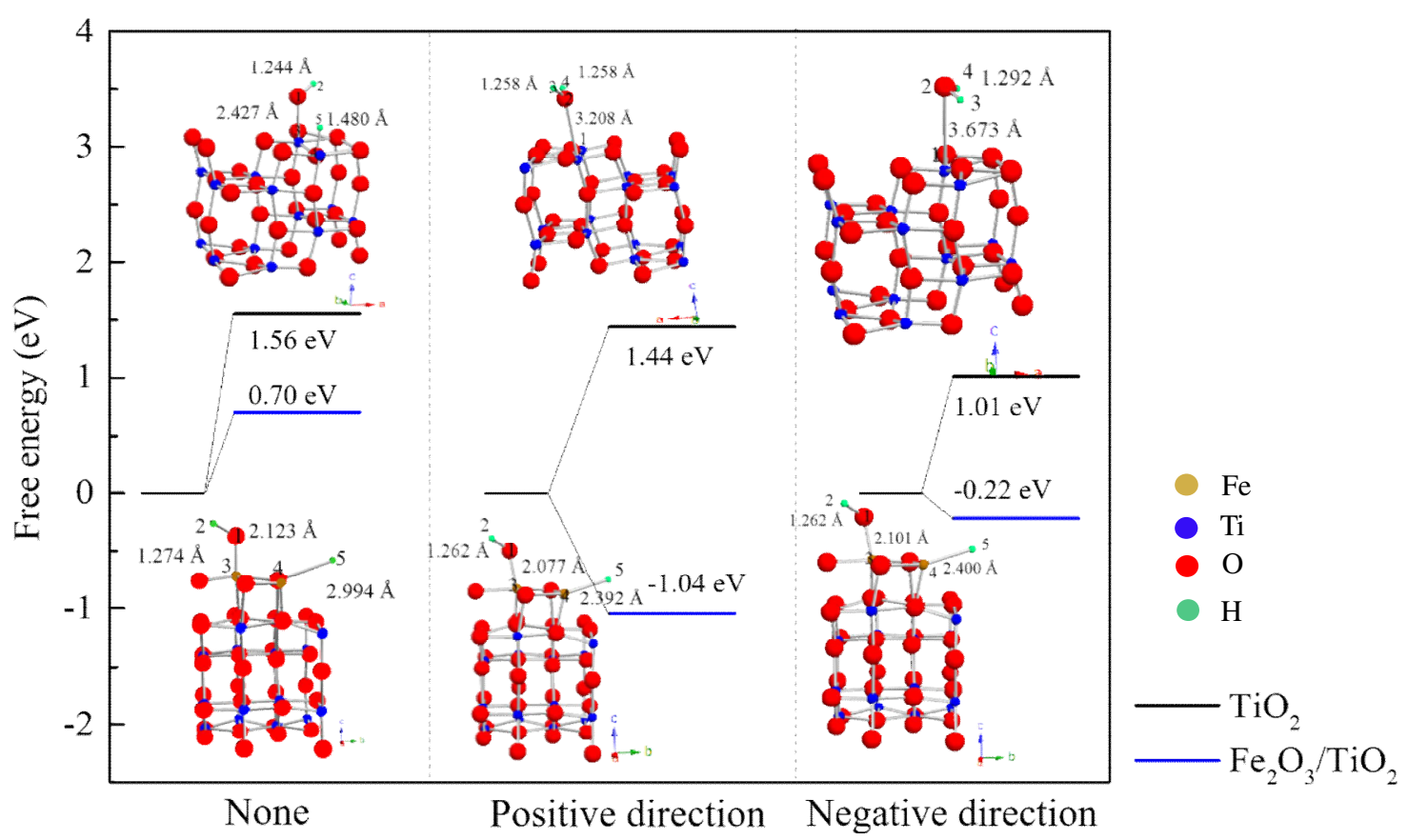

(b)

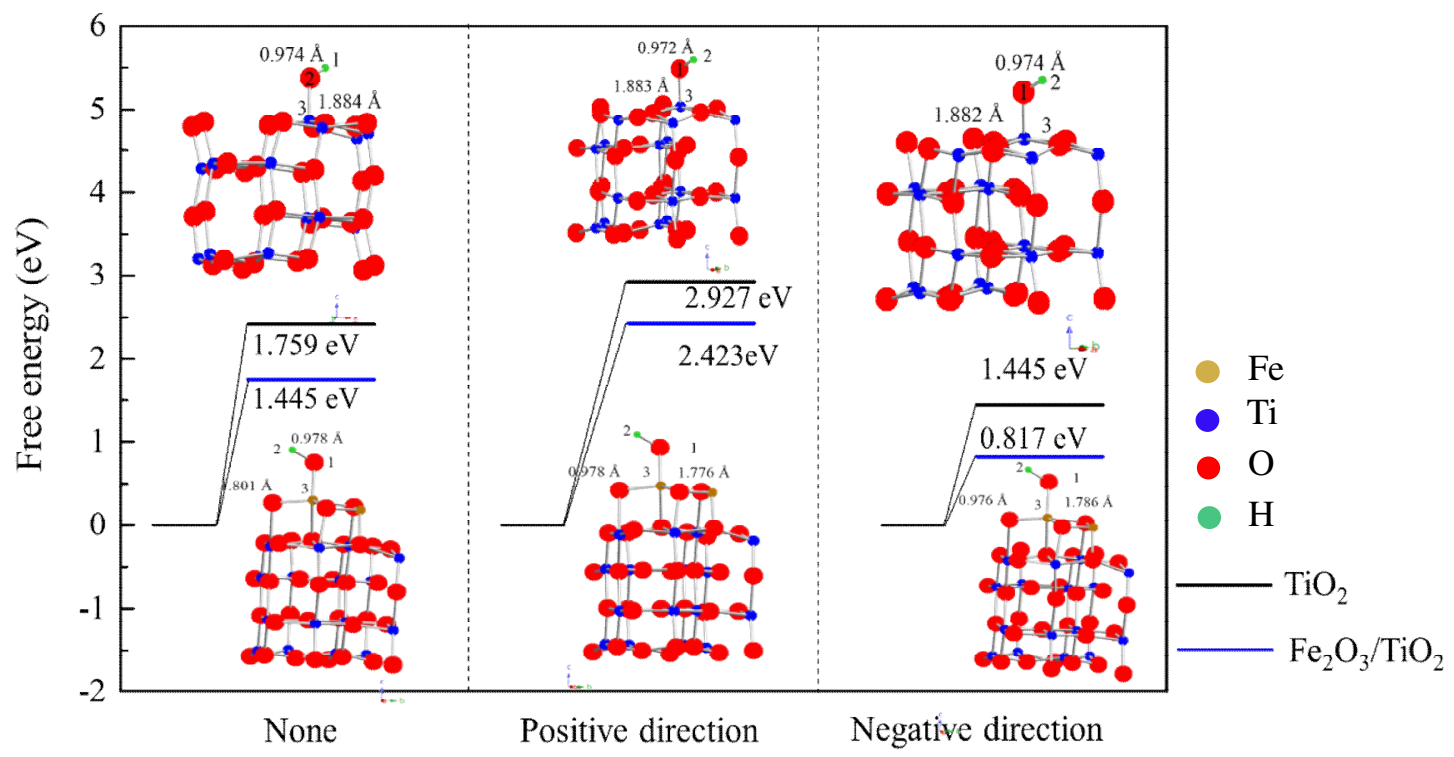

Figure 9. Free energy of formation of (a) slab + hydroxyl $+H$, and (b) slab + hydroxyl. 
(a)

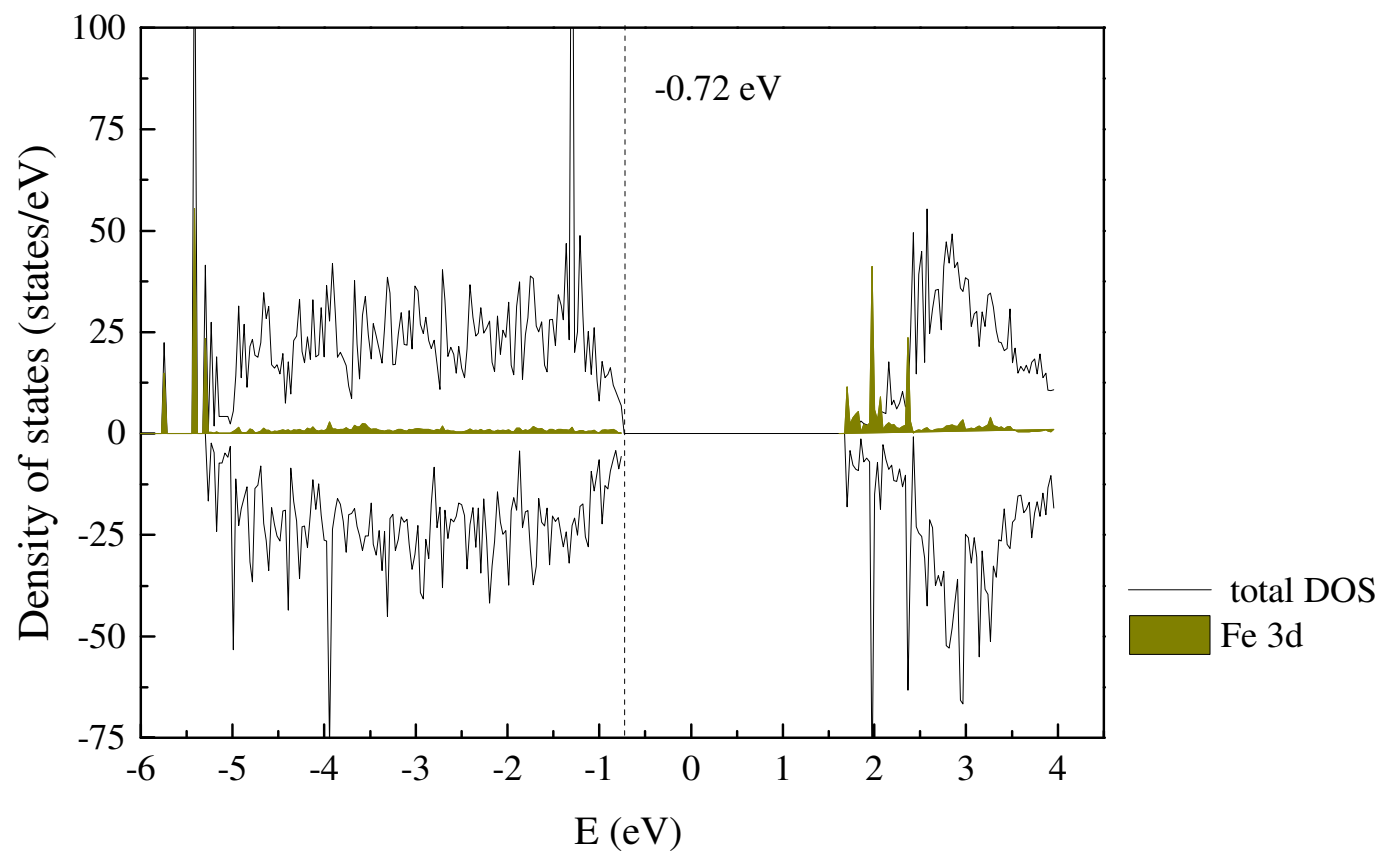

(b)

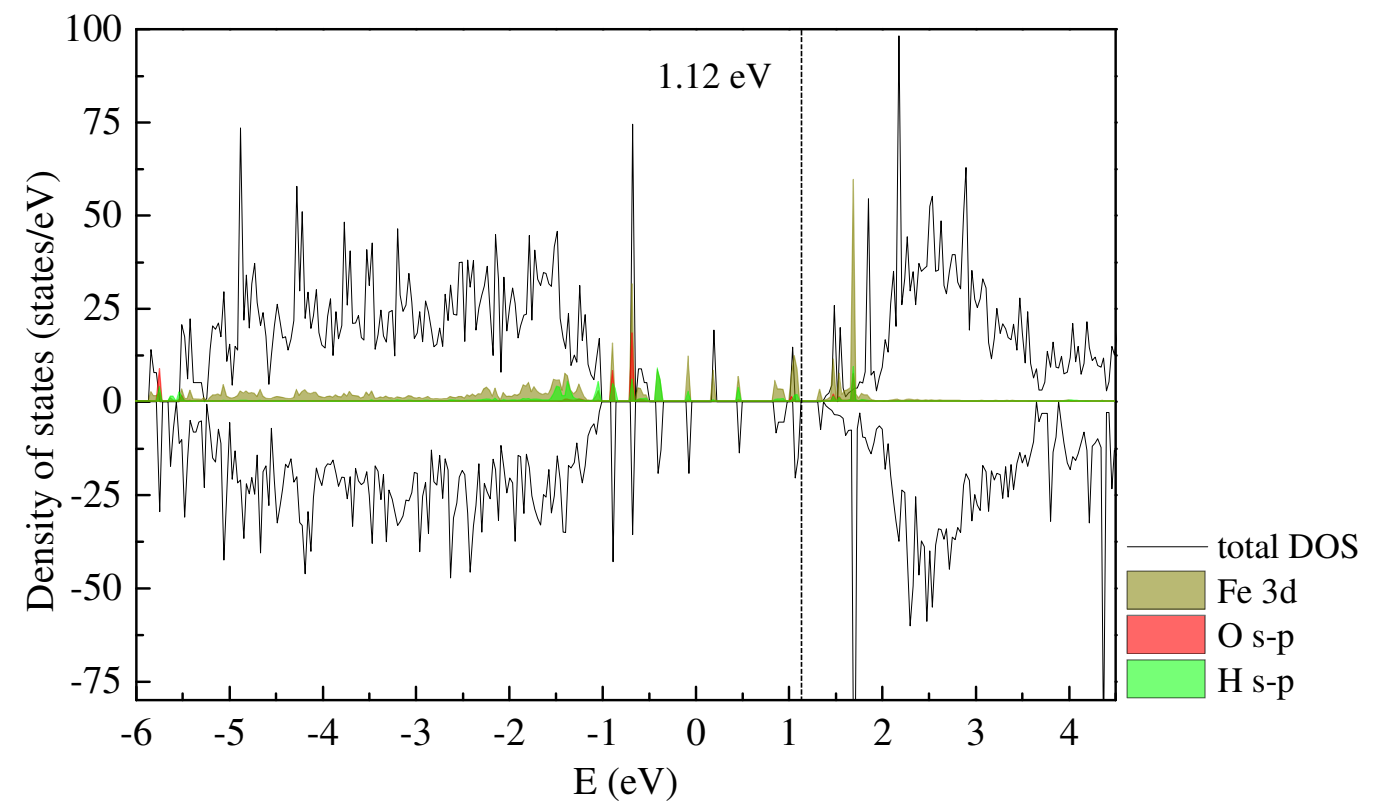


(c)

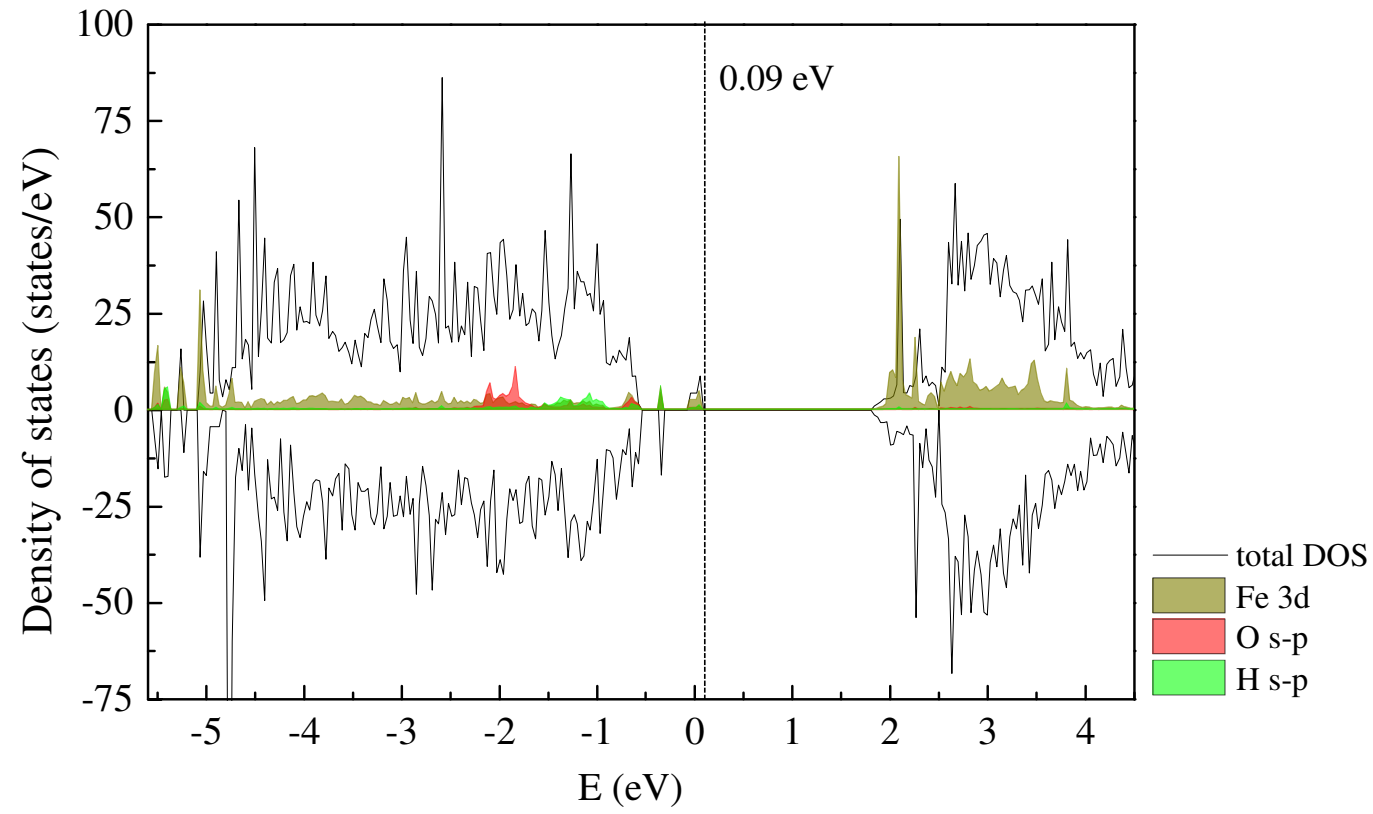

(d)

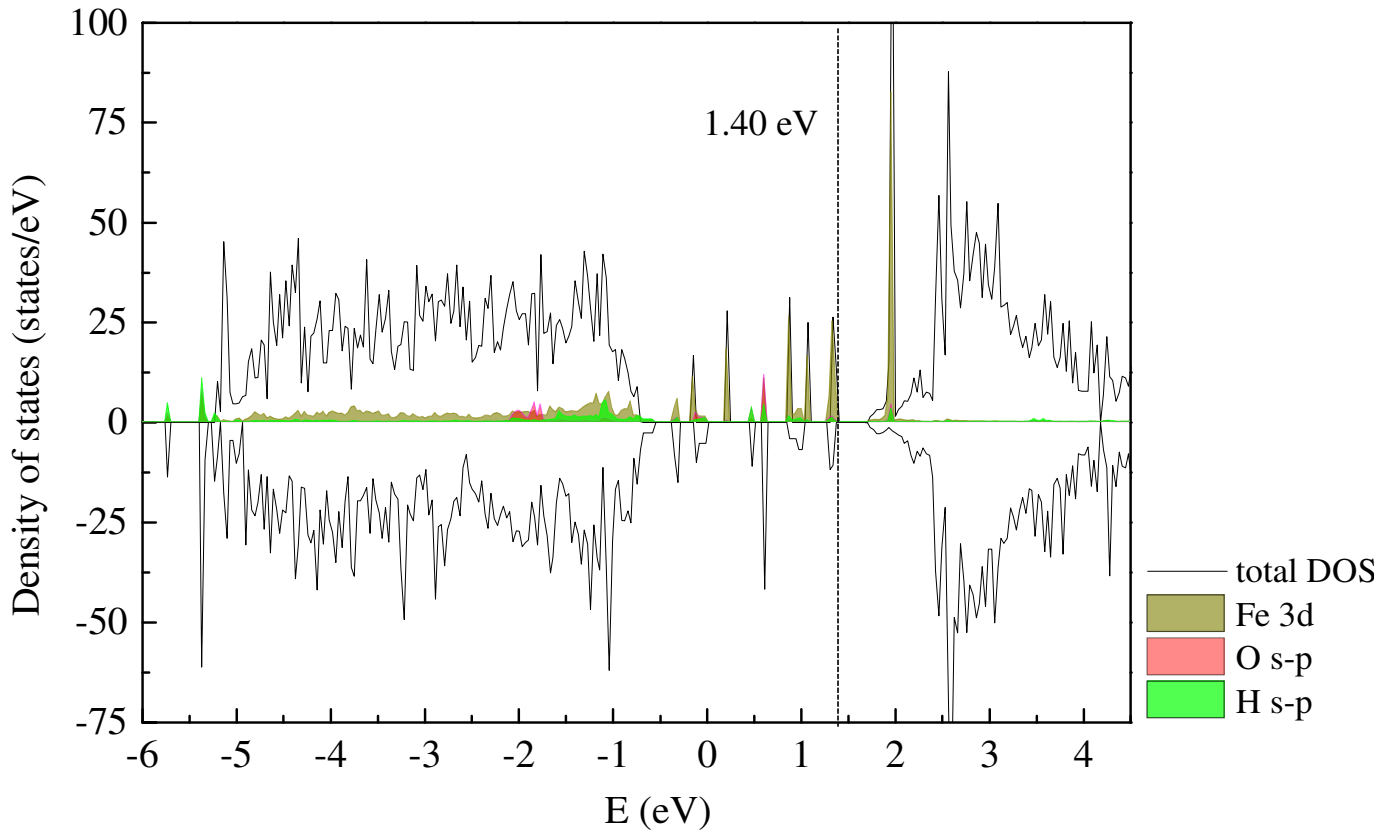

Figure 10. Projected density of state for bare $\mathrm{Fe}_{2} \mathrm{O}_{3} / \mathrm{TiO}_{2}$ (a), $\mathrm{Fe}_{2} \mathrm{O}_{3} / \mathrm{TiO}_{2}+$ hydroxyl + hydrogen (b) without an electric field, (c) $\mathrm{Fe}_{2} \mathrm{O}_{3} / \mathrm{TiO}_{2}+$ hydroxyl + hydrogen with a positive electric field, and (d) with a negative electric field, respectively. Dashed lines denote the Fermi level. 
(a)

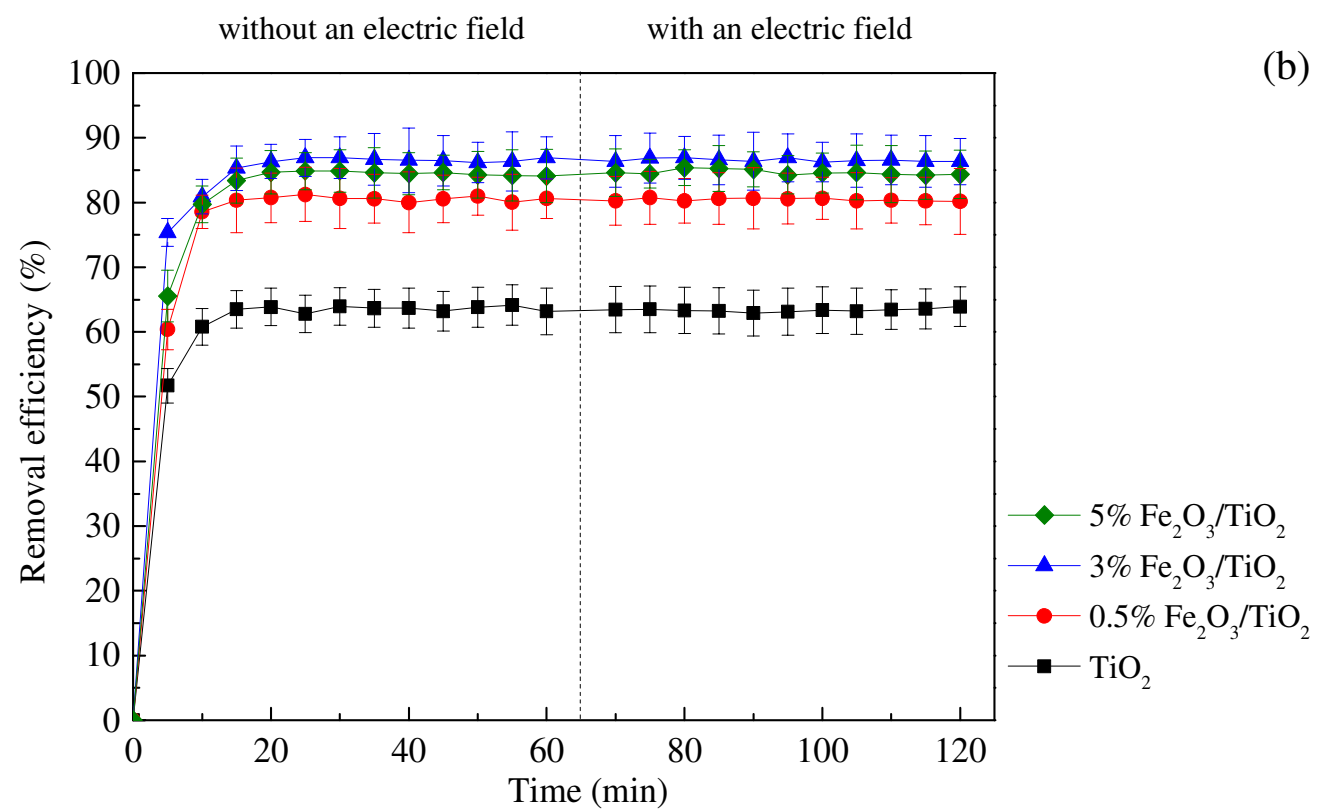

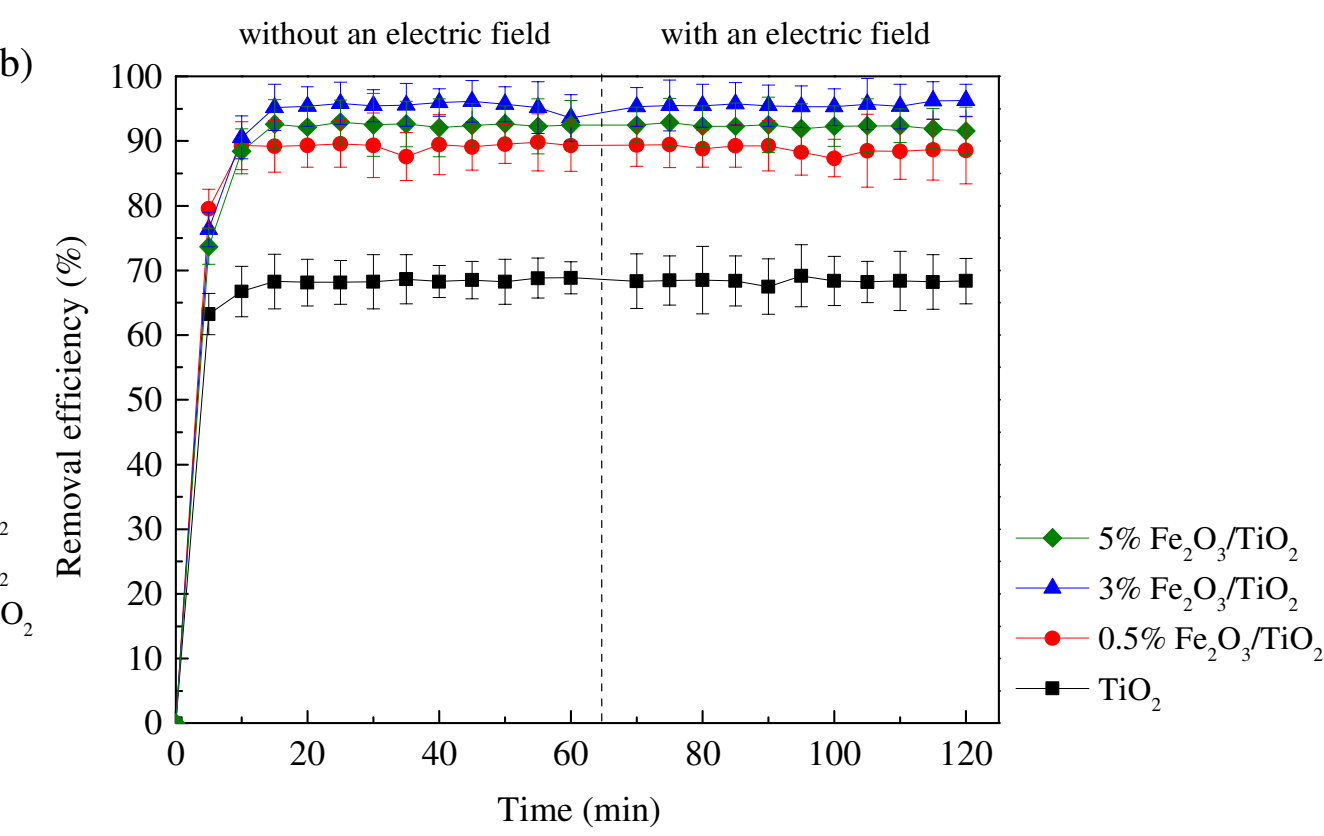

Figure 11. Removal efficiency of $\mathrm{CHOH}$ by neat $\mathrm{TiO}_{2}$ and $0.5-5 \% \mathrm{Fe}_{2} \mathrm{O}_{3} / \mathrm{TiO}_{2}$ without $\mathrm{H}_{2} \mathrm{O}$, (a) in the absence and (b) presence of $\mathrm{UV}$ irradiation. The overall flow rate of $700 \mathrm{~mL} / \mathrm{min}$, influent $\mathrm{CHOH}$ concentration of $1.50 \mathrm{ppm}$, the mass of $0.3 \mathrm{~g}$ catalysts, the power of $15 \mathrm{~W}$ for UV irradiation, and $5 \mathrm{~W}$ for the electric field. 
(a)

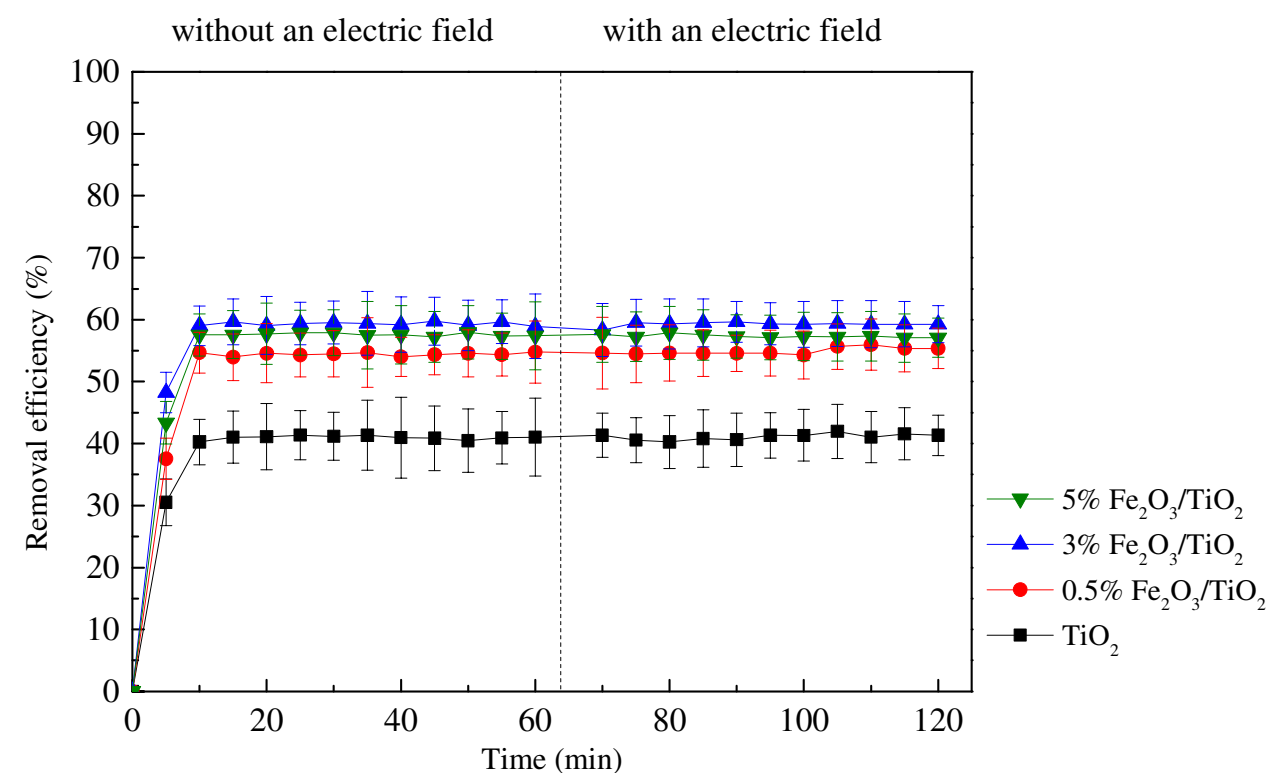

(b)

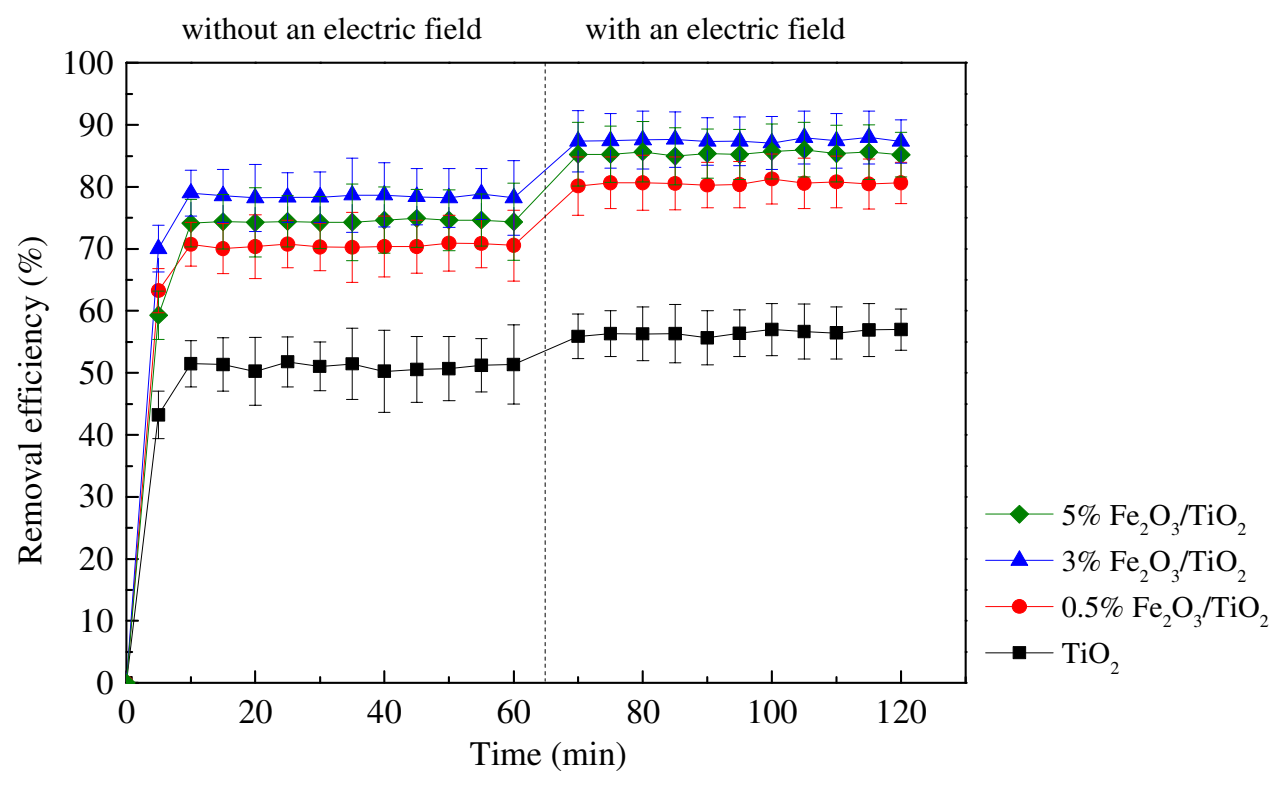

Figure 12. Removal efficiency of $\mathrm{CH}_{2} \mathrm{O}$ by neat $\mathrm{TiO}_{2}$ and $0.5-5 \% \mathrm{Fe}_{2} \mathrm{O}_{3} / \mathrm{TiO}_{2}$ at a relative humidity of $50 \%$, (a) in the absence and (b) presence of UV irradiation. The overall flow rate of $700 \mathrm{~mL} / \mathrm{min}$, influent $\mathrm{CHOH}$ concentration of $1.50 \mathrm{ppm}$, the mass of $0.3 \mathrm{~g}$ catalysts, the power of $15 \mathrm{~W}$ for $\mathrm{UV}$ irradiation, and $5 \mathrm{~W}$ for the electric field. 
(a)

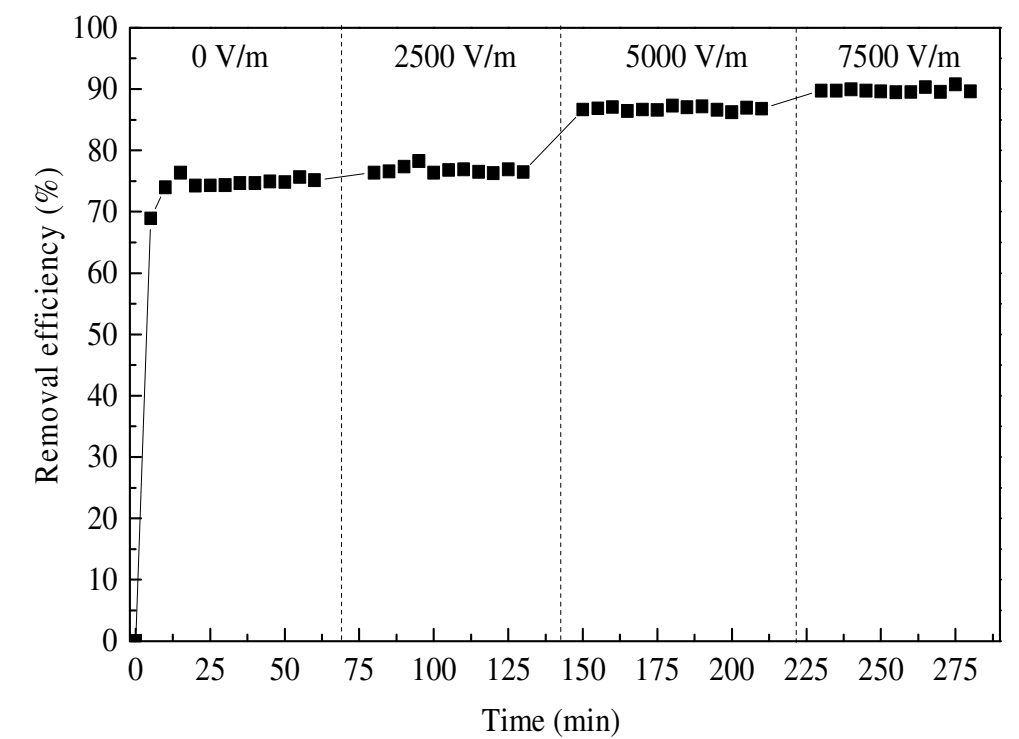

(b)

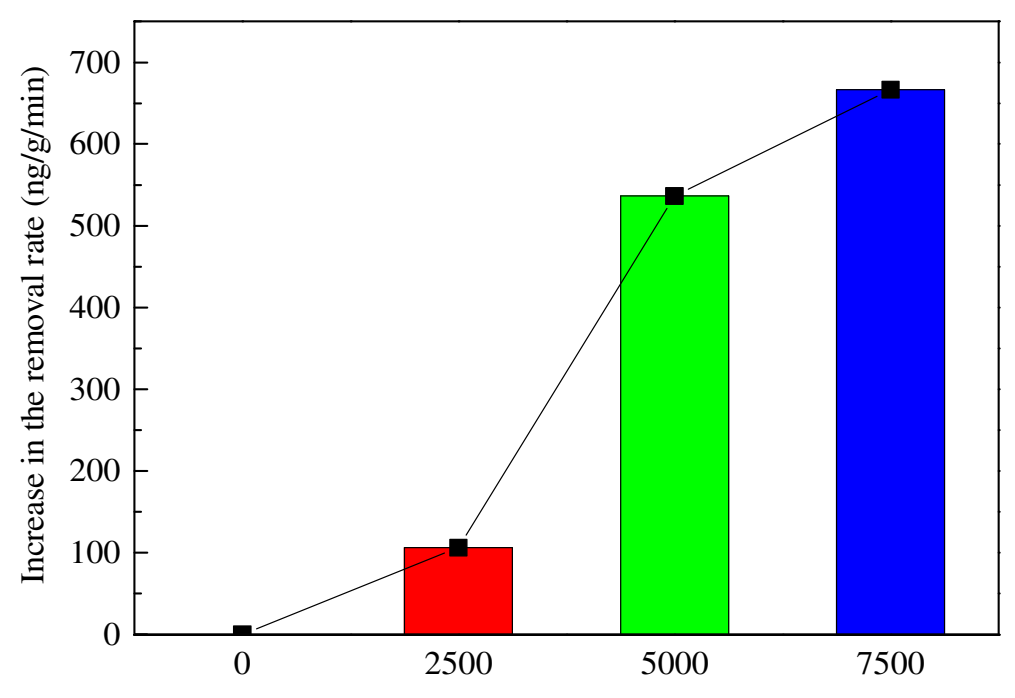

Strength of electric field $(\mathrm{V} / \mathrm{m})$

Figure 13. (a) Removal efficiency of $\mathrm{CHOH}$ by $3 \% \mathrm{Fe}_{2} \mathrm{O}_{3} / \mathrm{TiO}_{2}$, and (b) increment of the removal rates of $\mathrm{CHOH}$ by $3 \% \mathrm{Fe}_{2} \mathrm{O}_{3} / \mathrm{TiO}_{2}$ at a relative humidity of $50 \%$ under different strengths of electric field. The overall flow rate of $700 \mathrm{~mL} / \mathrm{min}$, influent $\mathrm{CHOH}$ concentration of 1.50 ppm, the mass of $0.3 \mathrm{~g}$ catalysts, the power of $15 \mathrm{~W}$ for $\mathrm{UV}$ irradiation, and $5 \mathrm{~W}$ for the electric field. 

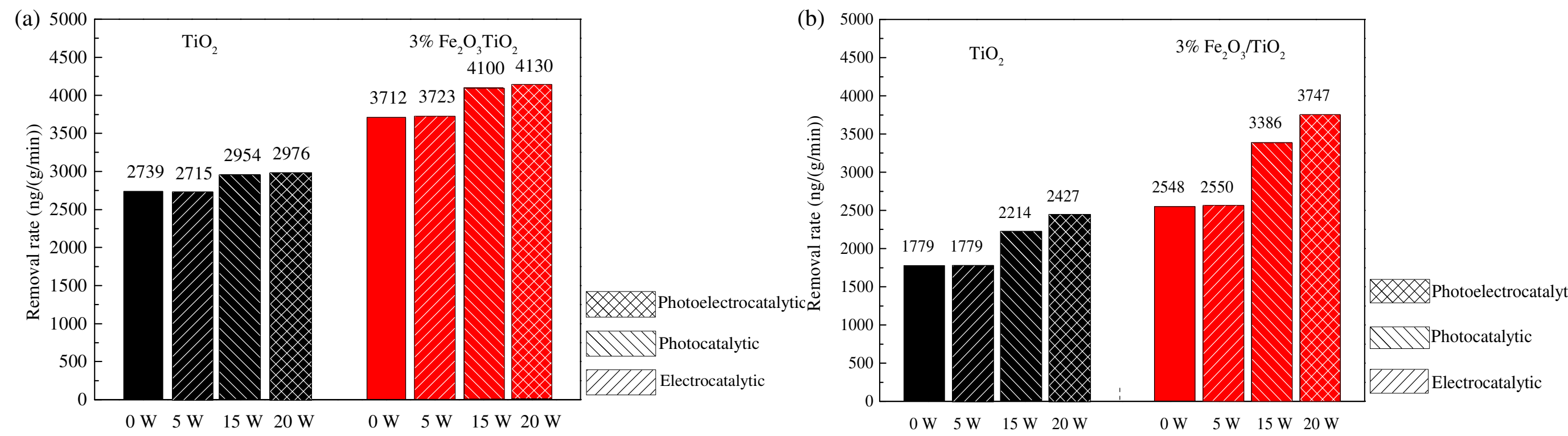

Figure 14. Removal rate of $\mathrm{CHOH}$ with different energy input (a) without $\mathrm{H}_{2} \mathrm{O}$, and (b) with $\mathrm{H}_{2} \mathrm{O}$. 


\section{Figures}

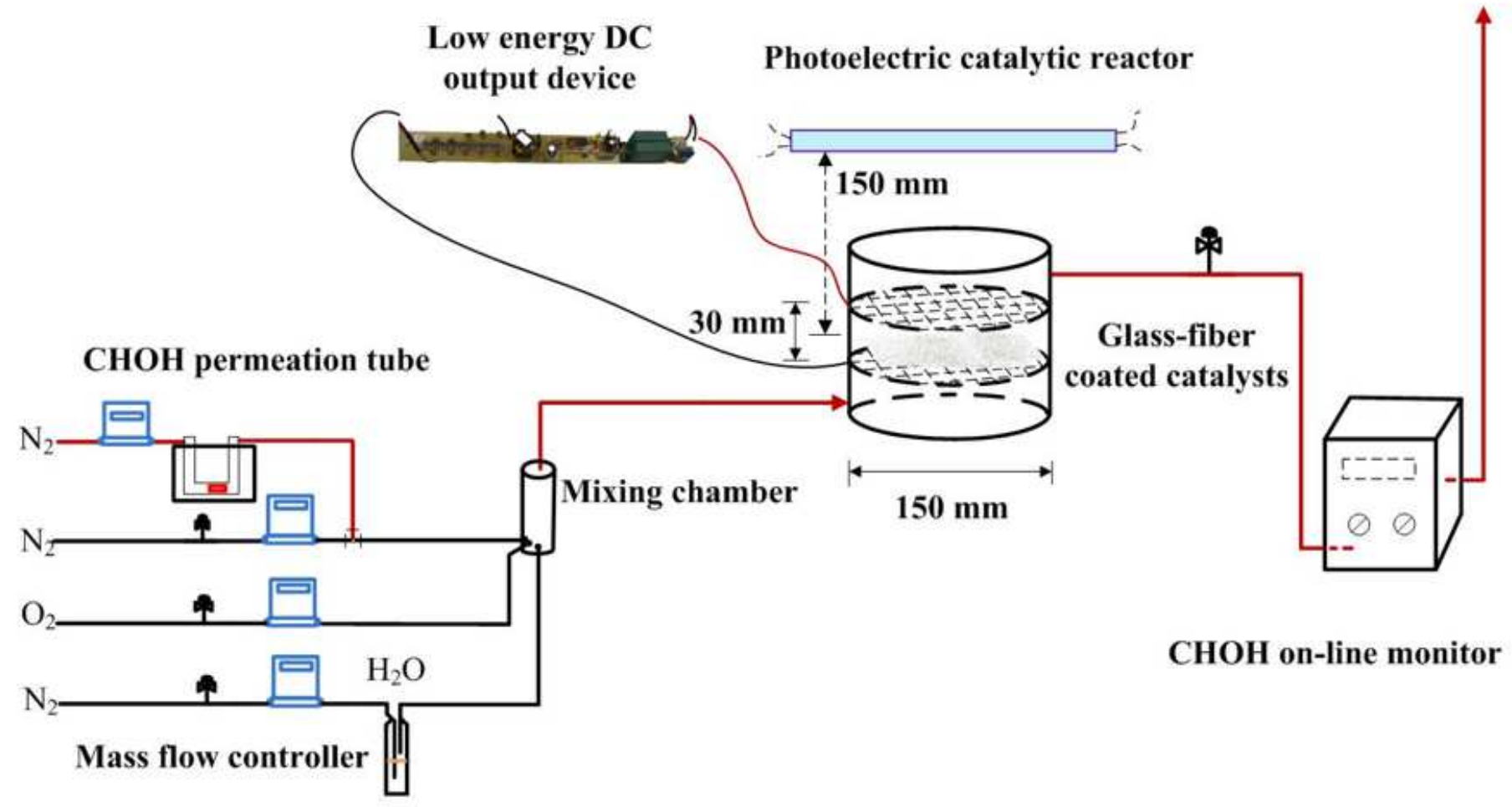

Figure 1

Diagram of the photoelectrical catalytic reaction system.
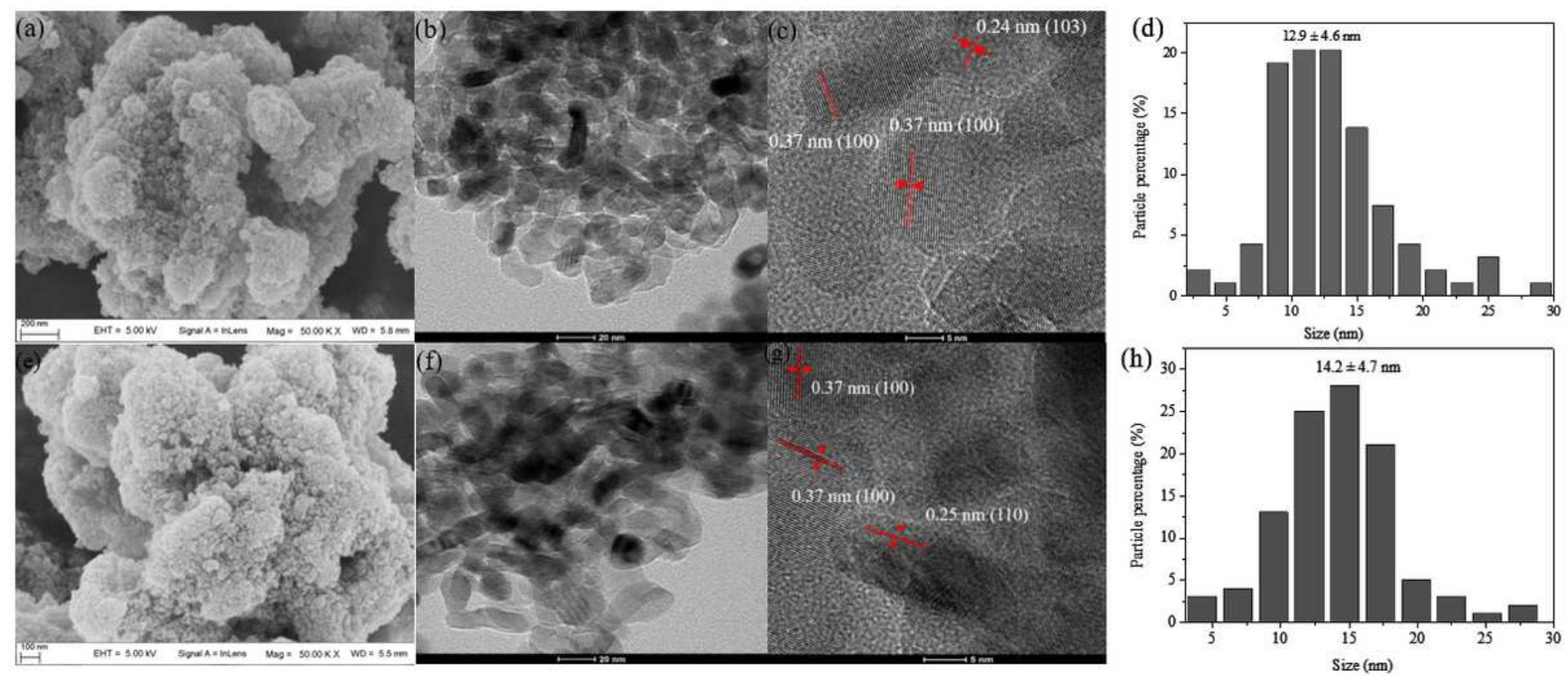

Figure 2 
Morphology of TiO2 (a) SEM, (b)-(c) TEM, (d) size distribution, and 3\%Fe2O3/TiO2 (e) SEM, (f)-(g) TEM, (h) size distribution.
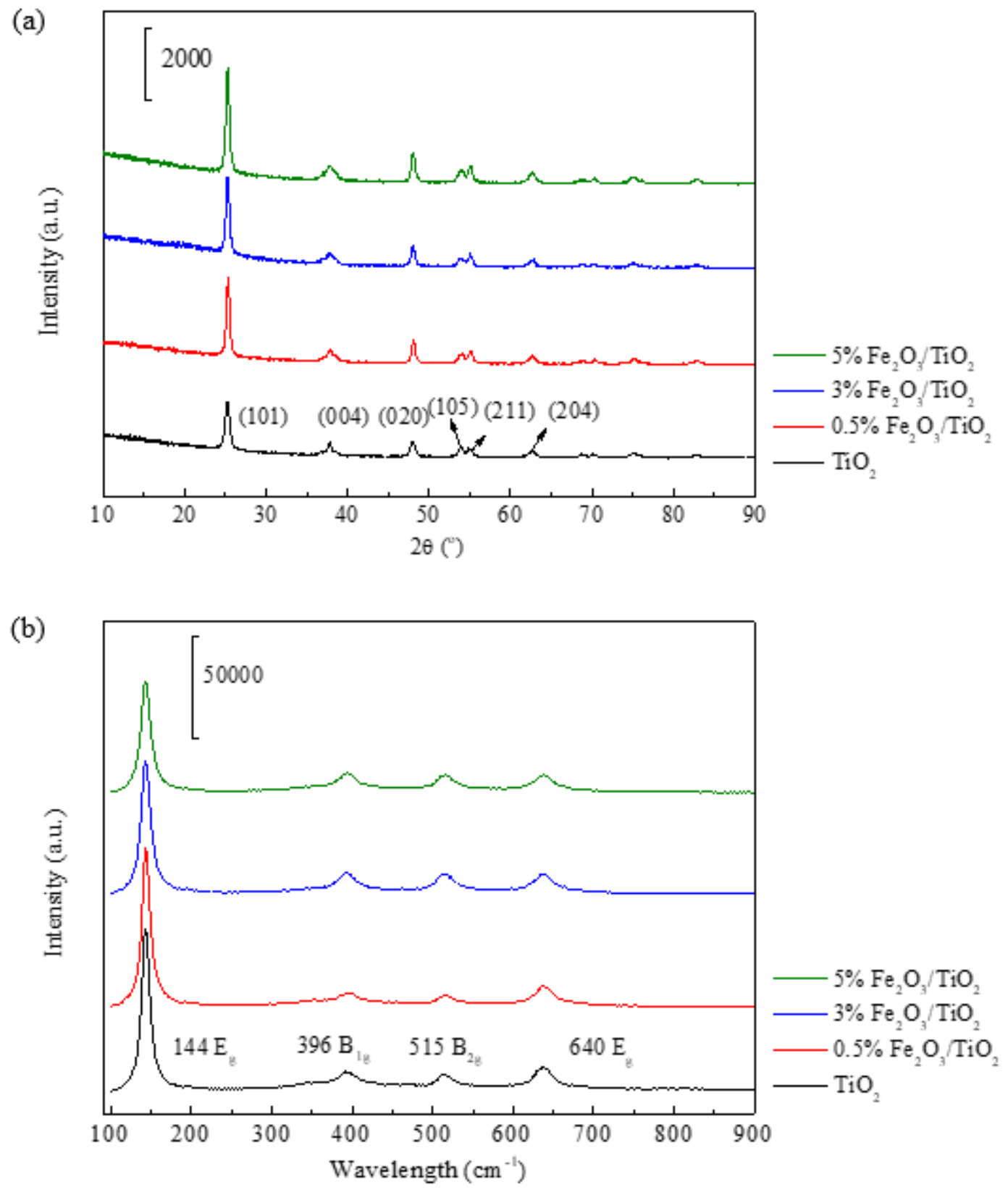

Figure 3

(a) XRD and (b) Raman patterns of TiO2 and 0.5-5\%Fe2O3/TiO2. 
(a)
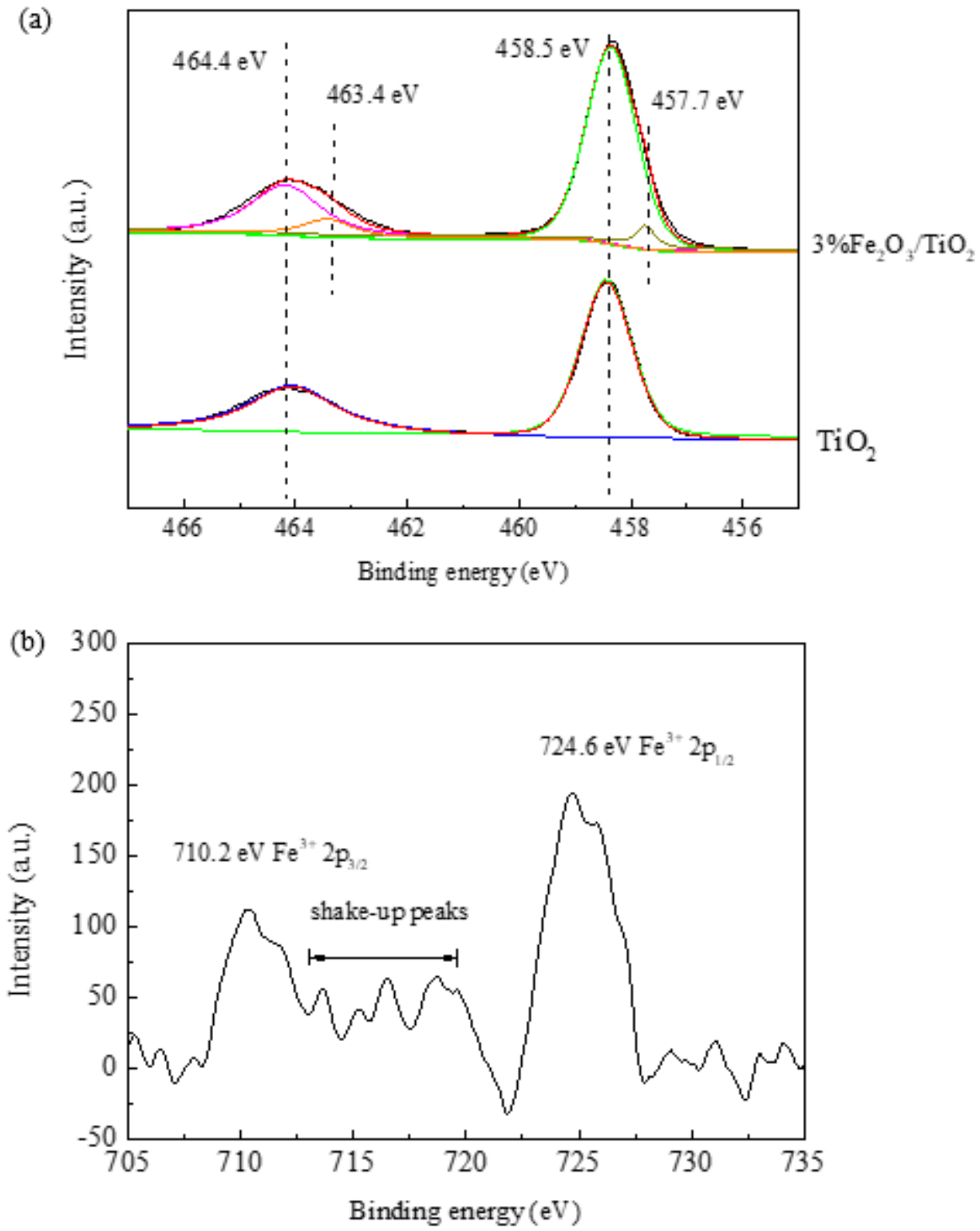

Figure 4

Figure 4. Binding energies of (a) Ti 2p1/2, Ti 2p3/2 for TiO2 and 3\%Fe2O3/TiO2, and (b) Fe 2p1/2. 


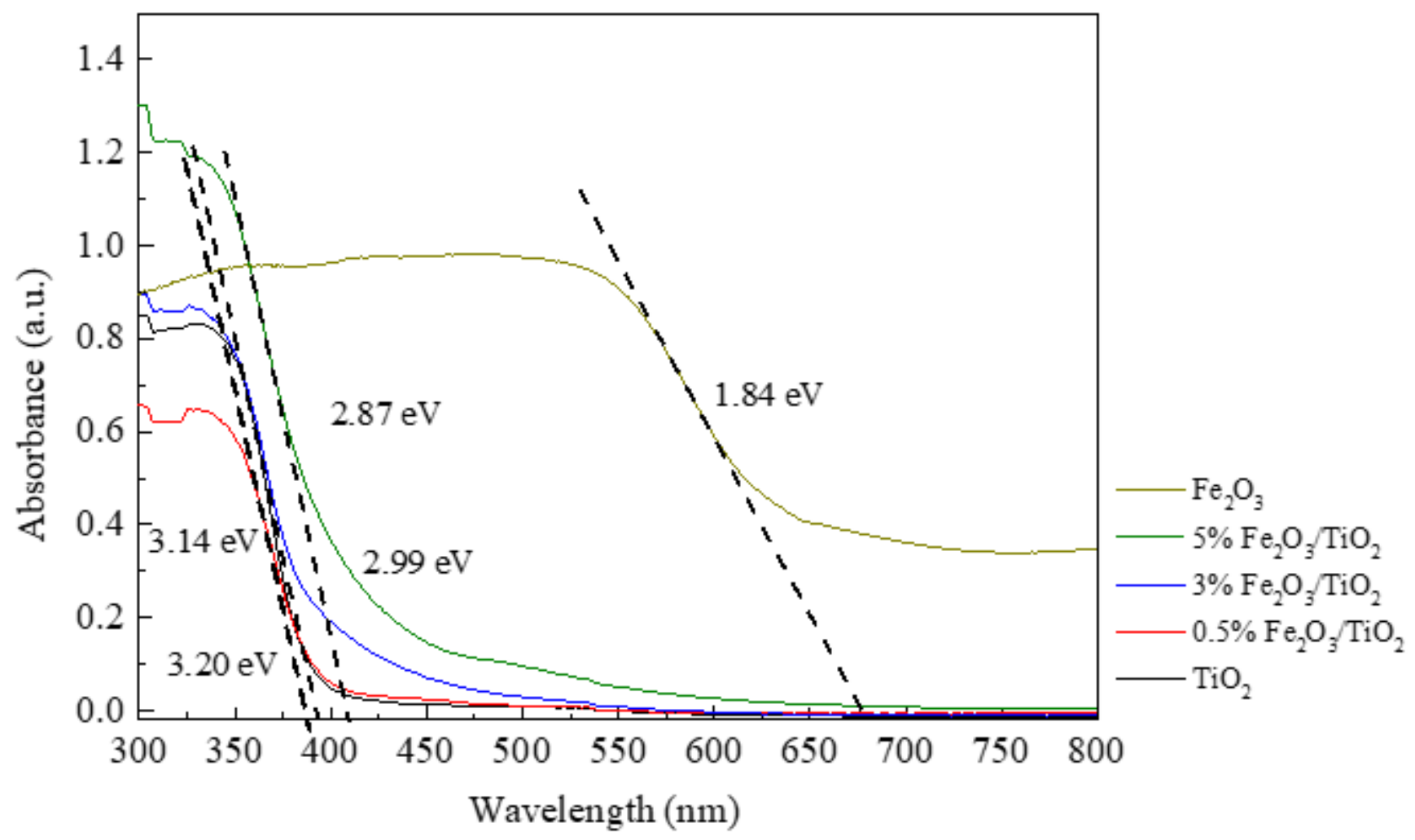

Figure 5

UV-Visible spectra of TiO2, 0.5-5\%Fe2O3/TiO2, and Fe2O3. 
(a)

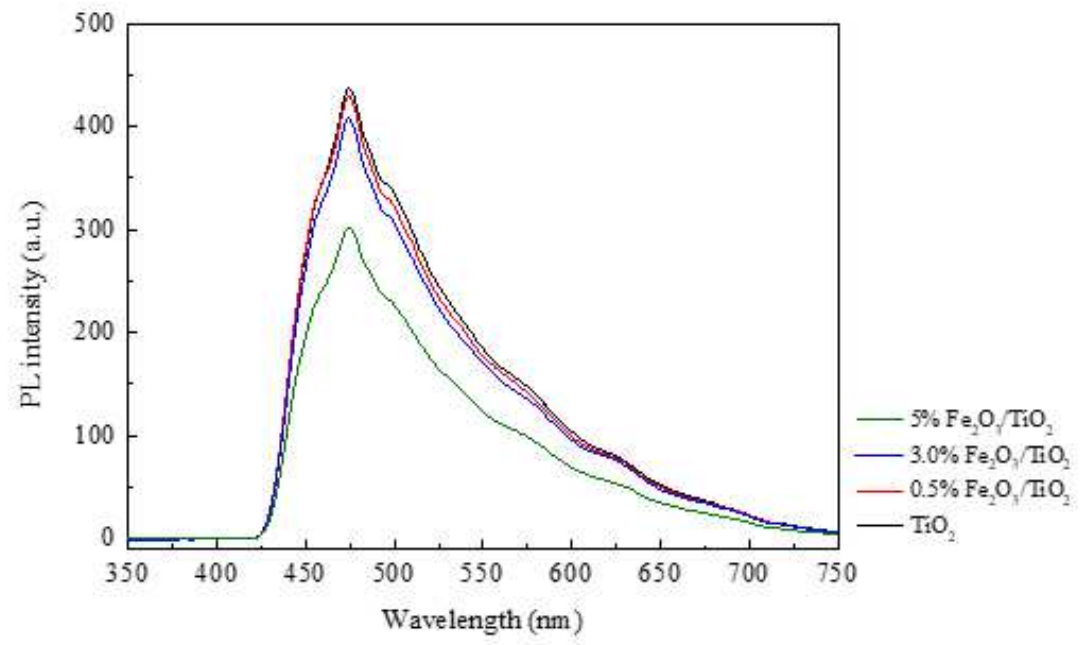

(b)

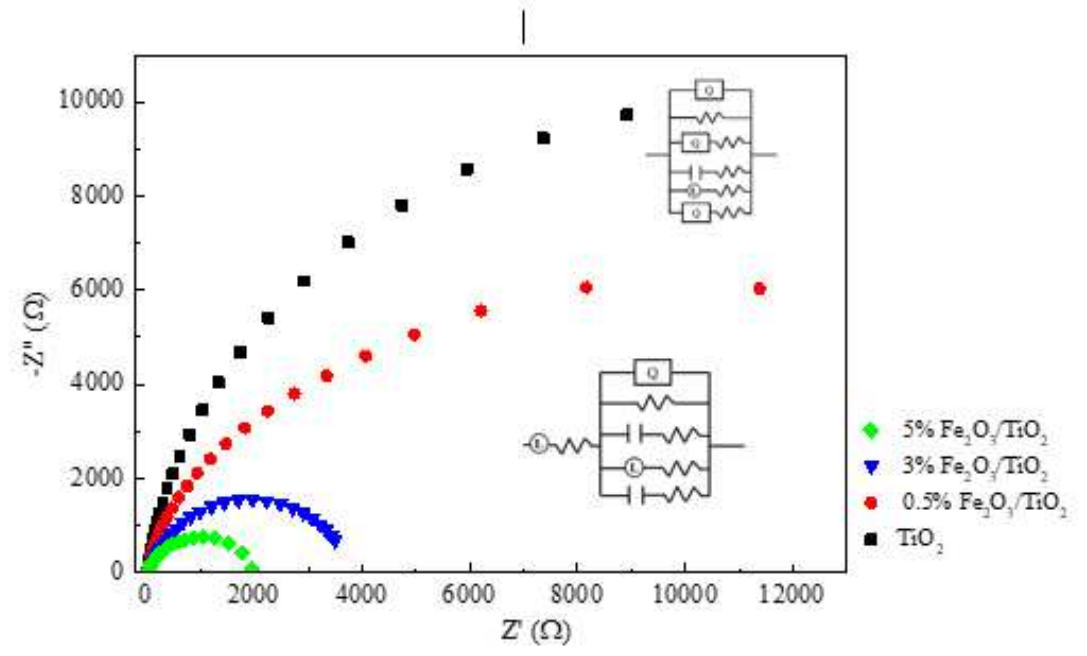

(c)

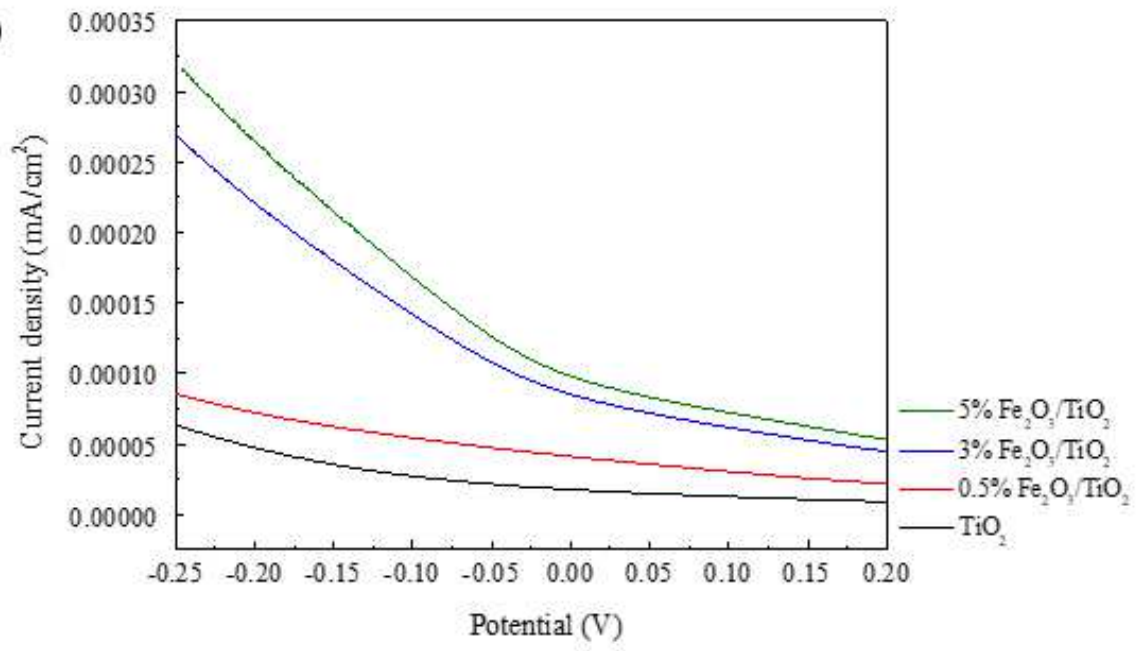

Figure 6

(a) PL spectra, (b) simulated EIS, and (c) LSV patterns of TiO2 and 0.5-5\%Fe203/TiO2. 
(a)

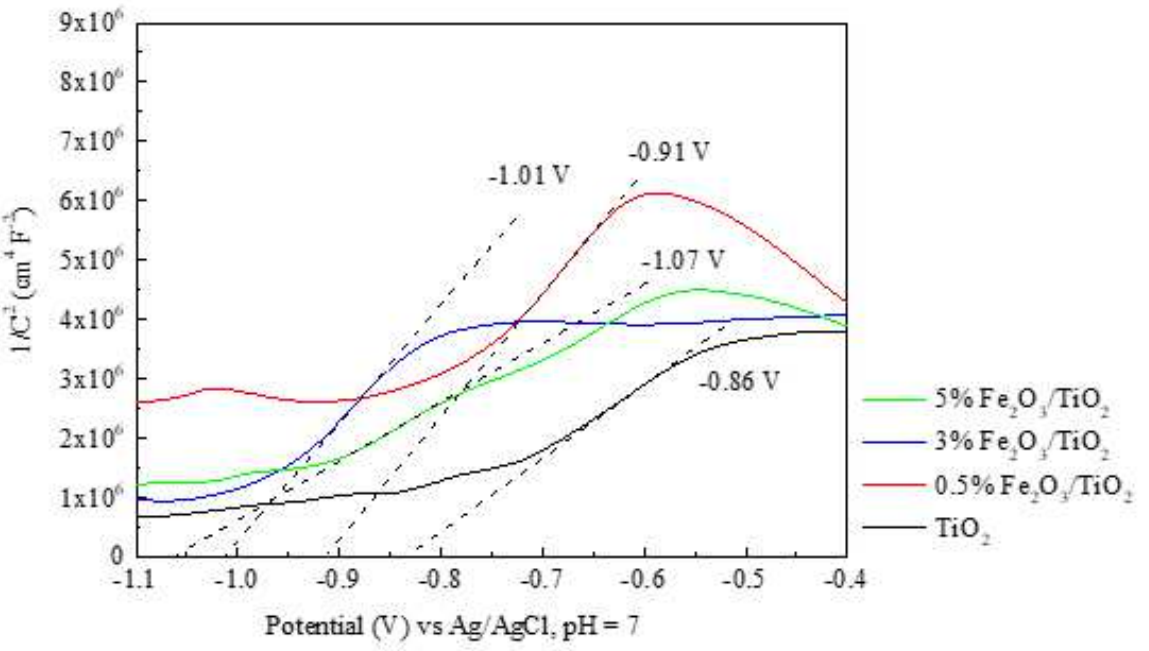

(b)

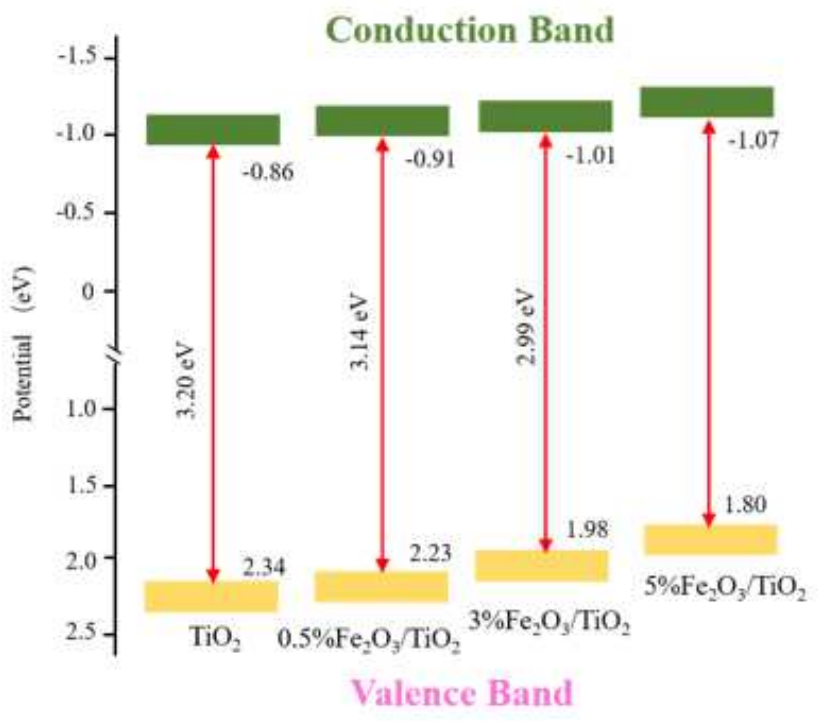

(c)

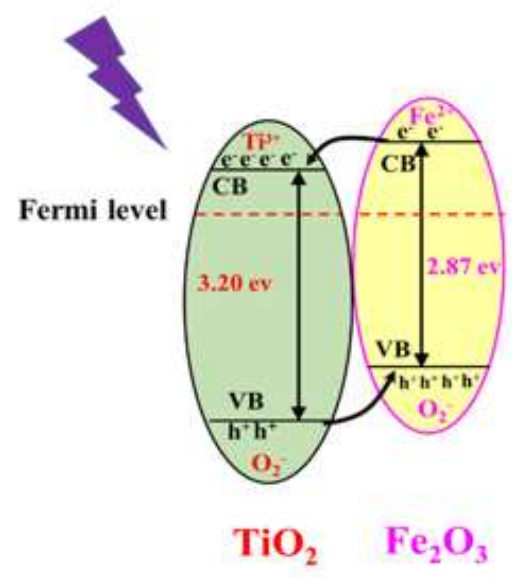

Figure 7

(a) Mott-Schottky plots of TiO2, 0.5-5\%Fe2O3/TiO2, and Fe2O3 at $100 \mathrm{~Hz}$ using an Ag/ AgCl electrode at $\mathrm{pH}=7.0$, (b) electronic structure of $\mathrm{TiO} 2$ and $0.5-5 \% \mathrm{Fe} 2 \mathrm{O} 3 / \mathrm{TiO} 2$, (c) schematic diagram of photogenerated electron-hole pairs transferring at the interface of Fe203/TiO2, and Fe2O3. 


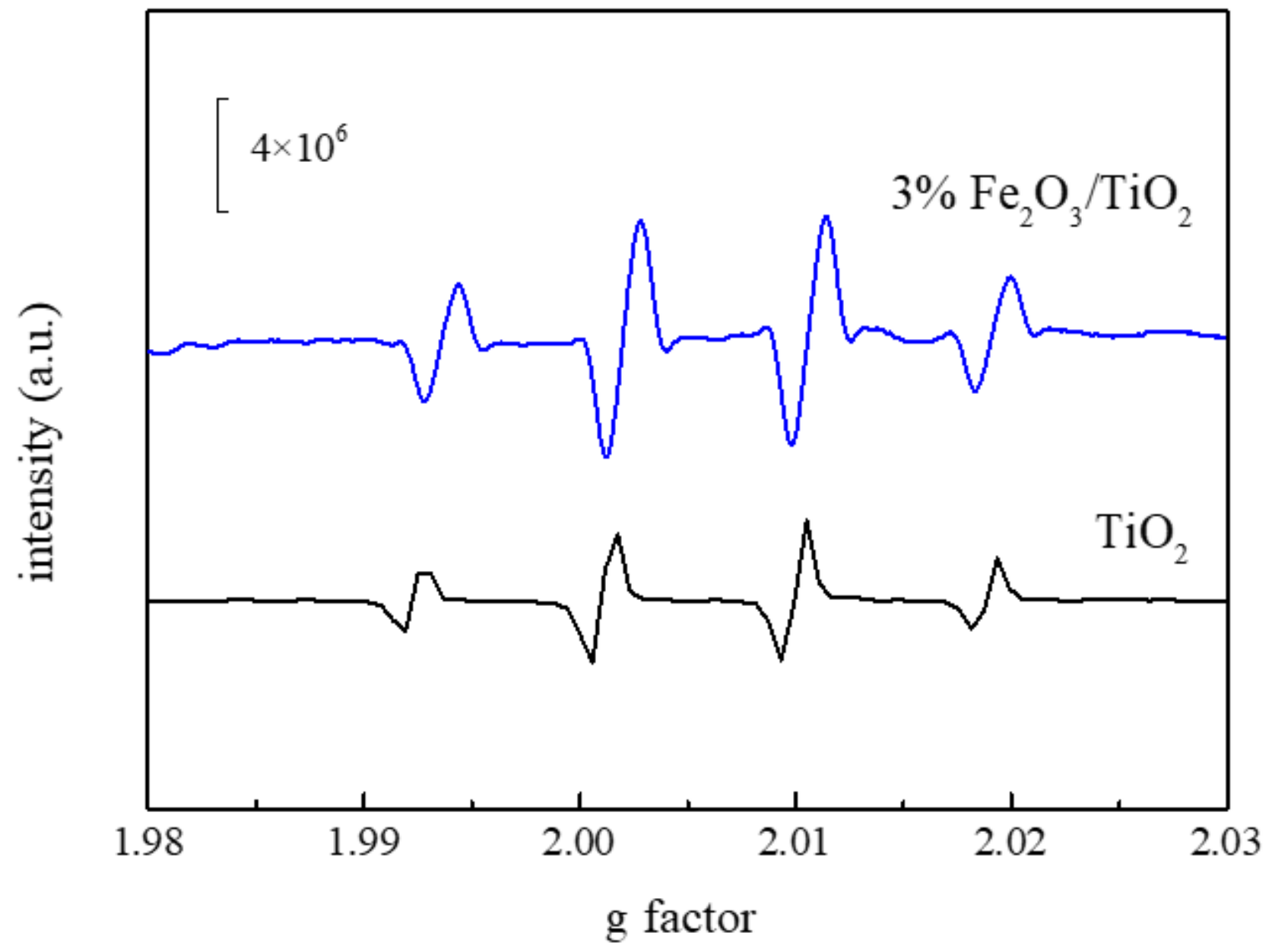

Figure 8

EPR patterns of TiO2 and $\mathrm{Fe} 2 \mathrm{O} 3 / \mathrm{TiO} 2$. 
(a)

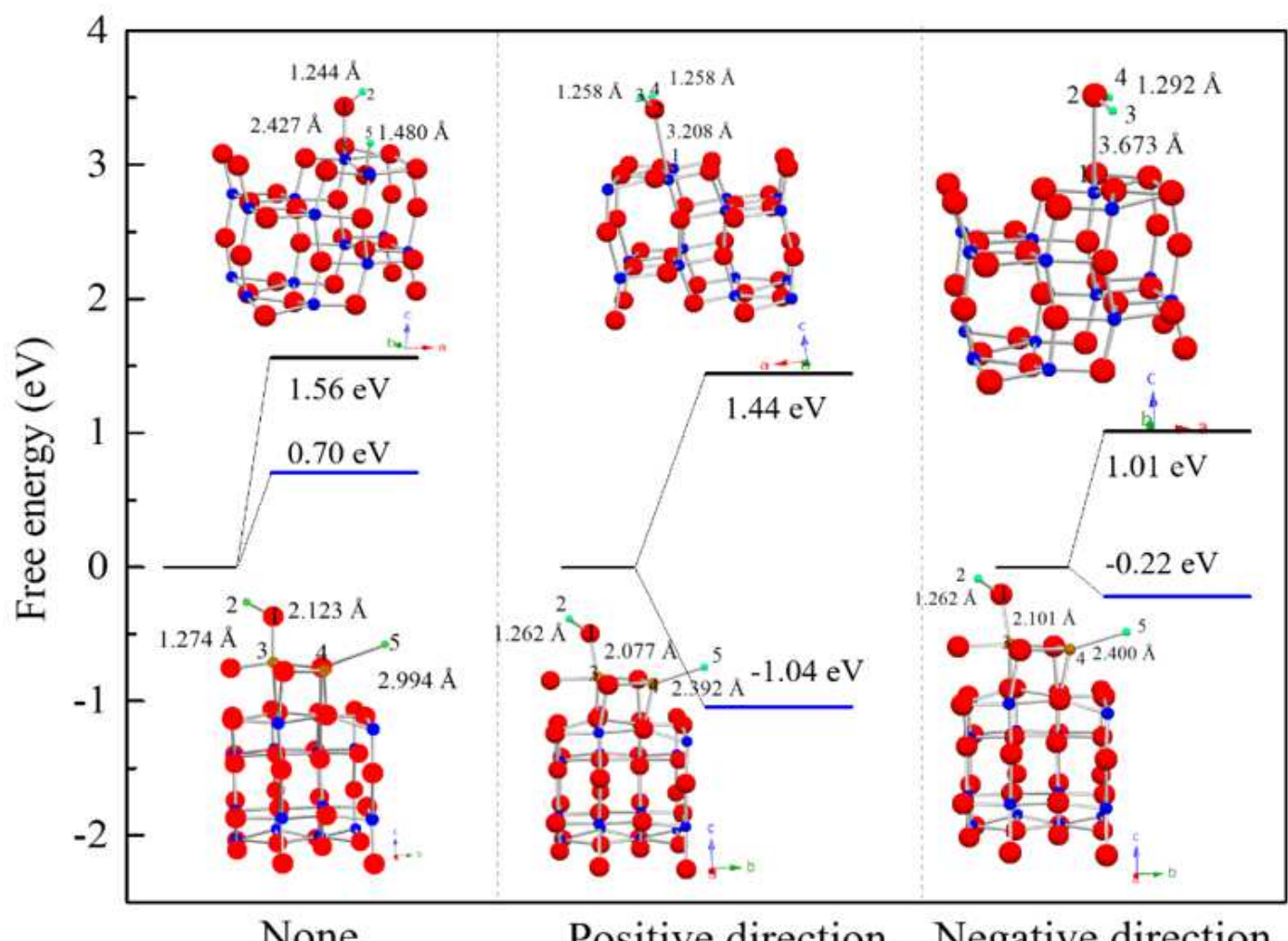

- $\mathrm{Fe}$

- $\mathrm{Ti}$

- O

- $\mathrm{H}$

$\mathrm{TiO}_{2}$

$\mathrm{Fe}_{2} \mathrm{O}_{3} / \mathrm{TiO}_{2}$

(b)

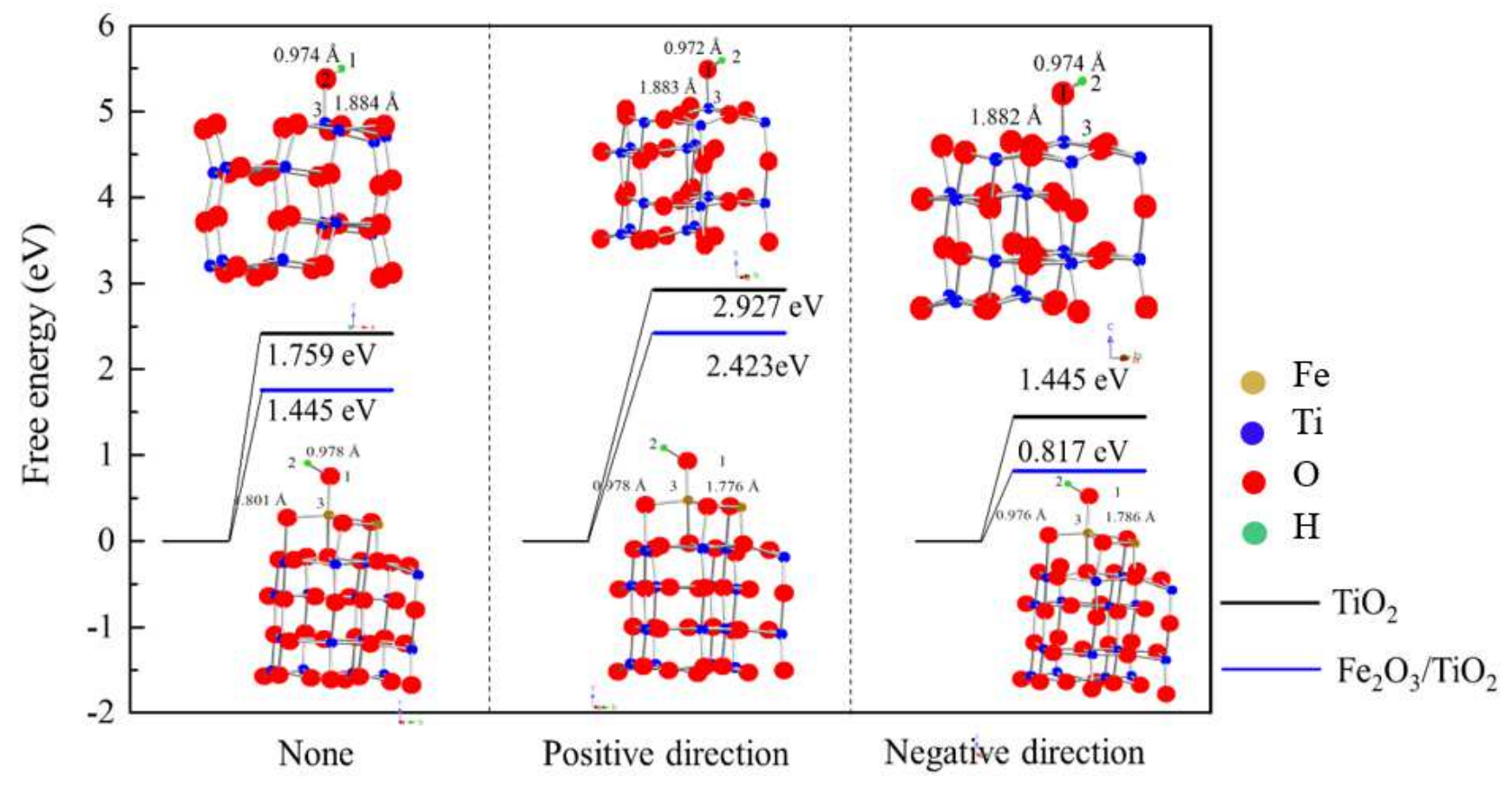

Figure 9

Free energy of formation of (a) slab + hydroxyl $+\mathrm{H}$, and (b) slab + hydroxyl. 
(a)

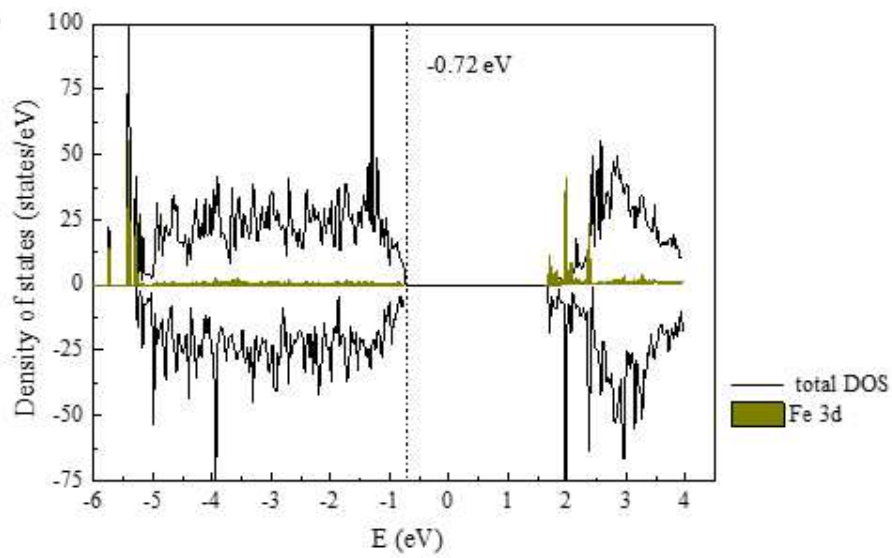

(b)

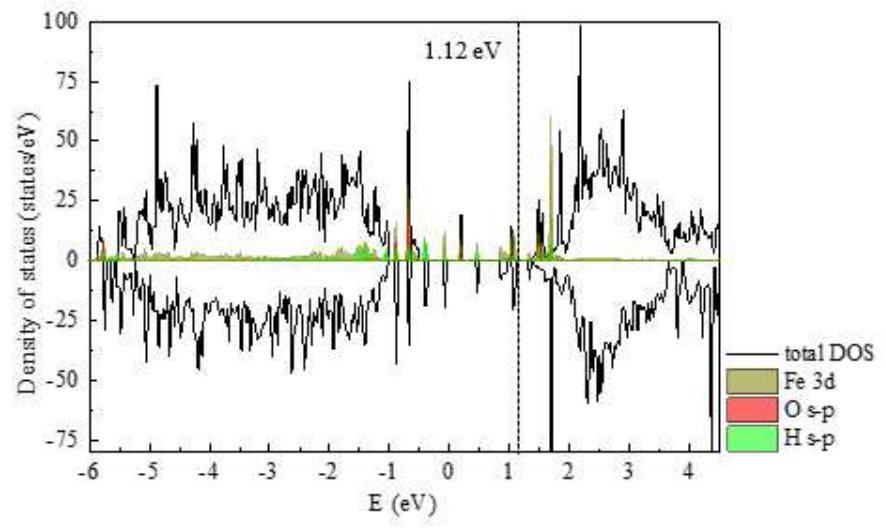

(c)

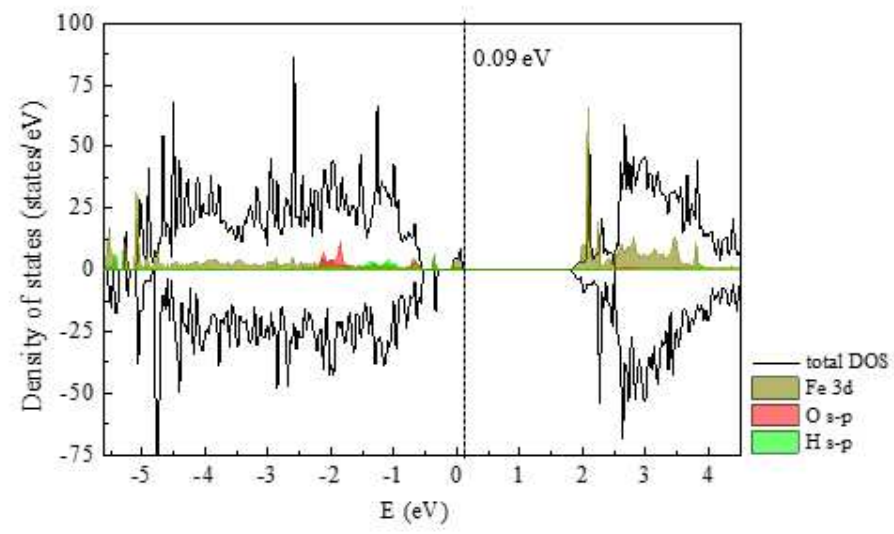

(d)

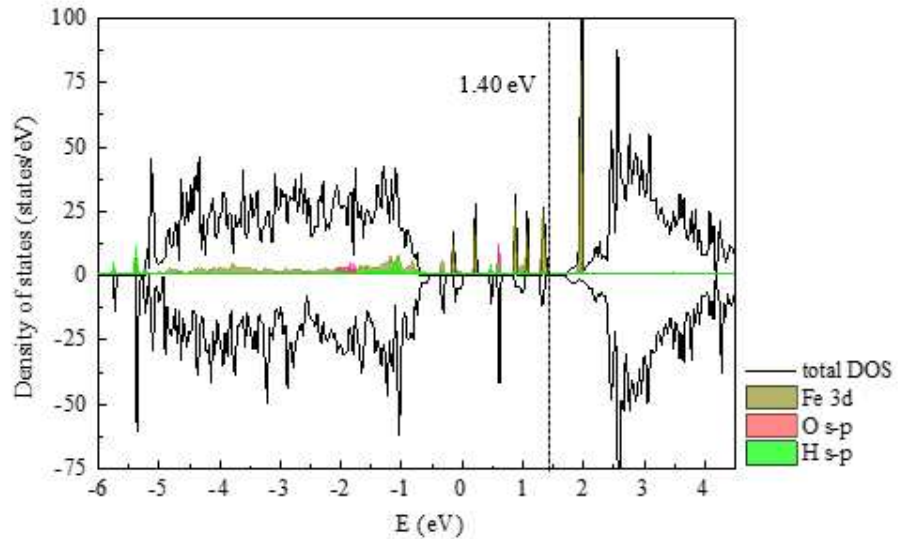

Figure 10

Projected density of state for bare Fe203/TiO2 (a), Fe203/TiO2 + hydroxyl + hydrogen (b) without an electric field, (c) Fe203/TiO2 + hydroxyl + hydrogen with a positive electric field, and (d) with a negative electric field, respectively. Dashed lines denote the Fermi level.

(a)

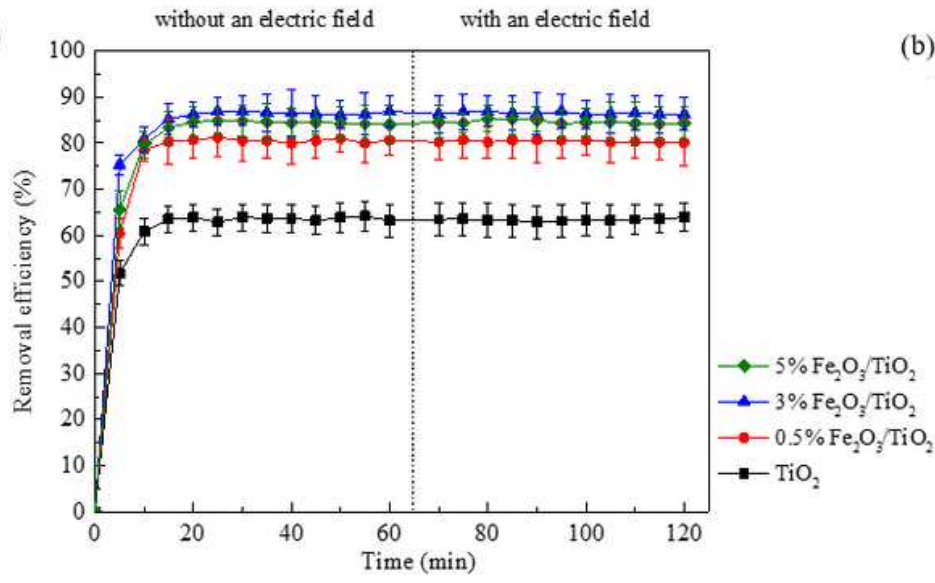

b)

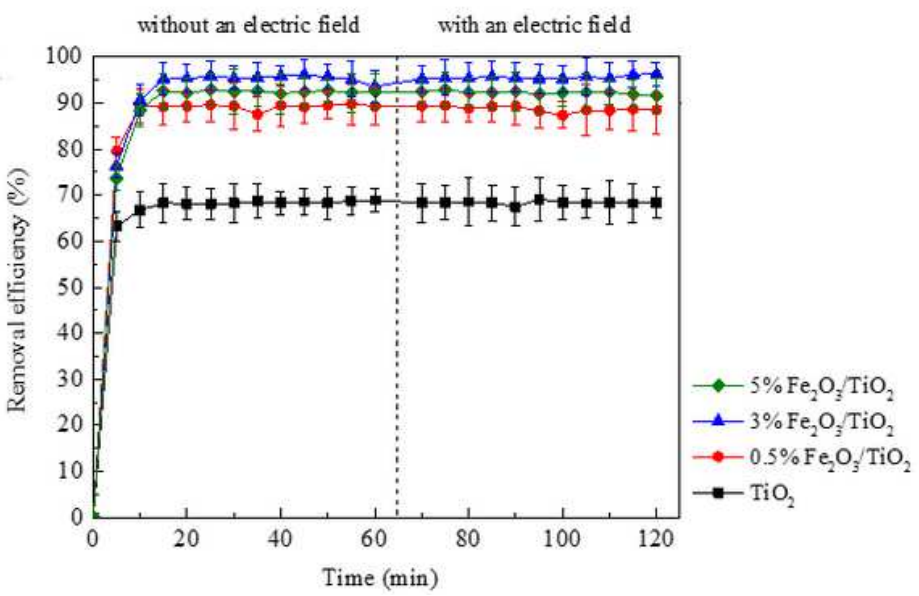

Figure 11

Removal efficiency of $\mathrm{CHOH}$ by neat $\mathrm{TiO} 2$ and $0.5-5 \% \mathrm{Fe} 2 \mathrm{O} 3 / \mathrm{TiO} 2$ without $\mathrm{H} 2 \mathrm{O}$, (a) in the absence and (b) presence of UV irradiation. 
(a)

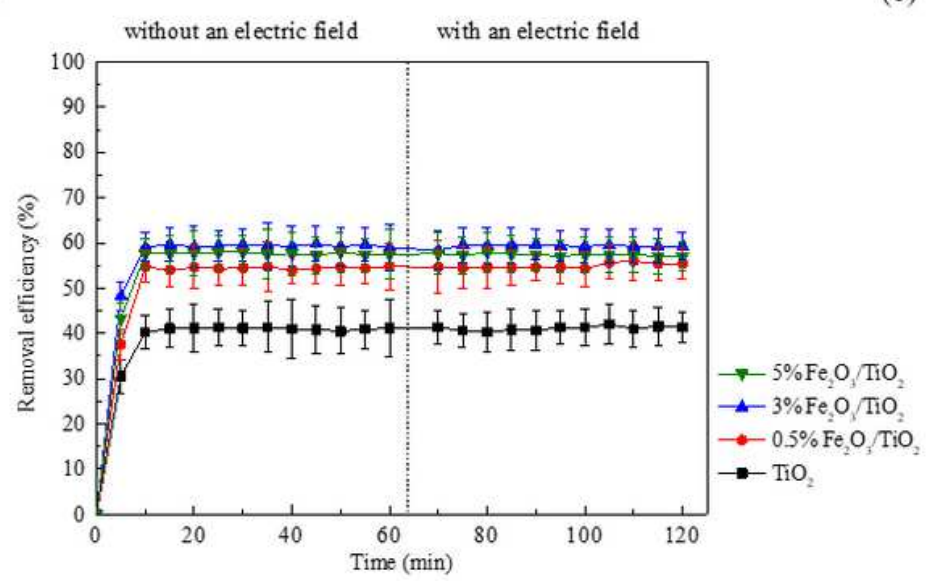

(b)

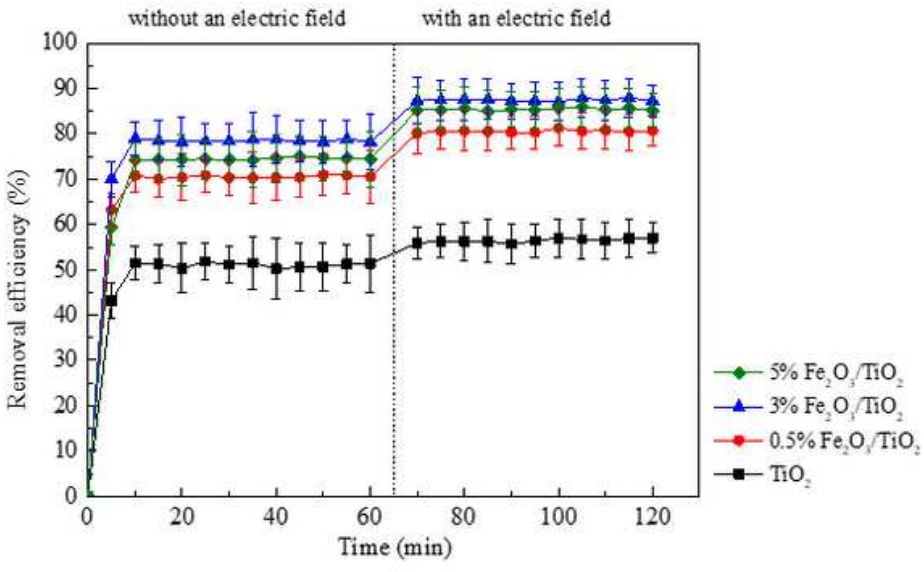

Figure 12

Removal efficiency of $\mathrm{CH} 2 \mathrm{O}$ by neat $\mathrm{TiO} 2$ and $0.5-5 \% \mathrm{Fe} 2 \mathrm{O} 3 / \mathrm{TiO} 2$ at a relative humidity of $50 \%$, (a) in the absence and (b) presence of UV irradiation.

(a)

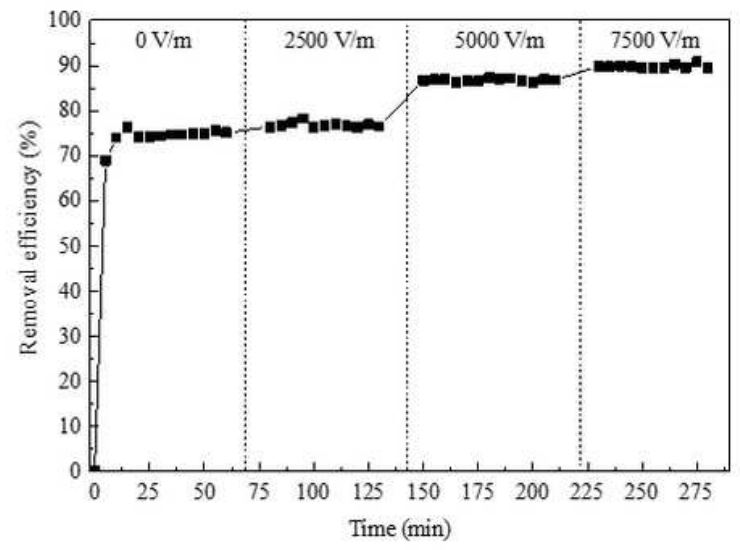

(b)

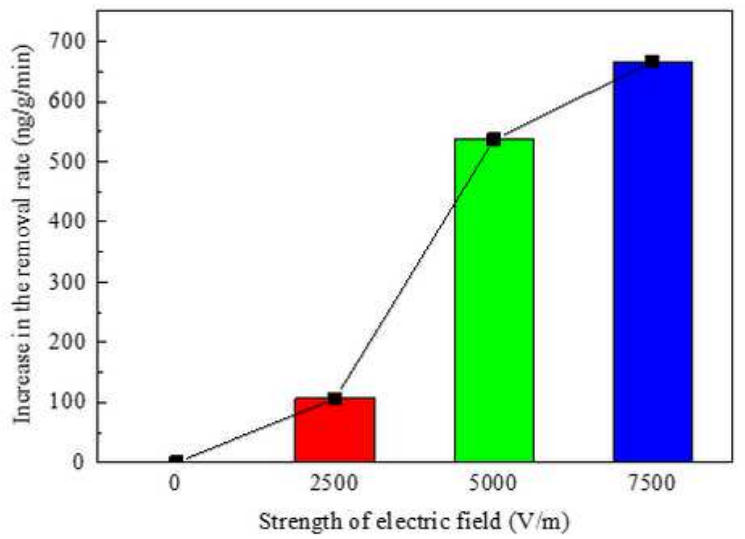

Figure 13

(a) Removal efficiency of $\mathrm{CHOH}$ by $3 \% \mathrm{Fe} 2 \mathrm{O} 3 / \mathrm{TiO} 2$, and (b) increment of the removal rates of $\mathrm{CHOH}$ by $3 \% \mathrm{Fe} 2 \mathrm{O} 3 / \mathrm{TiO} 2$ at a relative humidity of $50 \%$ under different strengths of electric field.
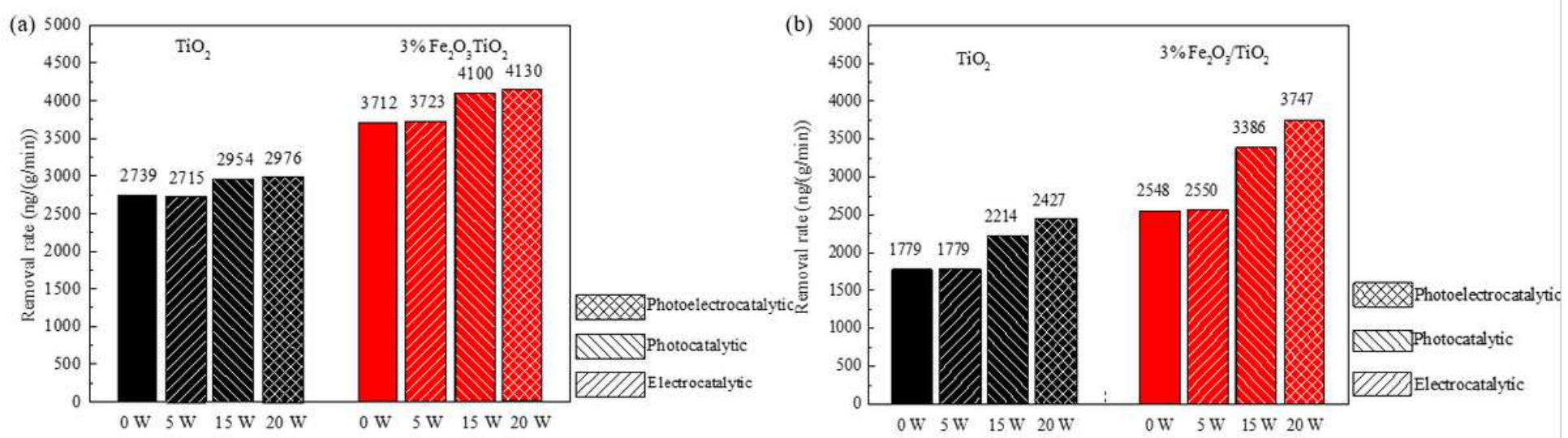
Figure 14

Removal rate of $\mathrm{CHOH}$ with different energy input (a) without $\mathrm{H} 2 \mathrm{O}$, and (b) with $\mathrm{H} 2 \mathrm{O}$.

\section{Supplementary Files}

This is a list of supplementary files associated with this preprint. Click to download.

- Supplementarymaterials.docx 